Portland State University

PDXScholar

$1-1-1983$

\title{
An investigation of the reliability, subscale intercorrelations, and validity of the Administrator role perception inventory
}

Anne Skirven Wax

Portland State University

Follow this and additional works at: https://pdxscholar.library.pdx.edu/open_access_etds Let us know how access to this document benefits you.

Recommended Citation

Wax, Anne Skirven, "An investigation of the reliability, subscale intercorrelations, and validity of the Administrator role perception inventory" (1983). Dissertations and Theses. Paper 406.

https://doi.org/10.15760/etd.406

This Dissertation is brought to you for free and open access. It has been accepted for inclusion in Dissertations and Theses by an authorized administrator of PDXScholar. Please contact us if we can make this document more accessible: pdxscholar@pdx.edu. 


\title{
AN INVESTIGATION OF THE RELIABILITY, SUBSCALE INTERCORRELATIONS, AND VALIDITY OF THE ADMINISTRATOR ROLE PERCEPTION INVENTORY
}

By

Anne Skirven Wax
A dissertation submitted in partial fulfillment of the requirements for the degree of
DOCTOR OF EDUCATION
in
PUBLIC SCHOOL ADMINISTRATION AND SUPERVISION

\author{
Portland State University \\ The University of Oregon \\ (C) 1983 Anne Skirven Wax
}


TO THE OFFICE OF GRADUATE STUDIES AND RESEARCH:

The members of the Committee approve the dissertation of Anne Skirven Wax presented March 15, 1983.
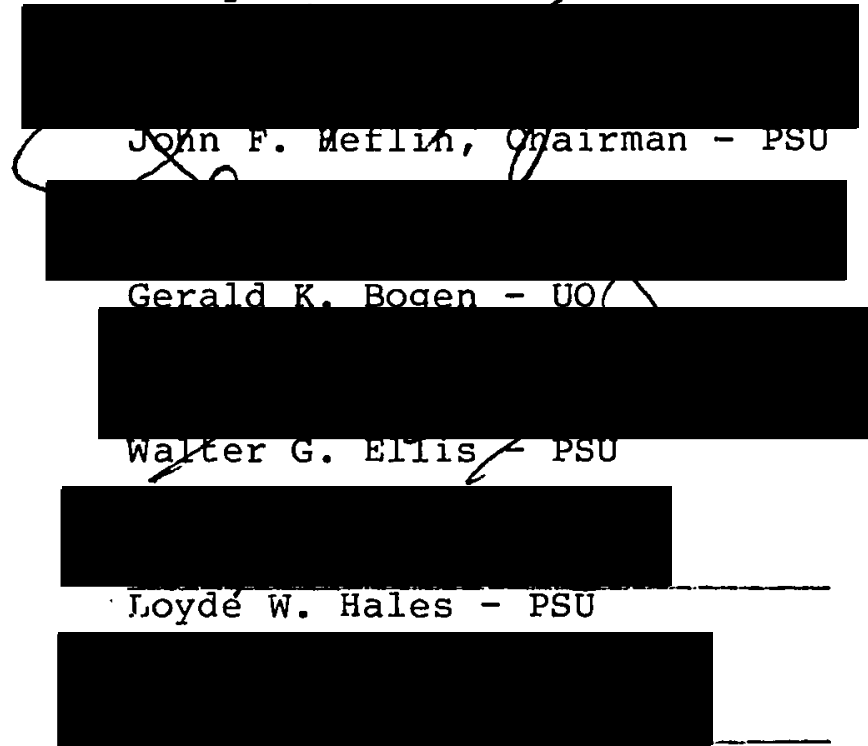

Michael E. Carl - PSU

APPROVED :

George V. Guy, Bi-Universfty Program Coordinator (Portland State University)

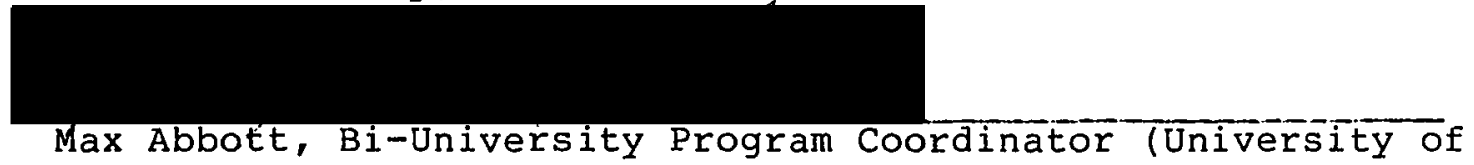
Oregon)

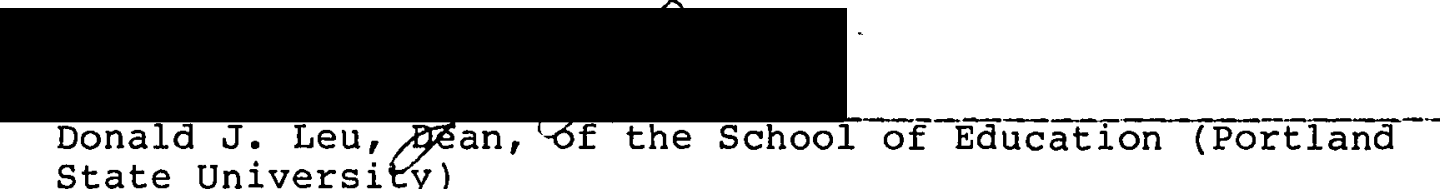

State University)

Stanley Răuch, Dean of Graduate Studies and Research (Portland State University) 
AN ABSTRACT OF THE DISSERTATION OF Anne Skirven Wax for the Doctor of Education in Public School Administration and Supervision presented March 15, 1983

Title: An Investigation of the Reliability, Subscale Intercorrelations, and Validity of the Administrator Role Perception Inventory.

APPROVED BY MEMBERS OF THE DISSERTATION COMMITTEE:
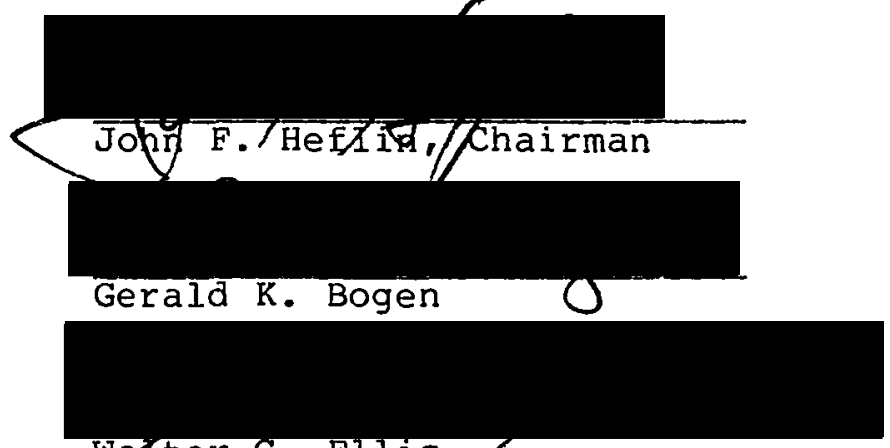

WaIter G. Ellis

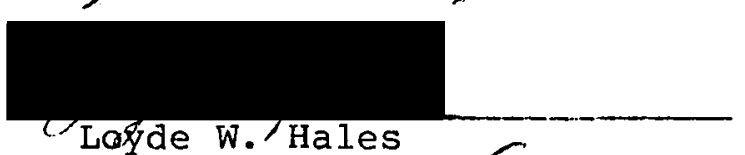

Loyde W.' Hales

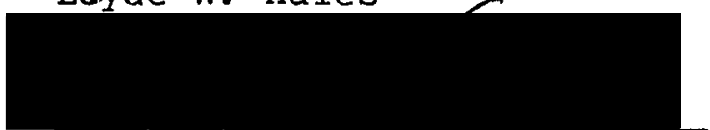

Michael E. Căr I

The purpose of this study was to investigate the reliability, subscale intercorrelations, and validity of the Administrator Role Perception Inventory (ARPI), an instrument developed by the investigator and a co-author in the year preceding the study. The ARPI is a 50 item, Likert- 
type scale which reflects variables thought to be associated with burnout: expectation, motivation, accomplishment, psycho-physical state, and relationships. These variables have their origins in the literature and in earlier research studies, although they may differ sightly in scope and terminology in their use for this study. Another variable, previously unresearched, was also included: it is called "time" and reflects a negative time orientation, a longing for the "good old days."

The inventory was mailed to all of the 2,113 active members of the Confederation of Oregon School Administrators during the middle of August, 1982. A random sample of this population also received materials for use by a colleague in providing observer ratings of the administrator from whom they had received the packet. The return rates for the ARPI and for the Colleague Questionnaire were 62 percent and 45 percent, respectively.

Analysis showed the Administrator Role Perception Inventory to have an internal consistency of .91 , as measured by coefficient alpha. The coefficients for the subscales fell between .70 and .85. As expected, there were substantial intercorrelations among the subscales, ranging from a low of .31 to a high of .63 , all significant at the .001 level. Total ARPI scores and the subscale scores were correlated with measures of self-perceived burnout, desire for 
early retirement, and felt job stress. All of these correlations were in the expected direction, were significant at the .001 level, and ranged from -.41 to -.59. The observer ratings, as indicated by the total scores on the Colleague Questionnaire, had a correlation of .31 with a .01 level of significance. Colleague perceptions of the administrators' level of emotional exhaustion were significant at the .01 level, $r=.36$. Correlations between separate observer measures (individual questions on the Colleague Questionnaire) and the subscale scores were substantially in the predicted direction, but not always significantly so.

A multivariate analysis of variance was performed on the five separate subscales of the ARPI: Expectation, Motivation, Accomplishment, Psycho-physical State, and Relationships, using the procedure found in Statistical Package for the Social Sciences Update 7-9. (Hull and Nie, 1981). The Time subscale and the total ARPI were excluded because these scales are comprised of items from the five separate subscales. Following the multivariate analysis of variance, a separate univariate analysis of variance was performed for each of the subscales, and for the ARPI. In each analysis, the three levels of burnout (low, moderate, high) were the independent variable. All pairs of means differed significantly at the .05 level, with the exception of the means for Relationships in the high and moderate burnout groups. 
It was concluded that the reliability and validity of the Administrator Role Perception Inventory as a measure of variables associated with burnout appear to be comparable to those of instruments similar in format or similar in purpose. Thus, the ARPI is an instrument which can be used for further research in educational administration as well as for organizational and staff development in school districts. 


\section{ACKNOWLEDGEMENTS}

I wish to express gratitude to Dr. John Heflin, chairman of my doctoral committee, and to the other members of the committee who also gave consistently of their time and support, Dr. Loyde Hales, Dr. Walter Ellis, Dr. Gerald Bogen, and Dr. Michael Carl.

Much appreciation is expressed to Dr. R. L. Rose and the staff of the Confederation of Oregon School Administrators, without whose cooperation this study would have been impossible.

I am also deeply indebted to Barbara Wiegele, Shirley Goodno, and Charles Lehman for their excellent technical advice and assistance.

To Dr. Charles Kingston, Arthur Biederman, and Delbert Fennell, who provided the inspiration and support to carry this endeavor to completion, I express my deepest thanks.

I thank my husband, Phil, and my daughter, Ellen, for their confidence and patience. I acknowledge the gifts of self-discipline and love of study from my late parents, Charles and Alden Skirven. 
TABLE OF CONTENTS

PAGE

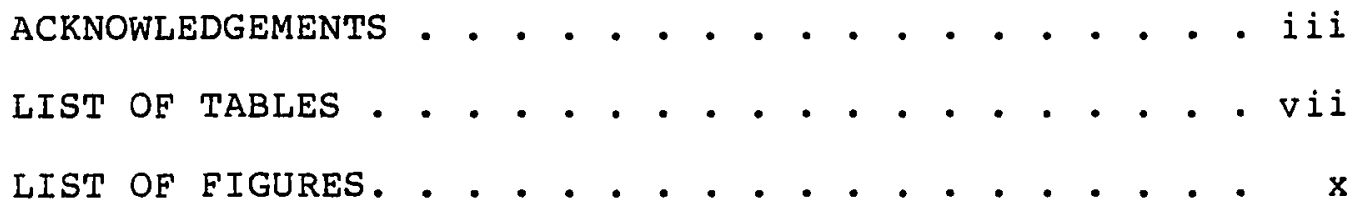
CHAPTER

I. INTRODUCTION . . . . . . . . . . . . . 1

Background . . . . . . . . . . . . 2

The Problem . . . . . . . . . . 6

Importance of the Study . . . . . . . 8

Contribution to Measurement . . . . 8

Contribution to Educational

Practice . . . . . . . . . 11

Organization of the study. . . . . . 15

II. REVIEW OF THE LITERATURE . . . . . . . 18

Scope of the Review. . . . . . . . . 18

Problems Encountered in the Review . . 19

Ambiguity of Conceptual Definitions. . . 19

Previous Studies: Scarcity of

Empirical Data . . . . . . . . . 22

Limited Target Population for the Review. 24

Results of the Review of the Literature. 25

Conceptual Framework . . . . . . . 25

Theoretical Bases. . . . . . . . 30

Measurement and Instrumentation. . . 34

Empirical Findings . . . . . . . . 38

Summary. . . . . . . . . . . . 46

III. NETHODOLOGY. . . . . . . . . . . . . 48

Development of the ARPI. . . . . . . 48

Item Writing . . . . . . . . . . . . 49

Definition of Terms. . . . . . . . 50

Testing the Instrument . . . . . . . 51

Selection of Subjects. . . . . . . 52

Administration of the ARPI . . . . . 53

Areas of Investigation . . . . . . . 54

Summary. • . . . . . . . . . 63 
IV. RESULTS. . . . . . . . . . . 65

Sample •. . . . . . . . . . . . . 65 Size . . . . . . . . . . . . . 65 Description. . . . . . . . . . . . 66

Scoring. . . . . . . . . . 73

Analysis of the Subscale and the ARPI. - 74 Overview of the Scores... . . . . 74 Expectation. . . . . . . . . . 75 Motivation . . . . . . . . . . 77 Psycho-physical state. . . . . . . 78 Relationships. . . . . . . . . . 78 Accomplishment . . . . . . . . . 81 Time . . . . . . . . . . . . . 82 Total ARPI . . . . . . . . . . . 83 Summary. • • • • • • • • • • • 83

Reliability. • . . . . . . . . . . 85

Subscale Intercorrelations - . • . . . 86

Valiaity . . . . . . . . . . . . . 86 Content Validity . •. . . . . . . . 86 Criterion-related Validity . . . . . 90 Summary. . . . . . . . . . . . 126

V. SUMMARY, CONCLUSIONS, LIMITATIONS,

$$
\begin{aligned}
& \text { AND RECOMMENDATIONS. . . . . . . . . } 128
\end{aligned}
$$

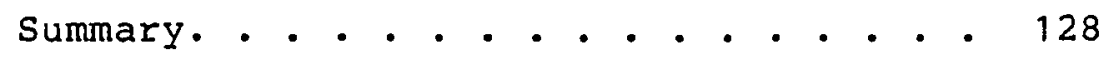

$$
\begin{aligned}
& \text { Conclusions. . . . . . . . . . . } 131 \\
& \text { Reliabilities Comparable to those } \\
& \text { of Similar Instruments . . . . . . } 131 \\
& \text { Subscale Interrelationship . • • • . } 133 \\
& \text { Validity Comparable to that of } \\
& \text { Other Instruments. . . . . . . . } 134 \\
& \text { Significant Correlations Affirm } \\
& \text { Previous Studies . . . . . . . . } 137 \\
& \text { Additional Variable Associated with } \\
& \text { Burnout synarome • • . . . • • } 137 \\
& \text { Insignificant Correlations Suggest } \\
& \text { Key to Burnout Debate. . . . . . } 138 \\
& \text { Iimitations of the Study . . . . . . . } 141 \\
& \text { Geographic Location. . . . . . . . } 141 \\
& \text { Seasonal Nature of the Job . . . . . } 141
\end{aligned}
$$




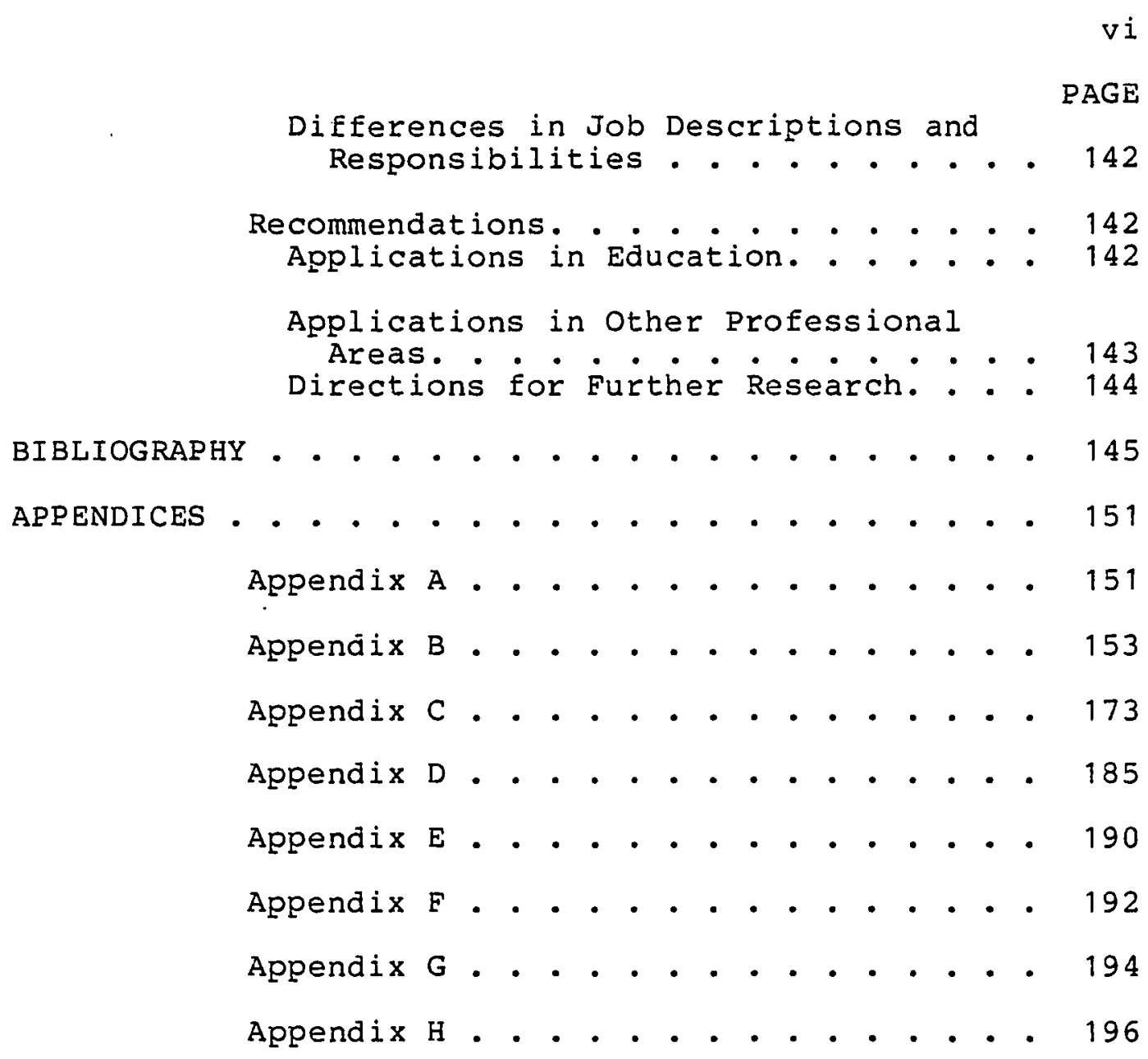


LIST OF TABLES

TABLE

PAGE

I Popular Publications with Articles on

Burnout: $1980-1982$. . . . . . . 2

II Source of Variables . . . . . . . . . 7

II Archives Searched . . . . . . . . . 20

IV Stages of Burnout . . . . . . . . . 27

$\mathrm{V}$ Situational Factors Contributing to Burnout . . . . . . . . . . 40

VI Factors within the Individual Contributing to Burnout. . . . . . . . . . . 43

VII Developmental Changes in the ARPI . . . . 56

VII Distribution of Administrators by Age . . 67

IX Distribution of Administrators by Administrative Position . . . . . . 68

$x$ Administrative Positions Represented in CosA and in Sample. . . . . . . . 69

XI Distribution of Administrators by Position Type. . . . . . . . . . . . 70

XII Distribution of Administrators by Job Location. . . . . . . . . . . 71

XIII Distribution of Administrators by Years in Present Position . . . . . . . . . 72

XIV Assignment of Items to Subscales.. . . . . 73

XV Means and Standard Deviations for Subscales and Total ARPI. . . . . . . . . . 75

XVI Frequency Distribution of Scores on Expectation.............. 76 
vii i

TABLE

PAGE

XVII Frequency Distribution of Scores on Motivation ..............

XVIII Frequency Distribution of Scores on Psychophysical state........... . 79

XIX Frequency Distribution of Scores on Relationships........... . 80

$\mathrm{XX}$ Frequency Distribution of Scores on Accomplishment............ 81

XXI Frequency Distribution of Scores on Time . 82

XXII Frequency Distribution of ARPI Scores. • . 84

XXIII Coefficient Alpha for Each Subscale and for Total ARPI............ 85

XXIV Subscale Intercorrelations . . . . . . 87

XXV Correlations between Stress Measures and ARPI Scores. . . . . . . . . 93

XXVI Correlations between Early Retirement and ARPI Scores. . . . . . . . . . 95

XXVII Correlations between Measures of SelfPerceived Burnout and ARPI Scores. . . 96

XXVIII Mean ARPI Scores of Burnout Groups . . . . 97

XXIX ANOVA for Level of Burnout and ARRI Scores . 98

XXX Correlations between Colleague Questionnaire Scores and ARPI Scores... . . . . 99

XXXI Correlations between Colleagues' Perceptions of Administrators' Emotional Exhaustion and ARPI Scores. . . . . . . 101

XXXII Measures of Valiaity for Expectation Subscale ........... . 102

XXXIII Mean Expectation Scores of Burnout Groups. 105

XXXIV ANOVA for Level of Burnout and Expectation Scores.............. . 105 
XXXV Measures of Validity for Motivation Subscale............. 108

XXXVI Mean Motivation Scores of Burnout Groups • 109

XXXVII ANOVA for Level of Burnout and Motivation Scores . . . . . . . . . . . 109

XXXVIII Measures of Validity for Psycho-physical

State Subscale........... . 112

XXXIX Mean Psycho-physical State Scores of Burnout Groups . . . . . . . . . 113

XI ANOVA for Level of Burnout and Psychophysical state Scores. . . . . . 113

XLI Measures of Validity for Relationships Subscale............. . 116

XLII Mean Relationships Scores of Burnout. . Groups . . . . . . . . . . . 118

XLIII ANOVA for Level of Burnout and RelationShips Scores............. . 118

XLIV Measures of Validity for Accomplishment Subscale. . . . . . . . . . 121

XLV Mean Accomplishment Scores of Burnout Groups . . . . • . . . . . . . 122

- XLVI ANOVA for Level of Burnout and Accomplishment Scores . . . . . . . . . 122

XLVII Measures of Validity for Time Subscale . 124

XLVIII Mean Time Scores of Burnout Groups . . . 125

XLIX ANOVA for Level of Burnout and Time Scores. 125 
1. Stress Questions on Job Data Sheet. . . 60

2. Early Retirement Questions on Job Data Sheet................ 61

3. Self-perceived Burnout Questions on Job Data Sheet.............. 61

4. Measures of Job Stress . . . . . . . 93

5. Measures of Desire to Leave the Job. . . 94

6. Measure of Self-Perceived Burnout. . . . . 96

7. Measure of Administrators' Emotional Exhaustion as Perceived by Colleagues. . 100

8. Measure of Administrators' Disillusionment as Perceived by Colleagues. . . . 103

9. Measure of Administrators' Motivation as Perceived by Colleagues. . . . . . . 107

10. Measure of Administrators' Physical Vigor as Perceived by Colleagues....... . 111

11. Measures of Administrators' Relationships as Perceived by Colleagues . . . . . . 115

12. Measures of Administrators' Sense of Accomplishment as Perceived by Colleagues. 120

13. Measure of Administrators' Time Orientation as Perceived by Colleagues . . . . . 123

14. Improved Questions on Early Retirement . . 138 
CHAPTER I

INTRODUCTION

Educational administrators face many challenges today--limited funding, collective bargaining, special interest pressure groups, and community politics, for example. How they perceive their roles can affect their effectiveness in carrying out their work. Stress and burnout may be related to role perceptions, and studies of these phenomena have been conducted with a wide variety of professionals. Though stress in school administrators has been studied, no work has been published on factors that may contribute to administrator burnout. The issue of burnout continues to generate disagreement within the ranks of school administrators; some doubt its existence, while others decry its dire consequences.

If the phenomenon exists in educational administrators, it can have important implications for school effectiveness and educational leadership. The purpose of this study is to make a contribution to the methods of inquiry into the subject of burnout in school administrators. 


\section{Background}

Burnout is a recently identified phenomenon. The Eirst reference to it in the literature appears to have been in 1974 by Freudenberger, a psychologist who identified the syndrome in himself and in his patients. Many articles and books on the topic have appeared within the last five years, and a number of definitions have been supplied. Even a cursory examination will reveal that burnout is receiving considerable attention in the popular press. Within the last two years, seldom a month passed without an article extolling the dangers of burnout, identifying its symptoms, or suggesting preventions and cures. As Cooley and Savicki (1981) pointed out, it has certainly become a "hot topic." Examination of Table I reveals the breadth and frequency of interest in burnout.

TABLE I

POPULAR PUBLICATIONS WITH ARTICLES ON BURNOUT: 1980-1982

April 1980

June 1980

January 1981

April 1981

April 1981

May/June 1981

July 1981

August 1981

September 1981

December 1981

April 1982
Wall street Journal

Time

Psychology Today

Sunday Oregonian

Wall Street Journal

Harvard Business Review

Black Enterprise

World Press Review

Time

Readers Digest

Health 
Furthermore, the numerous journal articles, workshops, and papers focusing on burnout have supported Morrow's assertion that it is a subject of interest to professionals in many fields (Morrow, 1981). It has been discussed in relation to education, social work, law enforcement and practice, medicine, and business.

There is speculation as to whether or not burnout is a truly new phenomenon, or merely a long-existing problem that has simply been newly-labeled with a catchy and descriptive term (Savicki and Cooley, 1980). It was suggested that burnout may have existed for years, but was viewed as a failing in an individual; such a person either overcame it or left his profession.

Perhaps this interest by the various professions is merely one more attribute of the "me" generation which came to maturity in the 30 years of economic affluence following World War II. As Wolfe (1976) pointed out, wartime spending created a boom that pumped money into all classes of society to a degree unparalleled in any other country or time. The effect was that people had enough money not only to change their standard and style of living, but to remodel their very selves--to focus intently and energetically on $\mathrm{ME}$. They no longer needed to accept the circumstances of their interpersonal and intrapersonal lives; boredom, hostility, anxiety, and disappointment could be dealt with. People could choose their feelings as easily as they could 
select their clothing; introspection, feedback, and encounter were some of the mechanisms employed. This entire phenomenon, which became known as the "human potential movement" intensified the preoccupation with self. (pp. 31-36) Wolfe commented that this movement represented a departure from the belief in serial immortality, i.e., a sacrificing for others for gains that would be realized in the future, beyond one's own lifetime. The "now" was all important; the link with the future, broken. (p. 48)

Although Wolfe did not address the issue itself, his observations about the "me" generation are useful in getting a perspective on burnout. Prior to that period of affluence, one could not have afforded the "gradual reduction of motivation and productivity with attendant loss of meaningfulness of work" (Otto, 1980). To allow oneself that posture would have been destructive to the future generations as well as to the existing one. Conversations about burnout have often produced at least one advocate of this view that burnout is no more than a self-indulgence dependent for its existence on an individual's degree of affluence and self-centeredness. Quite possibly, the tightening job market will direct attention away from the phenomenon, and burnout will become a word associated with easier times. Though the duration of interest in burnout may be relatively short, there is much evidence to support its existence. It has been studied in relation to social workers, 
counselors, prison personnel, and mental health workers (Maslach and Pines, 1977); Maslach and Jackson (1979) also studied it in relation to policemen. Its effect on teachers has been described by Bardo (1979) and by Bensky, Shaw, Gouse, Bates, Dixon, and Beane (1980). No studies of the burnout phenomenon have focused exclusively on school administrators, though Gmelch and Swent (1977) and Gmelch (1977) identified factors that are stressful to administrators.

Research on administrative burnout is needed; conversations with school administrators indicate that many think the phenomenon is purely imaginary. Others respond to the topic with vehemence, lamenting the numbers of their colleagues who appear to be victims of burnout. Certainly the fact that each year more and more experienced administrators are taking early retirement makes one consider the possibility of administrator burnout. It is true that recent legislation and district policies have made early retirement more financially attractive than ever before; however, one wonders if burnout may have been a part of the impetus for the development of the early retirement options. (See Appendix A for examples.) In any case, there is a good deal of speculation about the topic, and very little research that is more than conjectural or that is pertinent to school administrators per se. 
The Problem

One reason for the absence of research on administrator burnout is the lack of an instrument for identification and measurement of the phenomenon as it is manifested in this particular population. The Maslach Burnout Inventory was developed for use with people employed in the health and human service occupations (Maslach and Jackson, 1981). Other instruments have been used for special educators (Bensky, et. al., 1980) and for professional educators at all levels in general (Cooley and Savicki, 1981). None deals specifically with the phenomenon of school administrator burnout.

It is the purpose of this study to investigate the characteristics of the Administrator Role Perception Inventory, an instrument which was developed by the writer and a co-author in the year preceding this study. The reliability, scale intercorrelations, and validity of this instrument will be determined. A determination will be made as to the relationship between the Administrator Role Perception Inventory and its subscales and the burnout phenomenon.

The Administrator Role Perception Inventory (ARPI) is an instrument which reflects variables thought to be associated with burnout. These variables have their origins 
in the literature and in earlier research studies, though they may differ slightly in scope and terminology in their present use for this study. Table II summarizes the variables and their sources.

TABLE II

SOURCE OF VARIABLES

Variable

Origin

$\begin{array}{ll}\text { Psycho-physical state } & \text { Maslach and Jackson (1981) } \\ \text { Relationships } & \begin{array}{l}\text { Maslach and Pines (1977) } \\ \text { Bloch (1978) }\end{array} \\ \text { Motivation } & \text { Otto (1980) } \\ \text { Accomplishment } & \text { Maslach and Jackson (1981) } \\ \text { Expectation } & \begin{array}{l}\text { Warnath and Shelton (1976) } \\ \text { Leeson (1980) }\end{array}\end{array}$

Another variable, as yet unresearched, is also included. It is called "Time" and reflects a negative time orientation, a longing for the "good old days."

To summarize, in order for the Administrator Role

Perception Inventory to be a credible instrument for measurement, its validity and internal characteristics had to be determined and described. This necessitated an investigation of its reliability and subscale intercorrelations, 
and its correlation with the variables associated with burnout.

\section{Importance of the Study}

The research process in the social and behavioral sciences focuses on theory development, research design and implementation, and the interpretation of research findings for application in the field. This study is important for its contributions to the areas of measurement and also for its implications for educational practice.

\section{Contribution to Measurement}

A number of instruments which are purported to measure burnout are in existence. Examples are those included in the work of Freudenberger (1980), Leeson (1980), Garcia (1981), and Maslach and Jackson (1981). With the exception of the Maslach Burnout Inventory, little or no information is available concerning the development, testing, reliability, and validity of these instruments. Though they may have served their particular purpose well, they cannot be safely used in other situations. Thorough information on construction, reliability, and validity of the Maslach Burnout Inventory does exist. The preliminary form of 47 items was administered to a sample of 605 people, from a variety of health and service occupations: police, counselors, teachers, nurses, social workers, psychiatrists, psychologists, attorneys, physicians, and agency administrators. 
The second form of 25 items was administered to a new sample of 420 people: nurses, teachers, social workers, probation officers, counselors, mental health workers, and agency administrators. In each case, the sample was large enough to provide a minimum of ten responses per item. Thus, some credence can be given to the correlations supporting the validity of the instrument, and to the internal consistencies as estimated by Cronbach's coefficient alpha (Maslach and Jackson, 1981). The MBI scales are: emotional exhaustion, depersonalization, personal accomplishment, and involvement.

Otto, (1980) defined burnout as "the gradual loss of motivation and productivity with attendant loss of meaningfulness of work" (p. 59). He identified the following dimensions of the syndrome:

1. disillusionment

2. exhaustion

3. meaninglessness of work

4. diminished interest

5. diminished creativity.

This description of burnout was generated by a Delphic probe and is not contradictory to Maslach's conclusions.

In their research on counselor burnout, warnath and Shelton (1976) suggested that expectation discrepancy between what counselors expected in their jobs and what actually occurred is a factor in burnout. 
One might ask if administrator burnout is different from burnout in other professionals. This is not known, but two factors bear consideration in making such a comparison. Burnout has been associated with those who work with people having problems--what this writer characterizes as "deficit situations." The work of school administrators is much broader than that, though negatively-oriented, people problems do occur. Also, burnout has been associated with the degree of direct contact with clients. In schools, the direct clients are the students. However, for the administrators, clients also include other staff and parents; it is the teacher who has the responsibility for the preponderance of direct student contact. Another aspect of this comparison of client relationships is the fact that because of the job type and location, school administrators differ among each other in the amount of contact they have with students. Certainly a junior high school vice-principal has more direct student contact than does a superintendent. Thus, the jobs of school administrators would seem to differ significantly in terms of the nature of the problems encountered and the degree of direct client contact from the jobs of other human services workers. The Administrator Role Perception Inventory, an instrument which has been designed for use with school administrators, on the basis of variables known to be 
associated with burnout in other populations, (as well as one variable as yet unresearched), may provide the measurement tool needed to study burnout within this important professional group.

Contribution to Educational Practice

There is ample evidence that the principal is a vitalIy important factor in determining the effectiveness of a school. Clark, Lotto, and McCarthy (1980) conducted content, propositional, and descriptive analyses on 59 case studies, 38 research studies, and numerous interviews of leading educational writers and researchers. The data from these analyses were selected from an initial inventory of some 1200 studies. They screened these studies for: (1) focus on elementary schools (2) evidence that data had been empirically gathered and that quality designs had been employed, and (3) inclusion of an independent and dependent variable related to leadership, personnel, finance, curriculum and instruction, resources and facilities, or community. Two of the conclusions which emerged were: (1) The behavior of the leader is crucial in determining school success; this leader is frequently the motivation and support for school improvement. (2) The leader's attitude toward education and his or her expectations for the school are far more important to school success than any variables of years of training, experience, and personal characteristics such as sex, race, and age. (3) The effective leaders were 
active, not passive; they did more. They set goals and objectives, established standards, created a productive working environment, and acquired necessary support. The study, which constituted a meta-analysis of the problem of identification of factors which contribute to effective schools, is supported by many individual studies.

The Maryland State Department of Education sponsored a study comparing schools with high pupil achievement to schools with low pupil achievement. They found that one of the factors which accounted for differences between the two groups was the quality of the principal's leadership. Schools with high achievement tended to have principals with high expectations of staff and students and also to have the ability to help them meet these expectations. Furthermore, these principals spent more time outside their offices and inside classrooms (Austin, 1978).

The U. S. Office of Education contracted with the System Development Corporation to evaluate programs funded under the Emergency School Aid Act. As a result of the study, System Development Corporation stated that:

Strength of administrative leadership was a major factor in the schools' ability to improve student achievement. There was consistent evidence that improved achievement was more likely to be found in schools whose principals (a) felt strongly about instruction, (b) effectively communicated their viewpoints about instruction to teachers, through principal/teacher discussions, reviews of teaching performance, etc., (c) took a dominant role in decisions about the selection of instructional materials and in program planning and evaluation, and (d) emphasized academic 
standards by opposing the postponement of basic skill instruction and by requiring students who did not meet academic standards to repeat grades. (coulson, 1977, p. 43)

Additional substantiation of the importance of the principal's role as a factor in the quality of a school can be found in the study done by Brookover and Lezotte for the Michigan Department of Education. They concluded that in schools where pupil performance showed consistent improvement, the principal was more likely to be more assertive as an instructional leader and disciplinarian than in schools where performance was declining (Brookover and Lezotte, 1977).

When interviewed by Brandt (1982) for Educational Leadership, Edmonds, who is a leader in the effective schools movement, offered this description of the principals of effective schools:

Effective principals spend most of their time out in the school--usually in the classrooms. They are constantly engaged in identifying and diagnosing instructional problems.

These men and women spend a lot of time observing classes. But that's only half the formula. They are never content just to identify problems. Their diagnosis is always accompanied by the collegial offering of alternative ways to teach that particular content. What one observes, therefore, is a lot of interaction between teachers and principals ( $p .13$ ).

The following Senate resolution indicates that recognition of the principal's importance is not confined to educational circles:

If a school is a vibrant, innovative, childcentered place; if it has a reputation for excellence in teaching; if students are performing to 
the best of their ability, one can almost always point to the principal's leadership as the key to success. (U. S., Senate, in Lipham, 1981, p. ix)

The principal establishes the tone of the school, the quality of the program, and the responsiveness to the community; all of these acts involve "people" skills. Such skills may be sevarely affected when a person experiences burnout, since the phenomenon apparently causes one to withdraw from and depersonalize one's clients. Manifestations include spending less time with clients and thinking or talking about them in dehumanizing terms (Maslach, 1976). A principal who is behaving in this fashion could hardly be demonstrating high expectations of and frequent interactions with his or her clients (the staff and students). Thus, if burnout is a problem of school principals, there can be negative effects throughout the school.

Although the research has focused on the principal's leadership and its effect on the school, the role of the central office admnistrators should not be overlooked. The school principal does not exist in an organizational vacuum. Much of what he or she is able to accomplish will be influenced by the relationships with the central office administrators, whose own leadership will then be a factor affecting the building administrator. The following leadership skills (Giammatteo and Giammatteo, 1981) apply in all levels of organizations. 
1. Skills of personal behavior. The effective leader:

Is sensitive to feelings of the group.

Identifies self with the needs of the group. Learns to listen attentively.

Refrains from criticizing or ridiculing members' suggestions.

Helps each member feel important and needed. should not argue.

2. Skills of Communication. The effective leader: Makes sure that everyone understands not only what is needed but why.

Makes good communication with the group a routine part of the job.

3. Skills in equality. The effective leader recognizes that:

Everyone is important.

Leadership is to be shared and is not a monopoly.

A leader grows when leadership functions are dispersed. (pp. 3-4)

These leadership behaviors are contradictory to the behaviors of a person experiencing burnout. Thus, burnout at any level of administration is potentially harmful to the educational endeavor.

Because of the lack of research on burnout vis-a-vis school administrators and because of the possible severe consequences of such burnout, an instrument which will enable further research on burnout in this segment of educators is needed.

\section{Organization of the Study}

The study is divided into four remaining sections: review of the literature, methodology and instrumentation, 
results, and summary and conclusions. A brief description of each section follows:

Chapter II--Review of the Literature

Chapter II describes both the procedures of the review of the literature and the content of the review. The problems encountered in doing the review are detailed, and the scope of the review is outlined. Finally, the results of the review are presented.

\section{Chapter III--Methodology}

Chapter III explains the methodology used in the study. Although the development of the ARPI was not a part of the study, a brief review of this is given. The section on the testing of the instrument provides a discussion of the selection of the participants, the administration of the ARPI, and the areas of investigation. Important terms in the study are also defined in chapter III.

Chapter IV--Results

Chapter IV provides the results of the study. The sample on which it was conducted is described in terms of its size, age, administrative positions held, type of positions (line or staff), location of jobs, and years in present position. The scoring procedure and the subscales of the ARPI are explained. Frequency distributions of the administrative scores on the subscales and on the total ARPI are included. 
Measures of reliabiity, which are internal consistency coefficients, are given; the subscale intercorrelations are presented. The results related to content validity and criterion-related validity are supplied.

\section{Chapter V--Summary and Conclusions}

Chapter $V$ provides a summary of the study, and the conclusions drawn from it. The limitations of the study are addressed, as well as recommendations for further research. 
CHAPTER II

REVIEW OF THE LITERATURE

The purpose of this chapter is to integrate the findings of separate studies into a whole which indicates the present state of knowledge about burnout and aids in the development of the research paradigm. The chapter provides a description of the scope of the review, the problems encountered in performing the review, and the results generated by it.

\section{Scope of the Review}

Literature on the subject of burnout has appeared rather recently. The term "teacher burnout" is so new that its first listing as a separate heading in the Education Index occurred in the thirtieth volume (July, 1979 - June, 1980), according to Hillier (1981). Examples from other data archives have confirmed the newness of the topic; earliest references were: Education Resources Information Center, 1977; National Clearing House for Mental Health, 1978; and Dissertation Abstracts, 1980. In 1978, Maslach commented that, "There are virtually no other studies from which one can pull an entire and exact picture of the burnout problem" (p. 56). Edelwich and Brodsky (1980) also 
noted the difficulty of performing a review of the literature due to the newness of the field. (p. 36)

However, as Mattingly (1977) observed, "It is a term that is intuitively grasped and accepted" (p. 88). Perhaps this explains why burnout has become a subject of interest in such a wide variety of fields. It was necessary, therefore, to conduct a very wide search of data archives. (See Table III.) Searches were done electronically in June of 1981 and again in August of 1982. No limitation was placed on the years to be searched.

Because this study focuses on the investigation of the characteristics of a newly-developed and untested instrument, it was also necessary to include certain measurement issues in the review. Of particular interest were the specific characteristics of instruments similar to the ARPI, as well as the general characteristics of the type of instrument that the ARPI represents.

\section{Problems Encountered in the Review}

Three types of problems were encountered in the process of reviewing the literature of burnout. Conceptual definitions were ambiguous. Empirical data was scarce, and the population of articles was limited.

\section{Ambiguity of Conceptual Definitions}

Although much has been and is being written about burnout, definitions differ in clarity and in level of 
TABLE III

ARCHIVES SEARCHED

\begin{tabular}{ll} 
BIOL & Biological Abstracts \\
BOOK & Books Information \\
CHEM & Chemical Abstracts \\
CIJE & Current Index to Journals in Education \\
DISS & Dissertation Abstracts \\
ECER & Exceptional Child Education Resources \\
ERIC & Educational Resources Information Center \\
GPOM & Government Printing Office Monthly \\
HLTH & Health Planning and Administration \\
IHSP & State Publications Index \\
INFO & ABI Information \\
INSP & Science Abstracts, Series A, B, C \\
MESH & Index Medicus \\
MGMT & Management Index \\
NCMH & National Clearing House for Mental Health \\
NIMI & National Information Center for Special \\
NRIC & National Rehabilitation Information Center \\
SSCI & Social Science Index \\
\hline & \\
\hline
\end{tabular}


abstraction. Freudenberger (1974) first used a dictionary definition, "to fail, wear out, or become exhausted by making excessive demands on energy, strength and resources" (p. 159). Later, in 1980, he defined burnout as a condition of "fatigue or frustration brought about by devotion to a cause, way of life, or relationship that failed to produce the expected reward" (p. 13). Kahn (1978) defined burnout as a "syndrome of inappropriate attitudes towards clients and self often associated with uncomfortable physical and emotional symptoms ranging from exhaustion to insomnia to migraine and ulcers." He noted that, "deterioration of performance is a frequent additional element in the syndrome" (p. 61).

Many other psychological complaints have been identified as "burnout." Maslach (1978) identified this concern:

Let me further clarify the definition by explaining what $I$ do not mean by burnout. In some ways burnout is a very good term for the condition because it is evocative. People respond to it-they seem to know instinctively what it is. But it also has a drawback in that it has come to be used to describe just about everything. Burnout has been defined as a loss of creativity--not having new ideas. That is not what we are talking about. Others use burnout to describe their reactions to boredom--"Burning out on the assembly line" with nothing challenging, exciting, new, or different about the job. Again, that is not what we are talking about. Many times burnout refers to any form of job stress, and that seems far too wide a definition. (p. 56)

Pines and Maslach (1978) defined burnout as "a syndrome of physical and emotional exhaustion involving the 
development of negative self-concept, negative job attitudes, loss of concern and feeling for clients" (p. 233). Sparks (1979) said that the components of burnout were exhaustion, tension, and various physical ailments. "The feeling of being locked into a job routine," is spaniol's definition as reported in Reed (1979, p. 67). Gentile and McMillan (1980) said that it is a "debilitating psychological condition resulting from disgruntled employee experiences which foster low employee morale and productivity" (p. 332). Ricken (1980) called burnout "a person attempting to perform their (sic) job by merely going through the motions" (p. 21).

Veninga and spradley (1981b) defined burnout as "a debilitating psychological condition brought about by unrelieved work stress which results in depleted energy reserves, lowered resistance to illness, increased dissatisfaction and pessimism, and increased absenteeism and inefficiency at work" (p. 6).

Otto (1980), on the other hand, called burnout "a gradual reduction of motivation and productivity with attendant loss of compassion and inability to see work as meaningful" (p. 57).

Previous Studies: The Scarcity of Empirical Data

Although much has been written about burnout, empirical data was difficult to locate. Veninga and spradley 
(1981b) mentioned many of the more than 100 occupations they had'studied, using questionnaires and interviews. However, there was no accompanying data about sample size, how the samples were selected, what questions were asked, or data on the reliability and validity of the instruments. They explained:

Our goal was not to study a random sample and make statistical generalizations; rather, we hoped to describe some of the cultural patterns associated with work in our society. (p. 5)

Freudenberger (1980) stated that his work was the result of an examination of his own experiences and a compilation of the experiences of his patients.

Leeson (1980) conducted her research at a midwestern mental health hospital, interviewing social workers employed there. She provided thorough results, but, as she pointed out, the size and nature of the sample preclude generalizations to other populations.

The Delphi technique was used by Otto (1980) in his development of a definition of burnout, and he provided the data generated by his study. However, as he pointed out:

It is the purpose of the present investigation to further examine the phenomenon of burnout, its dimensions, the negative factors that accelerate and amplify it, and the positive things that can be done to avoid, alleviate, or cope with it. (p. 8)

The most complete empirical data on burnout continues to be that which was provided by Maslach and her associates, 
with detailed information on research design, sample size, validity, and reliability (Maslach and Jackson, 1981). In fact, her instrument, the Maslach Burnout Inventory, was used by both Leeson (1980) and Cooley and Savicki (1981).

\section{Limited Target Population for the Review of Literature}

As Cooper (1982) observed, reviewing research involves:

Specifying target and accessible population and considering how they might differ from one another. Identifying populations for research reviews is complicated by the fact that reviews involve two targets. First, the reviewer wants the finding to pertain to all previous research on the problem. - . Second, the reviewer hopes that the retrieved studies will allow generalizations to the unit of analysis that interests the topic area. (pp. 294-295)

For the review at hand, the first target was dealt with by the search of a broad variety of data archives as well as by attendance at conferences, acquisition of conference proceedings, and communication with those presenters whose work was pertinent to this study. However, as Cooper pointed out, "every past study does not have an equal chance of being retrieved by the reviewer" (p. 295). According to Greenwald (1975), about 50 percent of the researchers whose conclusion is a failure to reject the null hypothesis do not publish their results. (p. 5) Also, McNemar (1960) cautioned that when results do not correspond to the "conventional 
wisdom," they may not be as accessible to other researchers as those which do support the prevailing views.

It was the inability of the investigator to achieve the second target--finding studies that would allow generalization to a specific unit of analysis (school administrators)--that led to the development of an instrument for this specific purpose, the Administrator Role Perception Inventory. Not only were the results of most of the studies not generalizable because of methodological problems, none of them dealt with the population of school administrators.

\section{Results of the Review of the Literature}

The review of the literature will be treated in terms of the conceptual framework, which sets forth theoretical bases, instrumentation and measurement, and empirical findings.

\section{Conceptual Framework}

Conceptually, burnout has been viewed as an illness with attention being given to symptoms and techniques for treatment and prevention.

Symptoms. Burnout manifests itself through physical, emotional or psychological, and behavioral symptoms. Freudenberger studied the burnout phenomenon in individuals who worked in widely disparate organizations. He first detailed it in relation to staff members in alternative self-help and crisis intervention institutions (1974). Later, drawing on 
the experiences of the patients in his psychoanalytic practice, he discussed it in relation to employees in corporations (1977). In these articles, he identified the physical symptoms of exhaustion, frequent headaches, gastro-intestinal troubles, lingering colds, sleeplessness, and shortness of breath. He also stated that emotional symptoms included irritability, increasing rigidity, cynicism, quickness to anger, and paranoia. He identified the behaviors associated with burnout as: complaining about the organization, staying late at work or taking work home, changing from an enthusiastic contributor to a grim nonparticipator, Erequently using tranquilizers and barbituates, and accomplishing less at work.

Veninga and spradley (1981b) described the symptoms of burnout as they relate to five stages. Their classification of the symptoms is summarized in Table IV.

The definition of burnout vis a vis those in the health and social service professions was developed by Pines and Maslach (1978) and includes both the physical and emotional dimensions--"a syndrome of physical and emotional exhaustion involving a development of negative self-concept, negative job attitudes, loss of concern and feeling for clients" (p. 233). Maslach told of people who were burned out who made statements that they did not care anymore, that they had no feelings left, that they were drained (1978). Maslach and Jackson (1979) listed the following as possible 
TABLE IV

STAGES OF BURNOUT

\begin{tabular}{|c|c|c|c|}
\hline \multirow{2}{*}{$\begin{array}{l}\text { Burnout } \\
\text { Stage }\end{array}$} & \multicolumn{3}{|c|}{ Typical symptoms } \\
\hline & Physical & Emotional & Behavioral \\
\hline Honeymoon & energy & $\begin{array}{l}\text { enthusiasm } \\
\text { fulfillment } \\
\text { satisfaction }\end{array}$ & $\begin{array}{l}\text { working late } \\
\text { working hard }\end{array}$ \\
\hline $\begin{array}{l}\text { Fuel } \\
\text { Shortage }\end{array}$ & $\begin{array}{l}\text { temporary } \\
\text { but recurr- } \\
\text { ing exhaus- } \\
\text { tion } \\
\text { sleep dis- } \\
\text { turbance }\end{array}$ & $\begin{array}{l}\text { temporary but } \\
\text { recurring dis- } \\
\text { content } \\
\text { dissatisfaction } \\
\text { cynicism }\end{array}$ & $\begin{array}{l}\text { escape } \\
\text { activities } \\
\text { decreased } \\
\text { creativity } \\
\text { increased } \\
\text { accidents, } \\
\text { harder work, } \\
\text { less accomp- } \\
\text { lished }\end{array}$ \\
\hline $\begin{array}{l}\text { Chronic } \\
\text { Symptoms }\end{array}$ & $\begin{array}{l}\text { chronic ex- } \\
\text { haustion } \\
\text { physical } \\
\text { illness, } \\
\text { headaches, } \\
\text { heartburn, }\end{array}$ & $\begin{array}{l}\text { depression } \\
\text { anger }\end{array}$ & $\begin{array}{l}\text { loss of inter- } \\
\text { est in hobbies } \\
\text { decreased at- } \\
\text { tention span } \\
\text { expressions } \\
\text { of anger }\end{array}$ \\
\hline Crisis & $\begin{array}{l}\text { physical } \\
\text { symptoms } \\
\text { intensify }\end{array}$ & $\begin{array}{l}\text { deep disillu- } \\
\text { sionment } \\
\text { self-doubt } \\
\text { despair }\end{array}$ & $\begin{array}{l}\text { constant talk } \\
\text { about problems } \\
\text { at work; } \\
\text { complete with- } \\
\text { drawal }\end{array}$ \\
\hline $\begin{array}{l}\text { Hitting } \\
\text { the Wall }\end{array}$ & $\begin{array}{l}\text { alcoholism, } \\
\text { drug abuse, }\end{array}$ & $\begin{array}{l}\text { mental } \\
\text { illness }\end{array}$ & $\begin{array}{l}\text { complete } \\
\text { loss of } \\
\text { control of } \\
\text { life }\end{array}$ \\
\hline
\end{tabular}


physical symptoms: alcoholism, susceptibility to illness, ulcers, and frequent headaches. In 1976, Maslach listed the following behaviors associated with burnout: high absenteeism, quitting a job, use of derogatory terms when talking about clients, describing clients' problems through jargon, and strict adherence to rules and regulations with virtually no effort expended in finding creative solutions to problems. She pointed out that all of these behaviors have a similar goal--that of providing distance from the client.

Kahn's (1978) definition also identified the physical, emotional, and behavioral components of burnout. He stated that burnout was a

Syndrome of inappropriate attitudes toward clients and often associated with uncomfortable physical and emotional symptoms ranging from exhaustion to insomnia to migraine and ulcers. . Deterioration of performance is a frequent additional element in the syndrome. (p. 61)

Using a Delphi approach, Otto (1980) found that lack of motivation was the prime symptom of burnout.

Mattingly (1977) observed that there is no one checklist of symptoms for burnout, but that it is a pattern of symptoms that will have unique manifestations for each individual. She gave as examples: a reluctance to go to work, a feeling of dissatisfaction with what one is accomplishing, witharawal from others, inflexibiilty, hypersensitivity to noise, and loss of trust in colleagues.

It can be seen that burnout is a pattern of symptoms that are emotional, physical, and behavioral in nature. 
Common to all the descriptions of symptoms are exhaustion, lack of compassion for clients, and a feeling of lack of accomplishment. However, Savicki and Cooley (1980) made the important observation that the term "burnout" should be used "only in cases in which all of these symptoms are present" (p. 5). They were referring to those symptoms identified by Maslach and Jackson (1981) in their design of the Maslach Burnout Inventory: emotional exhaustion, depersonalization of clients, and lack of feeling of personal accomplishment. Savicki and Cooley continued:

Because these symptom clusters are relatively independent it may be possible that a person could show high scores in one or even two of the symptom areas without scoring in the same direction in the third area. Such people are obviously not occupationally happy and efficient, but are not burnedout according to this configural definition. ( $p$. 5)

Techniques for treatment and prevention. Veninga and Spradley (1981b) suggested the importance of consciously managing stress, separating oneself from one's job, and taking a stress inventory as techniques for the avoidance of burnout.

Freudenberger (1980) recommended reviewing and revising one's goals, examining one's relationships, taking days off, delegating responsibility, and striving to have a well-rounded life as general methods for coping with burnout. 
Truch (1980) provided the acronym READ as a prescription for combating burnout. It consists of relaxation, exercise, attitude and awareness, and diet. Edelwich and Brodsky (1980) recommended a similar program--separation of work from private life, development of outside interests, development of realistic expectations, and increased training.

In conclusion, it can be seen that a number of techniques for coping with burnout have been suggested. As in other aspects of study of this phenomenon, Maslach and Jackson provided the data to support their recommendations, which included time away from clients and discussion of problems with colleagues. Other recommendations have not been accompanied with empirical data, but certainly contributed interest and suggestions for further research.

\section{Theoretical Bases}

That a great discrepancy between expectation and reality, between efforts and outcome, are probably causes of burnout has the agreement of Freudenberger (1980), Warnath and Shelton (1976), and Veninga and Spradley (1981b). There is also agreement that stress is a major cause of burnout (Veninga and Spradley, 1981b; Maslach, 1976, Freudenberger, 1980). The generalized stress model presented in this section is useful in understanding burnout. This model can also accommodate the variable of expectation discrepancy 
when that variable is viewed as a stressor, and the cognitive dissonance theory of Festinger (1978) provides support for such a view.

Selye (1980) has defined stress as "'the nonspecific (that is, common) result of any demand upon the body' be it a mental or somatic demand for survival and the accomplishment of our aims" (p. vii). Elaborating upon this definition, Dohrenwend in Selye (1980) developed a stress model, It shows that a stressful event occurs and produces in the individual a state of stress. At this point, external factors such as social and material resources affect the individual. Also, the internal characteristics of the person (aspirations, values, skills, physical strengths and weaknesses) become a part of the situation. This interaction of the state of stress, the external influences, and the internal propensities will result in one of three general outcomes. According to this model, there may be psychosocial growth for the person, there may be no change, or there may be a negative change in the health or functioning of the individual. Dohrenwend and Dohrenwend summarized the model:

If a stressful life event impinges on an individual and certain unfavorable states of internal and external mediating factors are present, then dysfunctional behavior or illness will result. The occurrence of dysfunctional behavior or illness does not, however, imply the existence of a stress process, since changes in behavior or health can arise from other causes. (p. 3) 
From the previous discussion of the symptoms of burnout, it is evident that the burnout phenomenon superimposes nicely on this model of the life stress process, as it would be one example of the "adverse change in health or functioning." An early conception of the stress response was outlined by Cannon (1929) and has been called the "fight-orflight" response. Veninga and spradley (1981b) outlined four phases of the response: (1) Mobilization--biochemical changes take place causing physiological responses such as tensing of muscles, increase in pulse, heightened adrenalin secretion, and constriction of blood vessels. (2) Energy increase--the body's preparation for action causes large amounts of energy to be consumed. (3) Muscular involvement--the muscles respond with flight or fight, which was the reason for the mobilization and energy consumption. Return to equilibrium--the body returns to its normal state. The energy increase referred to by Veninga was called "adaptation energy" by selye (1969). He said that a person has a limited amount of this energy available when a stressor is encountered. After that energy has been consumed, the body requires a time away from the source of the stress in order to replenish its supply of adaptation energy. Without time for this replenishment, all the adaptation energy is consumed and the person becomes exhausted. 
Selye (1980) enumerated several principles for understanding stress.

A psychologic stressor can only act if it is appreciated as such. Otherwise, there is no stress; in fact, there is no demand. Under deep anesthesia, a person cannot be placed under stress of the most irritating boss, spouse, or financial calamity, just as exposure to $x$-rays makes no demand if we are completely protected by a lead screen.

The fact that all stress situations are apparently different does not nullify their nonspecificity. That both the event and the response to it are always specific is self-evident and was emphasized in the earliest papers on this subject. This is explained by two circumstances: (a) the stressor is always accompanied by specific side effects; (b) both internal and external presupposing or immunizing factors modify the response. These last factors have long been recognized in stress research; we call them conditioning factors. They may be internal (e.g. heredity, previous exposure to stress) or external (e.g. air pollution, traditions or education, seasonal variation).

Stress is not a yes or no phenomenon. We must recognize that stress can exist in various degrees. Different demands, and different intensities of the same demands, do not always cause equal stress reactions. Almost anything we feel or do represents a demand, but in each situation the role of stress may be more or less important. (p. xi)

In their review of comprehensive life event studies, Dohrenwend and Dohrenwend (in Seyle, 1980) were able to generalize about what was the common ingredient to stressful life events. They found that "stressful life events include those that involve change in the usual activities of most individuals who experience them" (p. 7). They also concluded that the degree of impact of a life event on an individual is related to the expectation the individual has 
of the stressfulness of that event. "We hypothesize that the impact of a life event on an individual will be determined by a learned normative expectancy concerning the stressfulness of that event" (p. 11).

To summarize, an event is stressful if it involves a change in the usual activities, thus placing a demand on the body, and if the event is perceived as stressful by the person experiencing it. The perception of the event as stressful is learned; that is, social norms enable one who has not experienced an event to have expectations about its stressfulness.

Measurement and Instrumentation

The issue of measurement and instrumentation is discussed in terms of general characteristics for measuring personality, self-concept, attitudes, values, and opinions. The issue of specific instrumentation for the assessment of burnout is also included.

General characteristics. The review of the literature indicates that burnout manifests itself through certain self-concepts, attitudes, opinions, and values. Therefore, measurement of these variables should provide a foundation for understanding of the measurement of the burnout phenomenon. Often this is accomplished by asking individuals to respond to a set of statements (items) by indicating their degree of agreement or disagreement. Each response is given 
a certain value, and that is the individual's item score. All the item scores taken together represent that person's position on the variable (Shaw and Wright, 1967).

Shaw and wright pointed out, also, that these items are often developed by Likert's scaling technique in which a sample of the target population is asked to respond to a large number of items, indicating their degree of agreement or disagreement. The responses are scored from 5 to 1, with 5 being the most positive. Items that are written in the negative are given a reverse scoring. The score for each scale is added up and then the total score for each item is correlated with the scale total. If an item has a high correlation with the scale total, it is retained. The explanation for the correlation of the items is that there is a single factor that is common to all of them (Green, 1954). This single factor is the variable (attitude, personality construct, value, or opinion) that one hoped to measure.

Shaw and wright (1967) said that the use of this procedure will produce moderately reliable scores. Sometimes unidimensionality is inferred when there are high item correlations with the total score, but these high correlations could indicate that there are two or more very strong factors, rather than just one.

In this method, there is no attempt to achieve units of equal intervals, and Shaw and wright have cautioned that 
though Likert-type scales are often reliable and valid, interpretation of individual profiles must be based upon the entire distribution of the scores; in other words, a score has meaning only in relation to the other scores in the sample. They pointed out the importance of standardizing the scale on a sample drawn from the target population. Because burnout appears to affect the entire individual, personality assessment, the "description of what an individual is like at any given moment in time" (Edwards, 1970 , p. 1) also became a source of information on measurement techniques and existing instruments that might be applicable in the problem of assessing burnout. Several instruments for measuring personality, attitudes, and stress bore some relation to the topic and provided useful examples of methods of establishing reliability and validity. Some of these instruments and a summarization of their internal characteristics and measures of validity are included in Appendix F.

Measures and intrumentation related to burnout. The Maslach Burnout Inventory is apparently the only measure of burnout that has been assessed in terms of its internal characteristics. It consists of 25 statements relating to one's feelings, perceptions, and attitudes about work. The individual evaluates each statement in terms of how frequently he or she experiences that feeling, perception, or attitude and how intensely it is experienced. Four 
subscales are used: emotional exhaustion, depersonalization, personal accomplishment, and personal involvement. The preliminary form of 47 items was administered to a sample of 605 people, from a variety of health and service occupations: police, counselors, attorneys, physicians, and agency administrators. Four criteria were used in selecting the items to be retained. They were: low number of individuals checking the "never" response, wide range of subject response, a factor loading of .40 or more on only one of the sub-scales, and a high item-total correlation (Maslach and Jackson, 1981).1

Cronbach's coefficient alpha was used to obtain reliability coefficients of .83 for frequency and .84 for intensity, for the entire sale. The separate scales had the following reliabilities: emotional exhaustion, .89 for frequency and .86 for intensity; depersonalization, .77 for frequency and .72 for intensity; personal accomplishment, .74 for Erequency and intensity; involvement, .59 for frequency and .57 for intensity.

Criterion-related validity was shown by three methods: a subject's individual MBI score was correlated with observations made by somone who knew him or her well. A second

1 It is assumed that they are referring to the correlation between an item and its particular subscale, rather than between an item and the entire MBI. 
method was the correlation of the score with job characteristics expected to contribute to burnout. Thirdly, the scores were correlated with outcomes thought to be associated with burnout, such as dissatisfaction with chances for professional growth at work, perceived meaninglessness of work, and a dearth of feedback on job performance. (Maslach and Jackson 1981, p. 107)

\section{Empirical Findings}

The empirical findings related to the burnout phenomenon are covered in this section. They are organized according to the hypotheses with which they are associated.

\section{Job dissatisfaction and burnout as separate entities.}

Maslach and Jackson (1977) found that job dissatisfaction and burnout were separate entities. The correlation between emotional exhaustion and job satisfaction was -.23 ; between depersonalization and job satisfaction, -.23; and between personal accomplishment and job satisfaction, .17.

Maslach dealt with the issue of social desirability by having 40 graduate students in social welfare do both the MBI and the Crowne-Marlowe (1964) Social Desirability Scale. The scores showed no significant correlation (Maslach and Jackson, 1981).

Thus, Maslach and Jackson demonstrated that burnout and job dissatisfaction were not the same thing, and that 
individuals apparently did not let the social acceptability of certain answers prevent them from indicating their own feelings. A weakness in this conclusion is the question of generalizability from graduate students to employed professionals.

Specific techniques for avoiding burnout. Maslach and Jackson (1977) found in their study of physicians that:

Those scoring low on emotional exhaustion gave high effectiveness ratings to: seeking the advice of other staff regarding specific problems, and talking with their co-workers about any difficulties they were having. Physicians scoring high on personal accomplishment reported that effective coping strategies were: discussing with patients the limitations on their professional relationship with them, reading accounts of how others have handled specific problems, and talking to their spouse and or close friend about what has happened at work. (p. 27).

They also found that nurses who scored high on personal accomplishment found patient-centered techniques helpful. They tried to look at things from the patient's point of view and to use humor in their contact with patients. A separate study showed that nurses who felt supported and recognized by their co-workers and supervisors had lower scores on emotional exhaustion.

Situational factors. Situational, or external factors which contribute to burnout have been studied. Table V provides a concise listing of the factors and the supporting studies reported in this section. 
TABLE V

SITUATIONAL FACTORS CONTRIBUTING TO BURNOUT

\begin{tabular}{|c|c|}
\hline Factors & Authors \\
\hline role ambiguity & $\begin{array}{l}\text { Kahn (1978); Schwab and } \\
\text { Iwanicki (1982); Rizzo, } \\
\text { House, and Lirtzman }(1970) ; \\
\text { Maslach and Jackson }(1981)\end{array}$ \\
\hline role conflict & $\begin{array}{l}\text { Kahn (1978); Schwab and } \\
\text { Iwanicki (1982); Rizzo, } \\
\text { House, and Lirtzman (1970) }\end{array}$ \\
\hline degree of client contact & $\begin{array}{l}\text { Maslach and Jackson (1977); } \\
\text { Pines and Maslach }(1978)\end{array}$ \\
\hline client-worker interaction & Pines and Maslach (1978) \\
\hline organizational system & $\begin{array}{l}\text { Freudenberger }(1980) \text {; Savicki } \\
(1981)\end{array}$ \\
\hline inadequacy of training & Warnath and shelton (1976) \\
\hline locus of control & $\begin{array}{l}\text { Maslach and Jackson }(1977) \text {; } \\
\text { Minahan (1980); Savicki } \\
(1980)\end{array}$ \\
\hline
\end{tabular}

Kahn (1978) identified role conflict as one of the most widespread stresses related to work. He listed as examples of role conflict: (a) incompatible demands, especially as related to working with people both within the organization and those outside it, (b) too many demands to be met at the same time, (c) demands which are too difficult. 
Rizzo, House, and Lirtzman (1970) measured role conflict and role ambiguity. They found only a slight positive correlation between these variables and anxiety. Role ambiguity was studied in terms of feedback on job performance. Maslach and Jackson (1981) found that nurses who received little feedback on their performance had higher scores on emotional exhaustion and depersonalization and lower scores on sense of accomplishment.

Maslach and Jackson (1977) also found that the degree of direct contact with the recipients of services was related to burnout. Physicians who spent more than 28 percent of their time directly with patients scored above the mean on emotional exhaustion, while those physicians who spent less than 17 percent of their time in direct contact scored below the mean.

Lack of control over factors affecting work is another factor associated with higher scores on emotional exhaustion (Maslach and Jackson, 1981). Sparks (1979) and Minahan (1980) also identified lack of control over work as factors that affect job attitudes.

In their study of health care workers, Maslach and Jackson (1977) made the following observations about the helper-client interaction: 
In most cases, the structure of the helping relationship is such that it promotes and maintains a negative perception of patients. In particular, four aspects of this relationship seem to be especially critical: the focus on problems, the lack of positive feedback, the type of patient contact, and the probability of change or responsiveness by patients. (p. 19-20)

Other situational factors that have been identified as causes of burnout are inadequate training which leads to unrealistic expectations (Warnath and Shelton, 1976) and organizational insensitivities (Freudenberger, 1980).

In 1971, Hackman and Lawler did a study which offered support for the expectancy theory while also including elements of the theories of Maslow and Herzberg. They sought to determine the nature of the overall relationship between job characteristics and the employees' attitudes and work behavior. In the same study, they sought to discover if the reaction to one's work is dependent on the kind of satisfaction one values. They looked at the work of 200 telephone company employees in 13 jobs and assessed these jobs for the core dimensions of autonomy, task identity, variety, and feedback. They also assessed the strength of desire for higher-order need satisfaction by asking employees how much they would like to obtain feelings of personal growth and development and accomplishment. The result was that the "better" the employee's job was in terms of the core dimensions, the more positively he responded to it in terms of attitude and behavior. When the employees performed well on such jobs, they experienced positive feelings. 
When they did poorly, they felt bad. On the jobs which were low, in the core dimensions, employees tended not to have such Feelings.

It was concluded that jobs high in the dimensions of autonomy, task identity, variety, and feedback established conditions in which workers could obtain personally rewarding experiences by doing well on the job. They also found that there were employees with low growth-need strength and that with these employees there was a low correlation with core dimensions and satisfaction. Thus, only workers with reasonable high strength of desire for higher order needs responded positively and productively to jobs rich in the core dimensions (Hackman and Lawler, 1971).

Factors within the individual. The following factors within individuals have been suggested as causes of burnout; these factors are summarized in Table VI.

\section{TABLE VI}

FACTORS WITHIN THE INDIVIDUAL CONTRIBUTING TO BURNOUT

FACTORS

Attitudes about self and job

Expectation discrepancy

Rigidity of strategies
SOURCES

Freudenberger (1980); Savicki (1981)

Leeson (1980); Maslach and Jackson (1977)

Cooley and Savicki (1981) 
In 1980, Savicki integrated his findings with those of Freudenberger. He presented this classification of factors within the individual which contribute to burnout:

Overcommitted: This person puts themselves (sic) last and therefore uses up energy in helping others in such a degree that they (sic) have very little left for themselves.

Achiever: This person defines their (sic) personal worth through achievement in the helping professions. Often times achievement depends on the change and behavior of another person. Since the achiever cannot control the behavior change of another person with very great precision, if at all, this person may lose their (sic) sense of self-worth.

Rescuer: This person gains his worth by defining others as in need of his help. This assumption of others being less than able to solve their own problems may be conveyed in subtle ways and may encourage rebellious or resisting behavior on the part of the recipient of help. Therefore, the rescuer's attempts may be frustrated by the very method in which he attempts to help.

Peacemaker: This person takes on himself the task of soothing all difficulties, keeping the lid on negative emotions. And since there are always negative emotions and things that cause stress among people, this person wears themselves (sic) out by taking on this impossible task and also becomes frustrated at the futility of it.

Catastrophizer: This person says to themselves (sic), 'if I don't do it, nobody else will,' and may also say, 'nobody can do it as well as I can.' This assumption leaves a great deal to be done by this one individual. (p. 4 )

Leeson (1980) found that the greater the discrepancy between expectation and extent of attainment, the greater the incidence and degree of burnout. Like Warnath and Shelton, 
she linked these expectations to the type of training the social workers had received.

Otto (1980) included the concept of a gradual decrease in motivation as part of his definition of burnout. Although Lawler and Suttle (1974) did not deal with the issue of burnout per se, they described an expectancy model for motivation. This model states that motivation is a function of the perceived likelihood that effort will lead to performance and that performance will lead to the desired outcome. For example, in order for a person to be motivated to get rid of a smoker's cough, he must perceive that his effort to quit smoking will lead to his becoming a nonsmoker, which in turn will cause the cessation of the cough (which he views as desirable.)

Lawler and suttle (1974) did a study involving 69 managers in a retail organization. They found that the attitudes of expectancy of these managers were significantly related to some measures of effort and performance. They also cited 28 studies in which correlation between job performance and expectancy were found. However, they found little support for the statement that expectancy attitudes cause performance.

Cooley and Savicki (1981) labeled one possible cause of burnout "too much of a good thing." They conjectured that people in the helping professions learn strategies that 
are very effective, but, as time passes, these people continue to apply the strategies in situations for which they are inappropriate. Faced with failure, the helper tries even harder, still using the same strategies. This continues until frustration becomes exhaustion.

\section{Summary}

This review of the literature has included the following aspects of the burnout phenomenon: the conceptual framework, a theoretical base, measures and instrumenation, and the empirical findings. Several problems were encountered in the process of the review. The conceptual definitions of burnout were ambiguous, and there was a scarcity of empirical data. Few studies pertinent to school administrators were found; those which were located, focused on stress rather than the burnout phenomenon.

Many authors agreed that emotional exhaustion, decreased sense of accomplishment, reduced motivation, and negative feelings about clients were some of the facets of burnout. There was unanimous agreement that stress is a major factor in burnout.

With the exception of the Maslach Burnout Inventory, apparently no instruments for measuring burnout have been assessed in terms of their reliability and validity. Because this instrument was developed and tested on populations which did not include school administrators, its use could not be generalized to them. It was apparent from 
this review that instrumentation for studying the phenomenon in the population of public school administrators is not in existence. It was this lack which gave impetus to the writer in developing her study of the Administrator Role Perception Inventory, an instrument which may provide important correlates between role perception and burnout. 
CHAPTER III

METHODOLOGY

Although the creation of the Administrator Role Perception Inventory (ARPI) is not the focus of this study, a brief discussion of its development will lend clarity to the methodological considerations in determining its characteristics. This discussion is included in Chapter III.

Also included in this chapter is aiscussion of how the instrument was tested. The selection of subjects, administration of the inventory, areas of investigation, and the definitions of important terms are also included.

\section{Development of the ARPI}

The review of the literature made apparent the lack of instrumentation suitable for assessing burnout in school administrators. It also became clear that the burnout phenomenon has multiple facets-physical, emotional, mental, and behavioral--that are manifested across the entire spectrum of a professional's role. That the items of the ARPI reflect this breadth was a guiding influence in item writing and selection. 
Item writing

The writer and the co-author began the item writing for the Administrator Role Perception Inventory in November of 1981, following the initial review of the literature. Originally, 11 variables that appeared to be related to burnout were considered. These variables were: locus of control, ego strength, expectation discrepancy, identification, temperament, involvement, motivation source, motivation quantity, acceptance, accomplishment and physical vigor. Items were written for each variable, and each item placed on a separate card. The cards were sorted and grouped again by logic into the 11 categories. This process continued over a period of about a month, along with editing for clarity, brevity, and relevance to school administrative roles. The result was an instrument with 138 items, divided among the 11 subscales.

The term "burnout" was deliberately omitted from the title and from all items on the instrument. Conversations with administrators had shown the prevalance of strong opinions about the phenomenon, and it was felt that the presence of "burnout" would stimulate those opinions and inject a considerable bias in the respondents' answers.

The first version of the Administrator Role Perception Inventory was field tested in February of 1982, in a suburban school district in the Portland metropolitan area. Twenty-eight school administrators participated. Analysis 
of participant comments and item-scale correlations resulted in the development of a second version of the ARPI, containing 66 items on six subscales: Psycho-physical state, Relationships, Accomplishment, Motivation, Expectation and Time. This instrument was field tested in April and May of 1982, in a large urban district and in a somewhat rural one, and with graduate students in educational administration. A total of 161 graduate students and administrators took part. Analysis similar to that done on the first version was completed, and a third edition of ARPI resulted. It contained 50 items on six subscales: Psycho-physical state, Relationships, Accomplishment, Motivation, Expectation and Time orientation. It is this form of the ARPI for which the internal characteristics and validity were studied.

\section{Definition of Terms}

The subscales of the final version of the Administrator Role Perception Inventory are defined as follows:

Expectation: The degree of discrepancy between one's reality and one's anticipated reality relative to one's job.

Relationships: The desire for and the quality of the continuous interaction with work-related colleagues and clients; the identification and involvement of self with colleagues and clients; and the acceptance of oneself by clients and colleagues. 
Motivation: The propensity to initiate action; the inclination toward proactivity.

Accomplishment: The sense of attainment of one's professional goals.

Psycho-physical state: The overall mental, emotional, and physical vigor and resilience of an individual. Time: The tendency to view the past as better than the present; a longing for the "good old days."

The entire scale of administrative role perception is defined as: the administrator's unique and private perception of his or her phenomenological world, in terms of expectation, motivation, accomplishment, relationships, psycho-physical state, and time orientation.

This total role perception is believed to be related to burnout, which is defined as a syndrome involving (1) decreased motivation, (2) expectation discrepancy, (3) negative attitudes toward self, clients, and job, and (4) physical and emotional exhaustion.

\section{Testing the Instrument}

In the description of the determination of the internal characteristics and the validity of the ARPI, three concerns are addressed. These issues are: selection of participants, administration of the instrument, and the areas of investigation. 
Selection of Subjects

Nunnally (1972) pointed out that the two important characteristics of any sample are:

That it be unbiased and that sufficient numbers of students [subjects] be involved. If the sample is unbiased, the precision with which the sample correlation estimates the real population correlation varies with the number of students [subjects] involved. Correlations based on 100 students [subjects] provide more accurate estimates than those based on 10 students [subjects]. Correlations based on 1,000 students [subjects] would provide much better estimates. (p. 88-89)

For this study, a sample population was desired that

would (1) assure at least 600 respondents, and preferably 1000, and (2) be representative of school administrators in Oregon. Judging that a better response rate would be obtained if the study were backed by a recognized and credible organization, the investigator sought the help of the Confederation of Oregon School Administrators ( $\operatorname{Cos} A)$. Dr. R. I. Rose, Executive Director of COSA, was initially contacted by telephone in December of 1981 about the possiblity of COSA's participation in the study. Dr. Rose explained the levels of support that could be requested of the $\cos A$ Council. In June of 1982 , the request for endorsement was accepted by the Council. (See Appendix B.) The Confederation of Oregon School Administrators is the largest organization of school administrators in the state. Its 2,113 active members included administrators from all levels and types of school administration. To in- 
sure an adequate number of responses, the decision was made to include the entire membership in the study.

\section{Administration of the ARPI}

On July 29, 1982, a packet of survey materials was prepared for each COSA member. The contents of each packet included a letter of endorsement from Dr. Rose of CosA, a letter of explanation from the investigator, a copy of the ARPI, the Job Data Sheet, and a postage-paid envelope for the return of the ARPI to COSA. (See Appendix C for examples.) Anonymity was guaranteed by the absence of any kind of identifying code of these materials. The packets were bundled by $z$ ip code for mailing.

One hundred and fifty-nine bundles contained three or more packets. From each of these 159 bundles, one packet was randomly removed. The materials in it were labeled with the $z$ ip code, and a zip code-labeled colleague Packet was inserted. (See Appendix D for contents.) The COSA member was instructed to give this Colleague Packet to a colleague, who would independently complete the information about the member and then return it in a separate, postage-paid envelope to $\cos A$. The entire mailing was sent out on August 15.

Two weeks later, a reminder notice was sent to every member. (See Appendix E for text of reminder.) Because of the concern for anonymity, it was not possible to determine which members had already returned their materials. 
Areas of Investigation

Two internal characteristics of the ARPI were investigated:

(1) reliability

(2) subscale intercorrelations

Two types of validity were studied:

(1) content validity

(2) criterion-related validity

Reliability. According to Marshall and Hales (1971), there are four sources of measurement error that can produce lowered test reliability. In this section, these four sources are identified, and the efforts to minimize each are described. Following this discussion is an explanation of the method used in the study to determine the reliability of the ARPI.

One source of error is due to the sampling of content, that is, the items comprising the instrument may not accurately represent the total pool of hypothetical items which could be used to measure the possession of each trait. Nunnally (1972) said:

The major source of error in most psychological measures relates to the sampling of content. Although the other sources of measurement error discussed in this section are important, the unreliability inherent in most tests is due to the fact that they are not long enough and not broadly representative enough of the content in a particular unit of instruction, an area of achievement, or an aptitude trait. Nothing helps to promote the precision (reliability) of a measuring instrument as 
much as having a relatively large number of items that diversely represent the content in a particular topic. (p. 101-102)

In this study, the attempt was made to include enough items to provide an adequate sample without making the instrument so long that potential respondents would discard it or complete only a part of it. 2 The original version of the ARPI contained 138 items and 11 subscales. Comments of the administrators who participated in the field test of this version indicated that it was much too long. A review of the item analysis also led to the collapsing of the 11 subscales into six. Thus, the second version contained fewer subscales and only 66 items. Analysis of the field test of this second version of ARPI resulted in the retention of the six subscales, but once again participants complained about the length of the instrument. The final version was shortened to 50 items comprising the six subscales. It was felt that reliability would suffer if the subscales were reduced further. Thus, results during the field tests were used to weigh the issue of sufficient length for reliability against sufficient brevity to prevent non-participation. Table VII summarizes the changes as the instrument was developed.

2 An adequate sample was considered to be one that would provide 10 items for each scale. 
TABLE VII

DEVELOPMENTAL CHANGES IN THE ARPI

\begin{tabular}{cccc}
\hline Version & Number of Subscales & Number of Items \\
\hline 1 & 11 & 138 \\
2 & 6 & 66 \\
3 & 6 & 50 \\
\hline
\end{tabular}

Diversity of items was another concern. A careful review of the literature provided examples of the diversity that was needed, and items were developed to reflect this diversity.

Another potential source of error is in the administration of the instrument. The circumstances of the day and how the administrator feels can affect the response. This is very difficult to control in a mailed questionnaire, but consideration was given to the issue. Most of the administrators who were surveyed work in schools. The time of year is probably an important factor in a building administrator's perceptions. Having the materials reach administrators during a time when conditions would be more alike for all of them was viewed as important to the reliability. At first, mid-June was selected for the mailing. This was postponed to mid-August for two reasons: (1) to allow presentation of the project to the $\cos A$ Council and (2) to conduct the research at a time when participants would more likely be rested, rather than very tired from the end of 
school activities. The two or three weeks preceding the opening of school are busy, but an administrator's schedule is generally more flexible than after teachers and students arrive. Discipline problems have not begun; parent complaints are rare. Often the administrator is taking part in an inservice experience that promotes a positive and optimistic view of the year to come. These conditions are certainly not uniform for all administrators, of course. Unsettled contracts, unpassed levies, and unfinished construction are examples of circumstances that would decrease the general quiet and calm of the weeks preceding the opening of school. Also, central office administrators have a different cycle of pressures than do building administrators. For the administrator who is putting a new program into place, completing last minute hiring, or implementing the August inservice activities, the last weeks in August would be quite busy. Nevertheless, it was felt that of all the weeks in the school year, these were more likely to be more similar than any others, for the majority of the population to be surveyed.

The fourth source of error is in the consistency of the variable. If the test is internally consistent, a person will respond similarly to similar items. In this study, items were written as unambiguously as possible. Participants in the field test of the first two versions offered many suggestions concerning the ambiguity of certain items. 
These suggestions were weighed and many were incorporated into the wording of the items in the version used for this study

Having addressed the source of potential error, the several ways of determining reliability can be addressed. The test-retest method addresses the concern about errors of measurement resulting from differences in individual and environmental circumstances at times the test is administered. Only one form of the test is used, so this method does not show error from sampling inconsistency. The additional expense and time required to carry out a test-retest procedure made such a method undesirable for this study.

The equivalent forms method is considered by Marshall and Hales (1971) to be the most complete in that it addresses the issue of day-to-day changes in circumstances as well as improper sampling of items. However, the necessity of constructing equivalent forms with the resulting increased time and expense made this method impractical.

Nunnally has said that the major problem in test reliability is from improper item sampling. The internal consistency method focuses on this source of error. Use of it requires no additional time or expense, and is considered to be a preferred procedure "when the retest method is not advisable and when alternate forms are not available" (NunnalIy, 1972, p. 111). Thus, coefficient alpha, a measure of internal consistency, was selected as the statistic to 
describe the reliability of the ARPI. It was calculated for each of the six subscales, as well as for the entire ARPI.

Subscale intercorrelations. The relationships among the subscales were determined by obtaining the Pearson product-moment coefficients of correlation for all pairs of subscales. These coefficients indicate the degree to which the pairs of subscales are measuring the same thing.

Content validity. Content validity has been defined by Kerlinger (1973) as, "the representativeness or sampling adequacy of the content" (p. 458). He continued:

Content validation is guided by the question: Is the substance or content of this measure representative of the content or the universe of content of the property being measured?. . . Content validation consists essentially in judgement. Alone or with others, one judges the representativeness of the items." (p. 458)

For the ARPI, judgement was made by the writer and the coauthor. The writer sought the opinions of practicing school administrators as to the nature of burnout; she incorporated the results of the review of the literature, she obtained information from and attended conferences related to burnout; she discussed the topic with colleagues in educational administration, public administration, and psychology. Finally, she field tested the early drafts, and studied the reliabilities with the co-author; together they judged which items would not hold up at all, and those items were discarded. Thus, although the matter of content validity is quite subjective, a number of methods were employed in order to establish that validity. 


\section{Criterion-related validity. Kerlinger defined}

criterion-related validity as follows:

... Criterion-related validity is studied by comparing test or scale scores with one or more external variables, or criteria known or believed to measure the attribute under study. (p. 459)

stress has been shown to be related to burnout. Therefore, coefficients of correlation were determined for the administrators' total ARPI scores and their subscale scores with these questions on the accompanying Job Data Sheet, as shown in Figure 1.

9. How much stress is in your work?

\begin{tabular}{cccccccc}
\hline 0 & 1 & 2 & 3 & 4 & 5 & 6 & 7 \\
none & some & moderate & 8 \\
able & & $\begin{array}{c}\text { tremen- } \\
\text { dous }\end{array}$
\end{tabular}

10. How much stress do you feel?

\begin{tabular}{cccccccc}
\hline 0 & 1 & 2 & 3 & 4 & 5 & 6 \\
none & some & moderate & 7 & 8 \\
able & tremen- \\
dous
\end{tabular}

Figure 1. Stress questions on Job Data Sheet

In addition, the desire to get out of one's job has been shown to be related to burnout (Maslach and Jackson, 1979). Thus, coefficients of correlation were determined for the administrators' total ARPI scores and their subscale scores with these questions on the Job Data Sheet, as shown in Figure 2. 


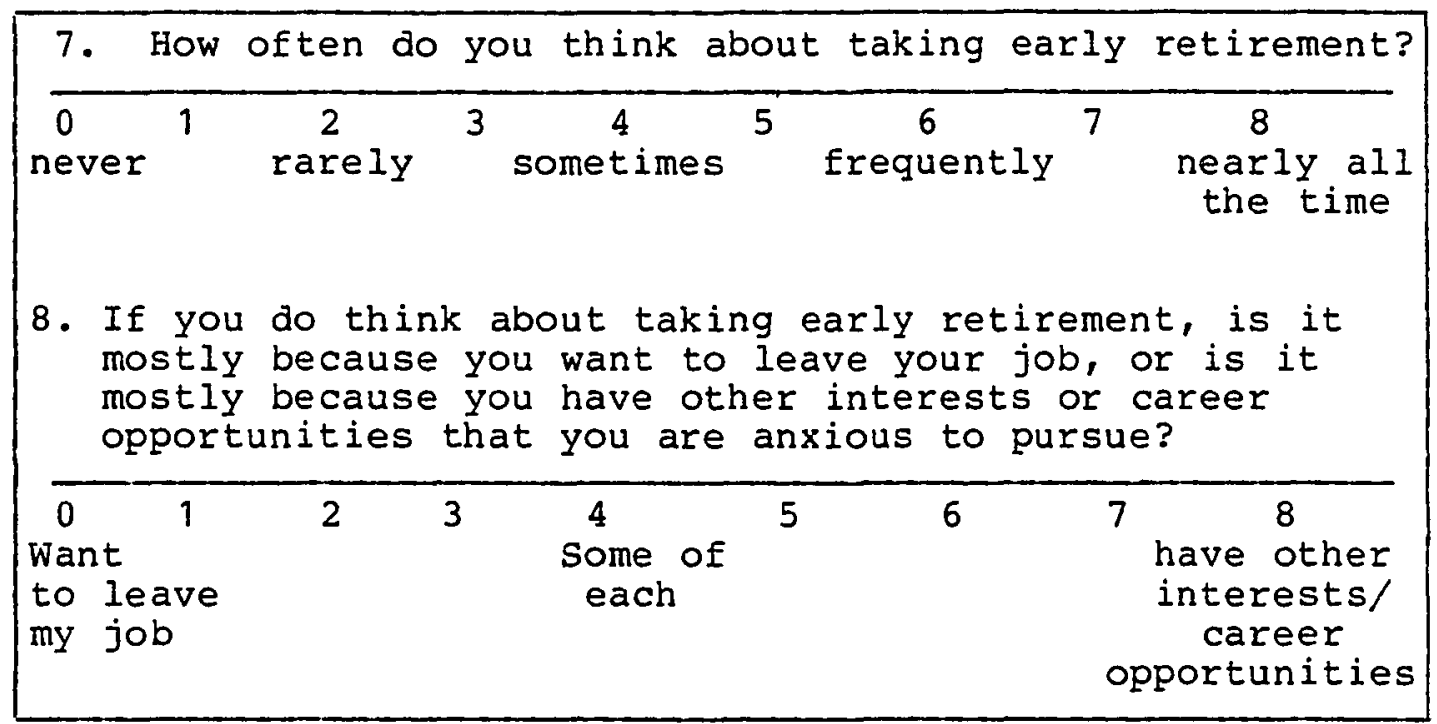

Figure 2. Early retirement questions on Job Data sheet.

Each of the subscales, except for Time, has been shown in the literature to be related to burnout. Thus, coefficients of correlation were determined for the administrators' total ARPI scores and their subscale scores with the self-report measure of burnout included on the Job Data Sheet, as shown in Figure 3 .

\begin{tabular}{|c|c|c|c|c|c|c|c|}
\hline $\begin{array}{c}0 \\
\text { none }\end{array}$ & 1 & $\begin{array}{c}2 \\
\text { some }\end{array}$ & 3 & $\begin{array}{l}4 \\
\text { moder- } \\
\text { ate }\end{array}$ & 5 & $\begin{array}{c}6 \\
\text { consider- } \\
\text { able }\end{array}$ & $\begin{array}{c}8 \\
\text { extreme }\end{array}$ \\
\hline
\end{tabular}

Figure 3. Self-perceived burnout question on Job Data Sheet. 
Further validation was achieved through the use of the Colleague Packet. A random sample of 159 administrators received the Colleague Packet as shown in Appendix D. The subjects were asked to give the packet to a colleague (superior, peer, or subordinate) who knew them well. This colleague was then instructed to fill in the Colleague Questionnaire. The questionnaire was composed of a series of observations about the administrator from whom it was received. In order to match the colleague and the subject, all materials sent to each were identified by $z$ ip code; only one set of subject-colleague materials was sent to any given zip code. Coefficients of correlation were determined for the administrators' total ARPI scores and their subscale scores with their colleagues' ratings of them on the colleague Questionnaire.

Additional analysis was done to establish the validity of the ARPI and its subscales. Using three levels of burnout as the independent variable, a multivariate, one-way analysis of variance was performed on the five separate subscales of Expectation, Motivation, Accomplishment, Psychophysical state, and Relationships; the scores on these subscales constituted the dependent variables. Alpha was set at .05. The Time subscale and the total ARPI scores were not included in this test since they are composed of items from the aforementioned subscales. 
With the rejection of the statistical hypothesis associated with the multivariate analysis of variance, the determination was made to continue the analysis by doing a univariate, one-way analysis of variance for each of the five separate subscales. This type of analysis was also done for the Time subscale and for the total ARPI. All statistical hypotheses were tested at the .05 confidence level.

\section{Summary}

The ARPI was developed during the year preceding the study. Subscales, which would attempt to measure various aspects of burnout discussed in the literature, were formed. Items were written for the subscales, and field-testing was done. The number of items was reduced from 138 to 50; the final list of subscales included Expectation, Motivation, Psycho-physical State, Accomplishment, Relationships, and Time. The subscale, Time, is composed of items from the other five subscales.

Al1 2,113 active members of the Confederation of Oregon School Administrators (COSA) received the ARPI and a questionnaire, the Job Data Sheet. This questionnaire contained measures of self-perceived level of burnout, desire to leave the job, and stress. A random sample of $\cos A$ members also received a packet to give to a colleague. This packet contained the Colleague Questionnaire, which provided observer ratings of the administrator. 
Reliability was assessed by means of coefficient alpha for internal consistency. Procedures for establishing content validity and criterion-related validity included review by colleagues in the field and the university, administrators self-perceptions as they correlated with the ARPI, and the ratings of the administrators' colleagues as they correlated with the ARPI. 


\section{CHAPTER IV}

\section{RESULTS}

Chapter IV provides a description of the sample used in the determination of the characteristics of the ARPI. Also included are the scoring procedures, a review of the subscale and ARPI definitions, score results, and the measures of reliability and validity.

\section{Sample}

The sample is described in terms of its size and also according to the age of the participants, their administrative positions, the types of positions they hold (line or staff), their job locations, and the number of years they have been in their present positions.

\section{$\underline{\text { Size }}$}

All of the 2,113 active members of the Confederation of Oregon School Administrators were included in the study. This membership constituted approximately 75 percent of Oregon's practicing public school administrators. 3

3The Oregon School Directory 1982-83 lists a total of 2809 FTE (full time equivalency) in administration. Some administrators hold more than one position and others are part-time, so 2809 is only an estimate of the number of individuals who hold public school administrative positions. However, it is intersting to note that $\operatorname{COSA}$ membership represents about 75 percent of Oregon's practicing public school administrators. 
A total of 1300 returns was received, or about 62 percent of those mailed. Thirty of these returns were received too late for inclusion in the data analysis; some of the 1270 returns used in the analysis had responses omitted on some items. Thus, the numbers of individuals referred to in subsequent discussion and tables will not always equal 1270 .

The Colleague packet was sent to 159 members. There were 77 returned Colleague Questionnaires; of these, 73 were usable because their matching ARPI was returned. Thus, the return rate for the Colleague Questionnaire was about 48 percent; the usable returns amounted to about 45 percent of those mailed.

\section{Description}

The distribution of the subjects in terms of age, position held, job location, job type, and years in present position follows.

Age. The mean age in years of the 1222 respondents who provided that information was 46 , with a range of 27 years to 65 years. Table VIII provides a summary of the distribution of subjects by age. 
TABLE VIII

DISTRIBTUION OF ADMINISTRATORS BY AGE

\begin{tabular}{cccc}
\hline Age in Years & Frequency & Percent & $\begin{array}{c}\text { Cumulative } \\
\text { Percent }\end{array}$ \\
\hline & & & \\
$63-65$ & 8 & 0.65 & 99.99 \\
$60-62$ & 80 & 2.78 & 99.44 \\
$57-59$ & 140 & 6.55 & 96.66 \\
$54-56$ & 141 & 11.46 & 90.11 \\
$51-53$ & 136 & 11.54 & 78.65 \\
$48-50$ & 139 & 11.13 & 67.11 \\
$45-47$ & 139 & 11.37 & 55.98 \\
$42-44$ & 148 & 11.37 & 34.61 \\
$39-41$ & 129 & 12.11 & 21.13 \\
$36-38$ & 83 & 10.56 & 10.57 \\
$33-35$ & 38 & 6.79 & 3.78 \\
$30-32$ & 7 & 3.11 & 0.57 \\
$27-29$ & 1222 & 0.57 & \\
\hline
\end{tabular}

Administrative position. A variety of administrative positions were included in the sample. Participants were asked to name their position, and these positions were then grouped into 26 categories, 21 of which were specific and 5 of which were general. Of the 1253 individuals who provided this information, approximately 54 percent were school building principals and vice-principals, while 17 percent were superintendents and assistant superintendents. Table IX provides detail on the distribution of subjects by administrative position. 
TABLE IX

DISTRIBUTION OF SUBJECTS BY ADMINISTRATIVE POSITION

\begin{tabular}{|c|c|c|}
\hline Position & Frequency & Percent \\
\hline $\begin{array}{l}\text { School District } \\
\text { Superintendent } \\
\text { Assistant Superintendent } \\
\text { Director of Curriculum/ } \\
\text { Instruction } \\
\text { Director of Counseling/ } \\
\text { Student Services } \\
\text { Director of Special Education } \\
\text { Director of Management Services } \\
\text { Director of Program Evalaution } \\
\text { Director of Curricular Area } \\
\text { Director of Special Programs } \\
\text { Director of Personnel } \\
\text { Director of Media } \\
\text { Director of Support Services } \\
\text { Director of Secondary Schools } \\
\text { Director of Elementary Schools } \\
\text { Other } \\
\text { Total }\end{array}$ & $\begin{array}{r}12 \\
23 \\
15 \\
3 \\
18 \\
8 \\
12 \\
8 \\
14 \\
5 \\
8 \\
48 \\
425\end{array}$ & $\begin{array}{l}0.96 \\
1.84 \\
1.20 \\
0.24 \\
1.44 \\
0.64 \\
0.96 \\
0.64 \\
1.12 \\
0.40 \\
0.64 \\
3.83 \\
33.92\end{array}$ \\
\hline $\begin{array}{l}\text { High School } \\
\text { Principal } \\
\text { Vice-Principal } \\
\text { Athletic Director } \\
\text { Other } \\
\text { Total }\end{array}$ & $\begin{array}{r}121 \\
119 \\
11 \\
18 \\
269\end{array}$ & $\begin{array}{r}9.66 \\
9.50 \\
0.88 \\
1.44 \\
21.47\end{array}$ \\
\hline $\begin{array}{l}\text { Junior High/Middle School } \\
\text { Principal } \\
\text { Vice-Principal } \\
\text { Other } \\
\text { Total }\end{array}$ & $\begin{array}{r}112 \\
78 \\
4 \\
194\end{array}$ & $\begin{array}{r}8.94 \\
6.23 \\
0.32 \\
15.48\end{array}$ \\
\hline $\begin{array}{l}\text { Elementary School } \\
\text { Principal } \\
\text { Vice-Principal } \\
\text { Othex } \\
\text { Total }\end{array}$ & $\begin{array}{r}346 \\
8 \\
6 \\
360\end{array}$ & $\begin{array}{r}27.61 \\
0.64 \\
0.48 \\
28.73\end{array}$ \\
\hline Other undesignated & 5 & 0.40 \\
\hline TOTAL ALL CATEGORIES & 1253 & 100.00 \\
\hline
\end{tabular}


The sample is comparable to the membership of COSA in terms of the proportions of superintendents, secondary principals, elementary principals, and supervisors, as shown in Table $\mathrm{X}$.

TABLE $X$

ADMINISTRATIVE POSITIONS REPRESENTED

IN SAMPIE AND IN COSA

Position

Percent in Sample

Percent in $\cos A$

Superintendents

14

11

Supervisors

15

16

Secondary Principals

19

15

Elementary Principals

28

30

Position type: Iine or staff. The sample was analyzed in terms of position type--line or staff. A line job was defined as "a position in the direct line of authority from superintendent to principal: direct and specific accountability for instruction: this defintion may extend to vice-principals." A staff position was defined as "a position whose function is to help line administrators; provides service, support, analysis." Table XI summarizes the distribution of subjects by position type. 
TABLE XI

DISTRIBUTION OF ADMINISTRATORS BY POSITION TYPE

\begin{tabular}{lcc}
\hline \multicolumn{1}{c}{ Category } & Frequency & Percent \\
\hline Line & 1038 & 82.71 \\
Staff & 202 & 16.10 \\
Combination Line/Staff & 15 & 1.20 \\
\hline TOTAL & 1255 & 100.00 \\
\hline
\end{tabular}

Job location: central office or school. Participants were categorized according to the location of their jobs; some individuals held more than one position and were located in more than one place. The categories used in this classification were: central office, elementary school, high, senior high school, two or more schools at different levels, central office and school, and other. The analysis indicates that 67.5 percent of the participants who answered this question were located exclusively in school buildings. Table XII provides distribution of subjects according to the location of their jobs. 
TABLE XII

DISTRIBUTION OF ADMINISTRATORS BY JOB LOCATION

\begin{tabular}{|c|c|c|}
\hline Location & Frequency & Percent \\
\hline Central office & 359 & 28.51 \\
\hline $\begin{array}{c}\text { Central office \& } s \\
\text { building }\end{array}$ & 47 & 3.73 \\
\hline Elementary school & 366 & 29.07 \\
\hline $\begin{array}{l}\text { Junior high or mid } \\
\text { school }\end{array}$ & 196 & 15.57 \\
\hline Senior high school & 263 & 20.89 \\
\hline School Combination & 25 & 1.99 \\
\hline Other & 3 & 0.24 \\
\hline TOTAL & 1259 & 100.00 \\
\hline
\end{tabular}

Years in present position. Participants were asked to indicate the number of years that they had been in the position which they held at the time of completing the questionnaire. Those who indicated six months to a year were categorized as having held the position for one year. Approximately 51 percent of the respondents had been in their positions for four years or less. Table XIII summarizes the distribution of subjects by years in present position. 
TABLE XIII

DISTRIBUTION OF ADMINISTRATORS BY YEARS IN PRESENT POSITION

\begin{tabular}{|c|c|c|c|}
\hline Years & Frequency & Percent & Cumulative Percent \\
\hline $\begin{array}{l}33 \\
32 \\
31 \\
30 \\
29 \\
28 \\
27 \\
26 \\
25 \\
24 \\
23 \\
22 \\
21 \\
20 \\
19 \\
18 \\
17 \\
16 \\
15 \\
14 \\
13 \\
12 \\
11 \\
10 \\
9 \\
8 \\
7 \\
6 \\
5 \\
4 \\
3 \\
2 \\
1 \\
0\end{array}$ & $\begin{array}{r}1 \\
3 \\
1 \\
3 \\
0 \\
2 \\
3 \\
1 \\
6 \\
2 \\
4 \\
10 \\
7 \\
14 \\
8 \\
14 \\
12 \\
24 \\
29 \\
21 \\
22 \\
34 \\
18 \\
43 \\
26 \\
48 \\
58 \\
87 \\
113 \\
116 \\
174 \\
172 \\
132 \\
57\end{array}$ & $\begin{array}{l}0.08 \\
0.24 \\
0.08 \\
0.24 \\
0.00 \\
0.16 \\
0.24 \\
0.08 \\
0.47 \\
0.16 \\
0.32 \\
0.79 \\
0.55 \\
1.11 \\
0.63 \\
1.11 \\
0.95 \\
1.90 \\
2.29 \\
1.66 \\
1.74 \\
2.69 \\
1.42 \\
3.40 \\
2.06 \\
3.79 \\
4.58 \\
6.88 \\
8.93 \\
9.17 \\
13.75 \\
13.60 \\
10.43 \\
4.51\end{array}$ & $\begin{array}{r}0.08 \\
0.32 \\
0.40 \\
0.64 \\
0.64 \\
0.80 \\
1.04 \\
1.12 \\
1.59 \\
1.75 \\
2.07 \\
2.86 \\
3.41 \\
4.52 \\
5.15 \\
6.26 \\
7.21 \\
9.11 \\
11.40 \\
13.06 \\
14.80 \\
17.49 \\
18.91 \\
22.31 \\
24.37 \\
28.16 \\
32.74 \\
39.62 \\
48.55 \\
57.72 \\
71.47 \\
85.07 \\
95.50 \\
100.00\end{array}$ \\
\hline TOTAL & 1269 & & \\
\hline
\end{tabular}


Thus, the sample for this study consisted primarily of line administrators with responsibility at the school building level. Most of the administrators had been in their present positions for two to three years. Their average age was 46 years.

\section{Scoring}

The ARPI consists of 50 items, divided equally among the five subscales of Expectation, Accomplishment, Motivation, Psycho-physical State, and Relationships. A sixth subscale, Time, is composed of items selected from the other subscales; these items are not, however, evenly distributed across the other subscales. Table XIV shows the assignment of the items to the subscales.

TABLE XIV

ASSIGNMENT OF ITEMS TO SUBSCALES

\begin{tabular}{lll}
\hline Subscale & \multicolumn{1}{c}{ Items } \\
\hline Expectation & $1,6,11,16,21,26,31,36,41,46$ \\
Motivation & $2,7,12,17,22,27,32,37,42,47$ \\
Psycho-physical State & $3,8,13,18,23,28,33,38,43,48$ \\
Relationships & $4,9,14,19,24,29,34,39,44,49$ \\
Accomplishment & $5,10,15,20,25,30,35,40,45.50$ \\
Time & $3,19,28,33,38,39,49,50$ \\
\hline
\end{tabular}


For each item, administrators marked one of the following responses: strongly disagree, disagree, neutral, agree, or strongly agree. These were scored from one through five, in that order. Each subscale, except Time, consists of 10 items, so the highest possible score would be 50 , and the lowest possible would be 10 for each subscale. The Time subscale has eight items; the highest possible score would be 40 , while the lowest possible would be 8 . The highest possible total ARPI score would be 250, while the lowest possible would be 50. The subscales are so designed that higher scores correspond with the more positive, "healthier" perceptions; therefore, the items written in the negative were given a reverse scoring.

\section{Analysis of the Subscales and the ARPI}

Included in this section are the descriptive statistics for the scores on the subscales and on the complete ARPI. An overview is presented first, followed by detailed descriptions.

\section{Overview of the scores}

The mean of the total ARPI inventory was 175.12 ; the means of the subscales ranged from 28.07 to 39.72 . The standard deviation of the entire inventory was 19.17; the standard deviations of the subscales ranged from 4.14 to 6.44. Table XV summarizes the statistics. 
TABLE XV

MEANS AND STANDARD DEVIATIONS FOR SUBSCALES AND TOTAL ARPI

\begin{tabular}{lcc}
\hline Subscale & Mean & Standard Deviation \\
\hline Expectation & 28.07 & 5.44 \\
Motivation & 35.30 & 4.71 \\
Psycho-Physical state & 32.96 & 6.44 \\
Relationships & 39.07 & 4.29 \\
Accomplishment & 39.72 & 4.14 \\
Timea & 28.68 & 4.71 \\
Total ARPI & 175.12 & 19.17 \\
\hline
\end{tabular}

atime is an eight item scale.

It is interesting to note that the descriptive statistics for the subscale scores and for the total ARPI scores for the group who received the Colleague Questionnaire are not significantly different from the total sample, affirming that this subsample is representative of the population of COSA active members. Statistics for the subsample can be found in Appendix $G$.

\section{Expectation}

The Expectation subscale rests on this definition of expectation: the degree of discrepancy between one's reality and one's anticipated reality, relative to one's job. The subscale is scored so that higher scores indicate less discrepancy between expectation and reality. The mean 
score was 28.07 ; the standard deviation was 5.44. The median was 27.89 ; the closeness of the mean and the median suggest that the distribution is generally symmetrical. The score which occurred most frequently was 28.00 Table XVI presents the frequency distribution of the scores.

TABLE XVI

FREQUENCY DISTRIBUTION OF SCORES ON EXPECTATION

\begin{tabular}{lccc}
\hline Score & Frequency & Percent & Cumulative Percent \\
\hline $44-46$ & 4 & 0.31 & 100.00 \\
$41-43$ & 8 & 0.63 & 99.69 \\
$38-40$ & 43 & 3.39 & 99.06 \\
$35-37$ & 113 & 8.90 & 95.67 \\
$32-34$ & 171 & 13.46 & 86.77 \\
$29-31$ & 230 & 18.11 & 73.31 \\
$26-28$ & 294 & 23.15 & 55.20 \\
$23-25$ & 211 & 16.61 & 32.05 \\
$20-22$ & 128 & 10.08 & 15.44 \\
$17-19$ & 58 & 4.57 & 5.36 \\
$14-16$ & 10 & 0.79 & 0.79 \\
\hline Total & 1270 & & \\
\hline
\end{tabular}


Motivation

The Motivation subscale rests on this definition of motivation: the propensity to initiate action; the inclination toward proactivity. The subscale is scored so that the higher scores indicate higher motivation.

The mean score was 35.30, with a standard deviation of 4.71. The median of 35.45 is quite close to the mean, indicating a generally symmetrical distribution. The mode was 34. Table XVII presents the frequency distribution of the scores.

TABLE XVII

FREQUENCY DISTRIBUTION OF SCORES ON MOTIVATION

\begin{tabular}{lccc}
\hline Score & Frequency & Percent & Cumulative Percent \\
\hline $48-50$ & 2 & 0.16 & 100.01 \\
$45-47$ & 24 & 1.89 & 99.85 \\
$42-44$ & 90 & 7.09 & 97.96 \\
$39-41$ & 195 & 15.35 & 90.87 \\
$36-38$ & 319 & 25.12 & 75.52 \\
$33-35$ & 301 & 23.70 & 50.40 \\
$30-32$ & 203 & 15.98 & 26.70 \\
$27-29$ & 91 & 7.17 & 10.72 \\
$24-26$ & 32 & 2.52 & 3.55 \\
$21-23$ & 10 & 0.79 & 1.03 \\
$18-21$ & 3 & 0.24 & 1.24 \\
\hline TOTAL & 1270 & & \\
\hline
\end{tabular}


Psycho-physical state

Psycho-physical state is defined as: the overall mental, emotional, and physical vigor of an individual. The subscale is scored so that higher scores correspond to greater vigor.

The mean score was 32.96 , with a standard deviation of 6.44. The median was 33.10 , suggesting a generally symmetrical distribution. The mode was 33.00. Table XVIII summarizes the distribution of the scores.

Relationships

Relationships has the following definition: the desire for and the quality of continuous interaction with work-related colleagues and clients; the identification and involvement of self with colleagues and clients, and the acceptance of oneself by clients and colleagues. This subscale is scored so that higher scores indicate stronger desire for and higher quality relationships; greater identification and involvement, and higher acceptance by clients and colleagues.

The mean score was 39.07 , with a standard deviation of 4.29. The median was 39.27, thus giving a generally symmetrical distribution. The mode was 40.00. Table XIX provides a frequency distribution of the scores. 
TABLE XVIII

FREQUENCY DISTRIBUTION OF SCORES ON PSYCHO-PHYSICAL STATE

\begin{tabular}{lrrr}
\hline Score & Frequency & Percent & Cumulative Percent \\
\hline $48-50$ & 8 & 0.63 & 100.00 \\
$45-47$ & 35 & 2.76 & 99.37 \\
$42-44$ & 66 & 5.20 & 99.61 \\
$39-41$ & 160 & 12.60 & 91.41 \\
$36-38$ & 189 & 14.88 & 78.81 \\
$33-35$ & 228 & 17.95 & 63.93 \\
$30-32$ & 204 & 16.06 & 45.98 \\
$27-29$ & 167 & 13.15 & 29.92 \\
$24-26$ & 122 & 9.61 & 16.77 \\
$21-23$ & 61 & 4.80 & 7.16 \\
$18-20$ & 20 & 1.57 & 2.36 \\
$15-17$ & 8 & 0.63 & 0.79 \\
$12-14$ & 1 & 0.08 & 0.16 \\
$9-11$ & 1 & 0.08 & 08 \\
\hline TOTAL & 1270 & & \\
\hline
\end{tabular}


TABLE XIX

FREQUENCY DISTRIBUTION OF SCORES ON RELATIONSHIPS

\begin{tabular}{lccc}
\hline Score & Frequency & Percent & Cumulative Percent \\
\hline $48-50$ & 29 & 2.28 & 100.01 \\
$45-47$ & 87 & 6.85 & 97.73 \\
$42-44$ & 234 & 18.43 & 90.88 \\
$39-41$ & 379 & 29.84 & 72.45 \\
$36-38$ & 305 & 24.02 & 42.61 \\
$33-35$ & 145 & 11.42 & 18.59 \\
$30-32$ & 66 & 5.20 & 7.17 \\
$27-29$ & 18 & 1.42 & 1.97 \\
$24-26$ & 5 & 0.39 & 0.55 \\
$21-23$ & 2 & 0.16 & 0.16 \\
\hline TOTAL & 1270 & & \\
\hline
\end{tabular}


Accomplishment

Accomplishment is defined as: the sense of attainment of one's professional goals. The subscale is scored so that higher scores correspond with higher feelings of accomplishment. The mean score was 39.72 , with a standard deviation of 4.14. The median score was 39.82, while the mode was 40.00. The closeness of the median and the mean suggest the generally symmetrical shape of the distribution. Table XX presents the frequency distribution of the scores.

TABLE $X X$

FREQUENCY DISTRIBUTION OF SCORES ON ACCOMPLISHMENT

\begin{tabular}{lccc}
\hline Score & Frequency & Percent & Cumulative Percent \\
\hline $48-50$ & 44 & 3.46 & 100.00 \\
$45-47$ & 103 & 8.11 & 96.54 \\
$42-44$ & 252 & 19.84 & 88.43 \\
$39-41$ & 429 & 33.78 & 68.59 \\
$36-38$ & 262 & 20.63 & 34.81 \\
$33-35$ & 116 & 9.13 & 14.18 \\
$30-32$ & 42 & 3.31 & 5.05 \\
$27-29$ & 19 & 1.50 & 1.74 \\
$24-26$ & 3 & 0.24 & 0.24 \\
\hline TOTAL & 1270 & & \\
\hline
\end{tabular}


Time

Time is defined as: the tendency to view the past as better than the present; a longing for the "good old days." The subscale is scored so that higher scores indicate the perception that the past is not better and little longing for the "good old days"--in other words, a contentment with the present.

The mean score was 28.70 , with a standard deviation of 4.70. The median score was 29.05 ; the mode was 31 . The distribution is generally symmetrical. Table XXI summarizes the distribution of the scores.

TABLE XXI

FREQUENCY DISTRIBUTION OF SCORES ON TIME

\begin{tabular}{lccc}
\hline Score & Frequency & Percent & Cumulative Percent \\
\hline $38-40$ & 33 & 2.60 & 100.01 \\
$35-37$ & 82 & 6.46 & 97.41 \\
$32-34$ & 234 & 18.43 & 90.95 \\
$29-31$ & 339 & 26.69 & 72.52 \\
$26-28$ & 279 & 21.97 & 45.83 \\
$23-25$ & 158 & 12.44 & 23.86 \\
$20-22$ & 110 & 8.66 & 11.42 \\
$17-19$ & 25 & 1.97 & 2.76 \\
$14-16$ & 8 & 0.63 & 0.79 \\
$11-13$ & 2 & 0.16 & 0.16 \\
\hline TOTAL & 1270 & & \\
\hline
\end{tabular}


Total ARPI

The administrative role perception is defined as: the administrator's unique and private perception of his or her phenomenological world, in terms of expectation, motivation, accomplishment, relationships, psycho-physical state, and time orientation. The scale is scored so that the higher scores correspond to the more positive, "healthier" outlook. The mean score was 175.07 , with a standard deviation of 19.08. The median was 174.56 , while the mode was 168.00. The distribution was generally symmetrical. Table XXIIprovides the frequency distribution of the ARPI scores.

Summary

In this section, scoring procedures have been presented. Subscale definitions and the definition of administrator role perception were reviewed. Scores were presented; all distributions were generally symmetrical for all subscales and for the total ARPI. 
TABLE XXII

FREQUENCY DISTRIBUTION OF ARPI SCORES

\begin{tabular}{lccc}
\hline Score & Frequency & Percent & Cumulative Percent \\
\hline & & & \\
$232-236$ & 2 & 0.16 & 100.02 \\
$227-231$ & 4 & 0.32 & 99.86 \\
$222-226$ & 4 & 0.32 & 99.54 \\
$217-221$ & 11 & 0.87 & 99.22 \\
$212-216$ & 16 & 1.26 & 98.35 \\
$207-211$ & 14 & 1.10 & 97.09 \\
$202-206$ & 46 & 3.62 & 95.99 \\
$197-201$ & 69 & 5.44 & 92.37 \\
$192-196$ & 77 & 6.07 & 86.93 \\
$187-191$ & 102 & 8.04 & 80.86 \\
$182-186$ & 125 & 9.85 & 72.82 \\
$177-181$ & 115 & 9.06 & 53.97 \\
$172-176$ & 139 & 10.95 & 42.96 \\
$167-171$ & 160 & 12.61 & 30.35 \\
$162-166$ & 91 & 7.17 & 23.18 \\
$157-161$ & 91 & 7.17 & 16.01 \\
$152-156$ & 73 & 5.75 & 6.26 \\
$147-151$ & 45 & 3.55 & 4.41 \\
$142-146$ & 29 & 2.29 & 2.45 \\
$137-141$ & 25 & 1.97 & 1.58 \\
$132-136$ & 11 & 0.87 & 0.79 \\
$127-131$ & 10 & 0.79 & 0.24 \\
$122-126$ & 7 & 0.55 & 0.08 \\
$117-121$ & 2 & 0.16 & 0.08 \\
$112-116$ & 0 & 0.00 & 0.08 \\
$107-111$ & 0 & 0.00 & 08 \\
$102-106$ & 0 & 0.00 & 0.00 \\
$97-101$ & 0 & 0.08 & \\
$92-96$ & 1 & & \\
\hline TOTAL & 1269 & & \\
\hline
\end{tabular}




\section{Reliability}

The aspect of reliability addressed here is the extent to which the items of the ARPI accurately represent the total pool of hypothetical items which could be used to measure the possession of each perception: expectation, motivation, psycho-physical state, relationships, accomplishment, and time, and also the total role perception. Measures of internal consistency using coefficient alpha were produced to assess this aspect of reliability.

Table XXIII shows the internal consistency for each subscale separately and for the entire scale.

\section{TABLE XXIII}

COEFFICIENT ALPHA FOR EACH SUBSCALE AND FOR TOTAL ARPI

Scale

Expectation

Psycho-physical state

Relationships

Motivation

Accomplishment

Time

Total ARPI
Coefficient Alpha

.71

.85

.75

.70

.78

.78

.91

Reliabilities for the subscales ranged from .70 to .85. The reliability for the total ARPI was .91. 


\section{Subscale Intercorrelations}

Table XXIV provides the coefficients of correlation of each subscale with each other subscale, showing the relationships between the pairs of subscales, and between the individual subscales and the total scale, ARPI.

The subscale intercorrelations range from .31 to .63 excluding Time, which is composed of items from the other subscales. Correlations between the subscales and Time are higher, as would be expected, since there is an overlap in items.

The correlations between the subscales and the total ARPI are also inflated because the total scale contains the items of the various subscales.

\section{Valiaity}

Content validity and criterion-related validity were the types of validation addressed in relation to the ARPI. A discussion of each type follows.

Content Validity

Content validity is essentially an issue of judgment, and the judgment was made during the development of the ARPI, which occurred prior to the beginning of this study. The three phases of this procedure were: (1) identification of the constructs to be investigated; (2) development and writing of the items to measure each construct; and (3) 
TABLE XXIV

SUBSCALE INTERCORRELATIONS

\begin{tabular}{|c|c|c|c|c|c|c|c|}
\hline & Expectation & Motivation & $\begin{array}{l}\text { Psycho- } \\
\text { physical } \\
\text { State }\end{array}$ & $\begin{array}{l}\text { Relation } \\
\text { ships }\end{array}$ & $\begin{array}{l}\text { Accomplish- } \\
\text { ment }\end{array}$ & Time & $\begin{array}{l}\text { Total } \\
\text { ARPI }\end{array}$ \\
\hline Expectation & & .35 & .56 & .31 & .34 & .50 & .70 \\
\hline Motivation & & & .58 & .46 & .64 & .66 & .78 \\
\hline $\begin{array}{l}\text { Psycho-physical } \\
\text { state }\end{array}$ & & & & .46 & .51 & .80 & .85 \\
\hline Relationships & & & & & .58 & .67 & .70 \\
\hline Accomplishment & & & & & & .66 & .77 \\
\hline Time & & & & & & & .86 \\
\hline Total ARPI & & & & & & & \\
\hline
\end{tabular}


examination of the performance of the items through field testing. A äiscussion of each phase follows.

Identification of the constructs to be investigated. The investigator and the co-author integrated a number of sources in an effort to insure that the ARPI would reflect those aspects of the phenomenological world of the administrator which appeared to be related to burnout.

The investigator began with a request of her fellow administrators for descriptions of the feelings and behaviors of a person whom they would describe as "burned out". This information was collected and saved for integration with that being gathered from the review of the literature.

The review of the literature was the main source of data for content validation. The influence of the literature on the final selection of the items and subscales is apparent from Table $I$ in Chapter $I$, in which it can be seen that five of the six subscales reflect concepts found in the literature.

Knowing that the subject of burnout was receiving a great deal of attention, it was felt that sources even more current than recent journals needed to be considered. Thus, information from presentations made at conferences such as the March, 1982, AERA meeting in New York were employed.

All of these sources were employed as the investigator and the co-author attempted to define the domain of the 
administrative role perception and the aspects that fit in that domain.

Item development and writing. Having identified the domain of administrative role perception as including the aspects of locus of control, ego strength, expectation, depersonalization-identification, isolation-involvement, temperament, motivation (quantity and source), rejectionacceptance, accomplishment, and physical vigor, it was necessary to identify the ramifications of each of these subscales and to write at least one item for each; the items had to logically reflect that aspect of the subscale they were to measure.

The items were placed on cards which were grouped and regrouped, edited and refined until the investigator and the co-author were satisfied with the logical consistency for each subscale. The first draft of the ARPI was produced; it contained 138 items.

Field testing. As described in Chapter III, the first draft was field tested, and the results were analyzed for item-subscale correlation and for subscale internal consistency (Pearson's coefficient of correlation and coefficient alpha). These reliabilities were of great help. If a measure is valid, it will be reliable. However, if it is not reliable, it cannot be valid. Items were examined for proper scale assignment, revised, or discarded. A second draft of 66 items was prepared. The original subscales had 
been collapsed and some items discarded as a result of the analysis. The new subscale called Relationships was developed from the original subscales of identification-depersonalization, acceptance-rejection, and involvement-isolation. All Motivation items were collapsed into one subscale. Items from physical vigor, ego strength, and temperament were placed in one subscale, Psycho-physical state. The locus of control items were all discarded. The second draft was field tested, and once again the results were analyzed. This analysis did not result in the elimination or reorganization of the subscales, but individual items were eliminated or modified. The result was the third draft of the ARPI, which is the focus of this study, and contains 50 items divided among the subscales of Expectation, Accomplishment, Psycho-physical State, Motivation, Relationships, and Time.

Thus, through the process of field testing and analysis, items were selected that appeared to be logically consistent with their subscale and showed a higher correlation with their subscale than with any other.

\section{Criterion-Related Validity}

Criterion-related validity is established by comparing the scores on the instrument for which validity is to be determined with measures of variables known or believed to be associated with the variable one is trying to measure. 
Criterion-related validity was investigated for the ARPI as a whole and for each of the subscales. Measures of selected variables known or believed to be associated with the phenomenon of burnout were correlated with the total ARPI scale and each of the subscales. In addition, a multivariate, one-way analysis of variance was performed on the five separate subscales of Expectation, Motivation, Accomplishment, Psycho-physical state, and Relationships, using the level of burnout as the independent variable. (The Time subscale and the total ARPI were not included in the analysis because they are comprised of items from the other scales.) The multivariate analysis of variance for the five subscales yielded a Hotelings $\underline{t}$ of .61220 with a calculated F of 74.08 (Hull and Nie, 1981). For 10 and 2420 degrees of freedom, at alpha equal .05, the table value of $F$ is 2.54 . Therefore, the statistical hypothesis that there was no difference among the means for the different levels of burnout was rejected $(p<.001)$. Then, with the three levels of burnout (high, moderate, low) as the independent variable, a univariate one-way analysis of variance was performed for each of the aforementioned five subscales, Time, and the total ARPI, using the procedure described in the statistical Package for the Social Sciences (Nie, Hull, Jenkins, Steinbrenner and Bent, 1975). For each significant univariate F, a Scheffe test (Glass and Stanley, 1970) was performed for all pair-wise mean comparisons. The results of these 
various tests are presented in subsequent sections of this chapter.

Two procedures for measurement were employed: comparison of the administrators' self-perceptions to their subscale and ARPI scores and (2) comparison of observer (colleague) scores on the Colleague Questionnaire to the administrators' subscale and ARPI scores. The following discussion describes the validation results for each subscale and for the total ARPI.

Validity of the Total ARPI. Job stress was one of the variables used in validation. It was measured by the use of two questions on the Job Data sheet, as shown in Figure 4. Administrators were instructed to complete the Job Data sheet immediately after responding to the ARPI. Scoring was converted to a $1-9$ scale in order to obtain the computer analyses desired. Higher scores indicate higher perceived stress; lower scores, lower perceived stress. In this case, the administrators' scores on the subscales and on the ARPI were being compared with their self-perceptions of job stress; thus, procedure (1) as described above was used for assessing the validity of ARPI. 


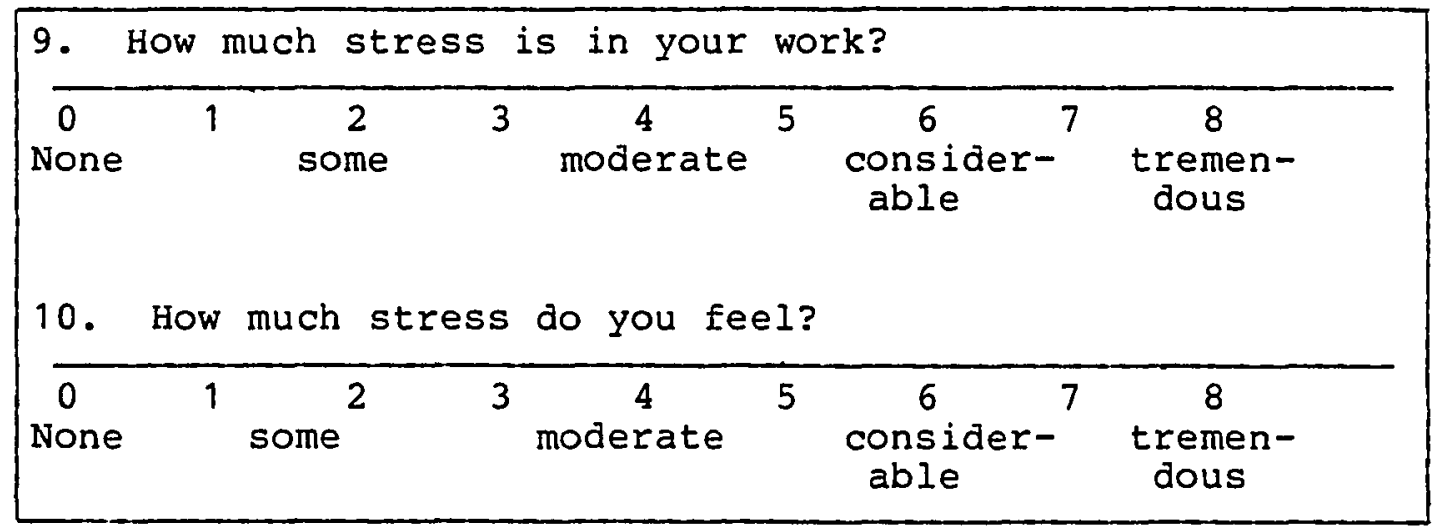

Figure 4. Measures of job stress.

Table XXV provides the coefficients of correlation between the ARPI scores and the measures of stress; these coefficients are significant at the .001 level.

TABLE XXV

CORRELATIONS BETWEEN STRESS MEASURES AND ARPI SCORES

Stress Questions Total ARPI Score

Amount of stress in work -.21 *

Felt stress $-.42 *$

*Significant at the .001 level. 
Another variable used in assessing the validity of the ARPI was the desire to leave the job. This variable was measured by the use of two questions on the Job Data sheet, as shown in Figure 5. Scoring was converted to a $1-9$ scale in order to obtain the computer analyses desired. Once again, procedure (1), in which the administrators' self-perceptions are correlated with ARPI scores, has been employed. As before, a high score on the ARPI indicates the positive role perception, while a high score on the retirement questions indicates a strong desire to get away from the job.

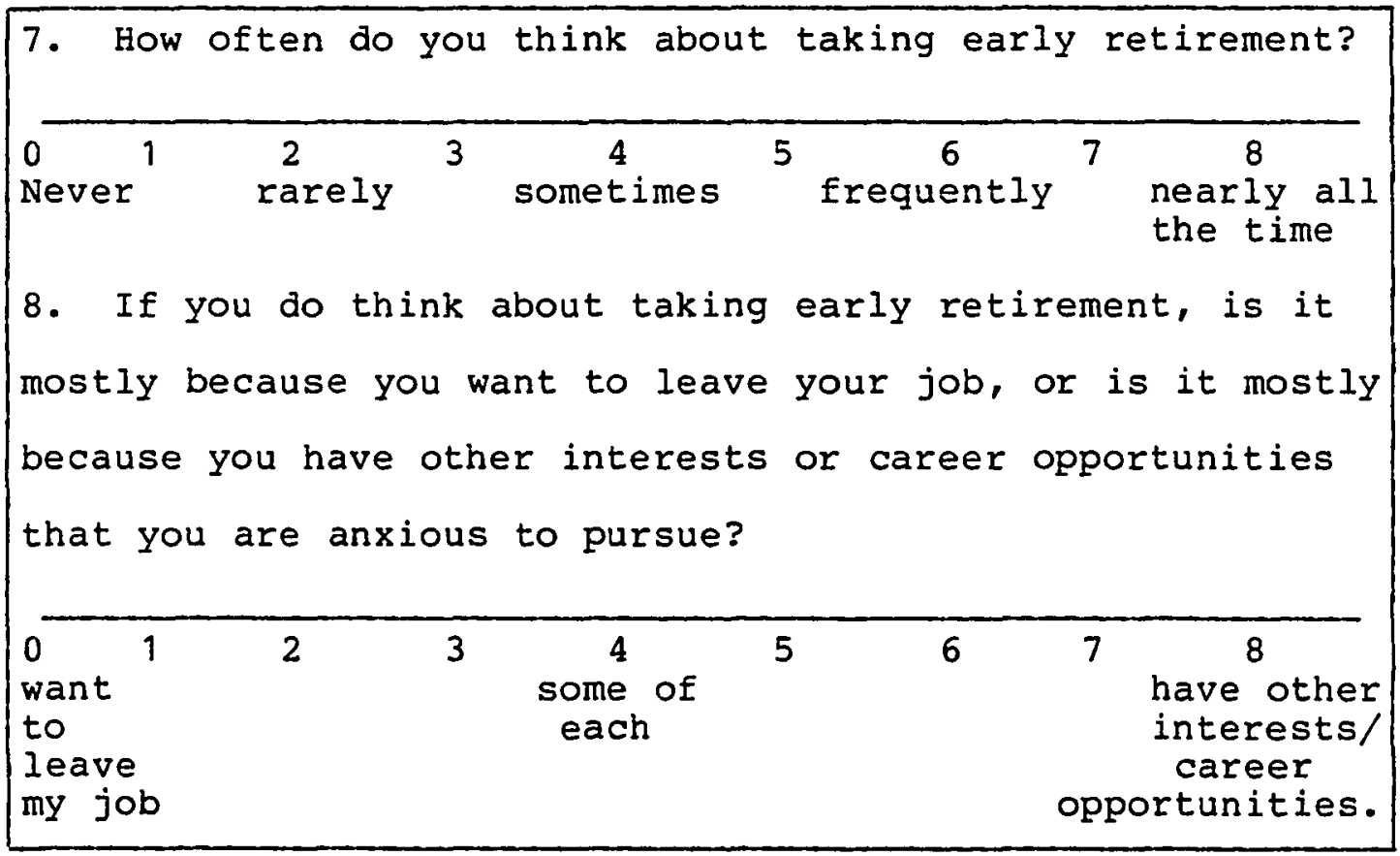

Figure 5. Measures of "desire to leave the job." 
Table XXVI provides the correlations between the total ARPI scores and the measures of desire to leave the job. The correlation with "desire for early retirement" is significant at the .001 level. The correlation with "reason for early retirement" did not reach significance.

TABLE XXVI

CORRELATION BETWEEN DESIRE FOR EARLY RETIREMENT AND ARPI SCORE

\begin{tabular}{lc} 
& Total ARPI Score \\
\hline Desire for early retirement & $-.41 *$ \\
Reason for early retirement & .09 \\
\hline
\end{tabular}

*Level of significance is .001.

A third variable used in assessing the validity of the ARPI was the measure of self-perceived level of burnout. This variable was measured by the use of a question on the Job Data Sheet. The administrators were instructed to indicate their current level of burnout, as shown in Figure 6. Scoring was converted to a 1 - 9 scale in order to obtain the computer analyses desired. In this case, administrators' scores on the ARPI have been compared with their self-perceptions of their level of burnout; thus, procedure (1) as described earlier was used for assessing the validity of the ARPI. 


\begin{tabular}{|lcccccccc|}
\hline 11. & Please & indicate & your current level of burnout. & \\
\hline $\begin{array}{l}0 \\
\text { None }\end{array}$ & 1 & $\begin{array}{c}2 \\
\text { some }\end{array}$ & 3 & $\begin{array}{c}4 \\
\text { moderate }\end{array}$ & 5 & $\begin{array}{c}6 \\
\text { considerable }\end{array}$ & $\begin{array}{c}7 \\
\text { extreme }\end{array}$ \\
\hline
\end{tabular}

Figure 6. Measure of self-perceived burnout.

Table XXVII provides the correlational data relating the degree of self-perceived burnout with the ARPI scores; the level of significance is .001 . In reading the table, it is important to remember that the ARPI score is in the opposite direction to the scoring on the level of burnout. The higher ARPI scores indicate the "healthier" perception; the lower burnout scores indicate the "healthier" condition.

TABLE XXVII

CORRELATION BETWEEN MEASURE OF SELF-PERCEIVED BURNOUT AND ARPI SCORES

Measure of self-perceived burnout ARPI Score

Level of burnout $-.59 *$

*Significant at .001 level.

Further use was made of procedure (1) in establishing the validity of the ARPI. The level of self-perceived burnout was recoded so that the nine levels were collapsed into three. Those administrators who scored a 1,2 , or 3 
were grouped as low burnout. Scores of 4,5 , or 6 were classified as moderate burnout. The high burnout classification included scores of 7, 8, and 9. An analysis of variance, using level of burnout as the independent variable and ARPI score as the dependent variable, was performed; the alpha level was set at .05. The statistical hypothesis that there would be no significant difference between the ARPI means of the three burnout groups ( $\mathrm{H}: \mathrm{H}_{1}$ $\left.=H_{2}=H_{3}\right)$ was rejected $(p<.001)$. Table XXVIII shows the means and standard deviations for the ARPI scores at each level of burnout. Table XXIX provides the analysis of variance.

TABLE XXVIII

MEAN ARPI SCORES OF BURNOUT GROUPS

\begin{tabular}{lccc}
\hline Group & Sample $\overline{\mathrm{x}}$ & $\mathrm{J}$ & $\mathrm{n}$ \\
\hline 1--low burnout & 185.09 & 15.99 & 623 \\
2--moderate burnout & 166.85 & 15.41 & 499 \\
3--high burnout & 151.69 & 16.83 & 96 \\
\hline
\end{tabular}


TABLE XXIX

ANOVA FOR LEVEL OF BURNOUT AND ARPI SCORES

\begin{tabular}{lrrr}
\hline Source of Variation & df & MS & F \\
\hline Between groups & 2 & 1651.49 & $113.93^{*}$ \\
Within groups & 1215 & 14.50 & \\
\hline
\end{tabular}

${ }^{*} \mathrm{p}<.01, .999^{\mathrm{F}} 2, \overline{\overline{1}} 2 \mathrm{6}_{15}{ }^{97}$

Since the statistical hypothesis was rejected, two or more of the means were not equal. Further analysis, using the Scheffe test, was conducted to see which pairs of the means differed significantly, at alpha $=.05$. Using the procedure outlined by Glass and Stanley (1970), the following pairs of means were tested: $\overline{\mathrm{x}}_{1}-\overline{\mathrm{x}}_{2} ; \overline{\mathrm{x}}_{1}-$ $\bar{x}_{3} ; \bar{x}_{2}-\bar{x}_{3}$. A significant difference was found for each pair, when compared against the critical value of 3.73. Calculations for this test are provided in Appendix H.

A fourth variable was employed in assessing the criterion-related validity of the ARPI. This was the total score on the Colleague Questionnaire; it represents the use of procedure (2) in which observers' scores are compared to the administrators' ARPI scores. The scoring direction is the same for both the ARPI and the Colleague questionnaire; the higher scores indicate the "healthier", more positive 
perceptions. The Colleague Questionnaire may be found in Appendix D.

The correlation between the total ARPI and the Colleague Questionnaire was significant at the .01 level. Table XXX illustrates.

TABLE XXX

CORRELATION BETWEEN COLLEAGUE QUESTIONNAIRE SCORE AND ARPI SCORES

Total ARPI score

Colleague questionnaire $.31 *$

*Significant at .01 level

Because emotional exhaustion has been associated with burnout by virtually every investigator of burnout, it, too, was included as a variable for assessing the validity of the ARPI. It was assessed by means of question 8 on the Colleague Questionnaire, as shown in Figure 7.

Since this item is written in the negative, the direction of scoring was reversed for analysis. Procedure (2), that of comparing the scores of observers with the administrators' ARPI scores, has been employed here.

The correlation between emotional exhaustion and the ARPI was significant at the .01 level, as shown in Table XXXI, and was in the expected direction. 


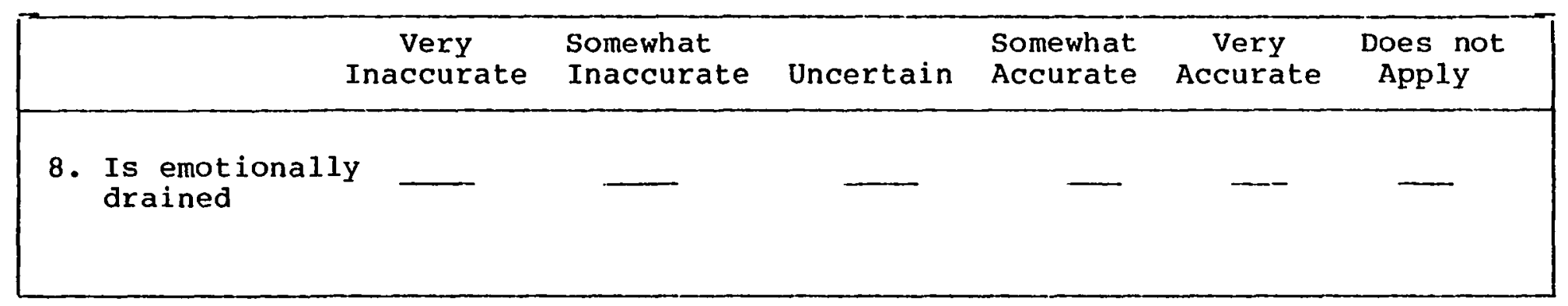

Figure 7. Measure of administrators' emotional exhaustion as perceived by colleagues. 
TABLE XXXI

CORRELATION BETWEEN COLLEAGUES' PERCEPTION OF ADMINISTRATORS' EMOTIONAL EXHAUSTION AND ARPI

ARPI Scores

Emotional exhaustion scores

.36 *

*Significant at the .01 level

To summarize, the criterion-related validity of the ARPI has been assessed through the comparison of the ARPI scores with six other measures: job stress, desire to leave the job, self-perceived level of burnout, general perceptions of others, and emotional exhaustion. In every case, the correlations were significant at least at the .01 level, except for "reasons for desiring early retirement", in which case there was no significant correlation.

Validation of the Expectation Subscale. The subscale was validated through the comparison of measures of other variables with the Expectation subscale scores. The measures of job stress, desire to leave the job, and level of burnout were subject self-perceptions. Emotional exhaustion and total Colleague Questionnaire scores were measures of the perceptions of others and were measured as described in the preceding sections. One additional variable was included for the validation of this subscale, that of observer 
perception of the disillusionment of the administrator. Question 11 on the Colleague Questionnaire was used to measure this, and is shown in Figure 8. Since the item is written in the negative, reverse scoring was used in the computer analysis; thus, a positive correlation would be expected with the expectation subscale.

The correlations between the Expectation subscale scores and the measures of the variables used in assessing validity are shown in Table XXXI.

TABLE XXXII

MEASURES OF VALIDITY FOR EXPECTATION SUBSCALE

Validity Measure

Expectation Subscale

Job Stress

Amount of stress in work

$$
\begin{aligned}
& -.27 * * * \\
& -.39 * * *
\end{aligned}
$$

Felt stress

Desire to leave job

Desire for early retirement

Reason for early retirement

$-.23 * \star *$

$.06 *$

Level of burnout

$$
-.37 * * *
$$

Colleague Questionnaire

.20

Emotional exhaustion

$.28 *$

Disillusionment

$.19 *$

*Level of significance at .05

**Level of significance at .01

$* * *$ Level of significance at .001 


\begin{tabular}{|c|c|c|c|c|c|c|c|}
\hline & & $\begin{array}{c}\text { Very } \\
\text { Inaccurate }\end{array}$ & $\begin{array}{l}\text { Somewhat } \\
\text { Inaccurate }\end{array}$ & Uncertain & $\begin{array}{l}\text { Somewhat } \\
\text { Accurate }\end{array}$ & $\begin{array}{c}\text { Very } \\
\text { Accurate }\end{array}$ & $\begin{array}{l}\text { Does not } \\
\text { Apply }\end{array}$ \\
\hline 11. & $\begin{array}{l}\text { Feels dis- } \\
\text { illusioned } \\
\text { about how } \\
\text { the job has } \\
\text { turned out. }\end{array}$ & & & & & & \\
\hline
\end{tabular}


The correlations between the Expectation subscale and the self-perceived measures of stress, desire to leave the job, and level of burnout are all significant at the .001 level, with the exception of reason for early retirement. This correlation only reaches the .05 level of significance.

The correlations between the Expectation subscale and the colleague perceptions are either insignificant or are significant at the .05 level. All correlations are in the expected direction.

As in the case of the ARPI, an analysis of variance, using level of burnout as the independent variable and the Expectation score as the dependent variable was performed; the alpha level was set at .05 . The statistical hypothesis that there would be no significant difference between the Expectations means of the three burnout groups $\left(\mathrm{H}: \mu_{1}=\right.$ $\left.\mu_{2}=\mu_{3}\right)$ was rejected $(p<.001)$. Table XXXIII shows the means and standard deviations at each level of burnout. Table XXXIV provides the analysis of variance.

Since the statistical hypothesis in the univariate analysis of variance was rejected, two or more of the means were not equal. Further analysis, using the scheffe test, was conducted to see which pairs of the means differed significantly at alpha $=.05$. Using the procedure previously described for the differences between the ARPI means, the following pairs of Expectation means were tested: $\bar{x}_{1}$ - 
$\overline{\mathrm{x}}_{2} ; \overrightarrow{\mathrm{x}}_{1}-\overline{\mathrm{x}}_{3} ;$ and $\overline{\mathrm{x}}_{2}-\overline{\mathrm{x}}_{3}$. A significant difference was found for each pair.

TABLE XXXIII

MEAN EXPECTATION SCORES OF BURNOUT GROUPS

\begin{tabular}{lccc}
\hline Group & Sample $\bar{x}$ & $\sigma$ & n \\
\hline 1--Low Burnout & 29.91 & 5.17 & 623 \\
2--Moderate Burnout & 26.43 & 4.87 & 499 \\
3--High Burnout & 24.24 & 5.43 & 96 \\
\hline
\end{tabular}

TABLE XXXIV

ANOVA FOR LEVEL OF BURNOUT AND EXPECTATION SCORES

\begin{tabular}{lrrr}
\hline Source of Variation & df & MS & F \\
\hline Between groups & 2 & 2430.33 & $94.53 *$ \\
Within groups & 1215 & 25.71 & \\
\hline
\end{tabular}

$\begin{array}{ccc}* \text { Significant at } .001 & \text { level } \\ .999 & F_{2,1215} & 6.97\end{array}$


Validation of the Motivation subscale. The subscale was validated through the comparison of measures of other variables with the Motivation subscale scores. The measures of job stress, desire to leave the job, and level of burnout were administrator self-perceptions. The Colleague Questionnaire total score, emotional exhaustion, and colleague perception of administrator motivation, all measures of the perceptions of others, were used in assessing the validity of this subscale. Question 9 on the Colleague Questionnaire was used to measure the latter variable, as shown in Figure 9.

Scoring for this variable was in the same direction as scoring for the Motivation subscale, where higher scores indicated greater motivation.

The correlations between the Motivation subscale and the measures of the variables used in assessing validity are shown in Table $\mathrm{XXXV}$.

Correlations between the Motivation subscale and the self-perceived measures of stress, desire to leave the job, and level of burnout are all significant at least at the .01 level, except for reason for early retirement.

Correlations between the Motivation subscale and the observer perceptions vary in significance. The correlation with the Colleague Questionnaire is significant at the .05 level; the other correlations are not significant. 


\begin{tabular}{|c|c|c|c|c|c|c|}
\hline & $\begin{array}{c}\text { Very } \\
\text { Inaccurate }\end{array}$ & $\begin{array}{l}\text { Somewhat } \\
\text { Inaccurate }\end{array}$ & Uncertain & $\begin{array}{l}\text { Somewhat } \\
\text { Accurate }\end{array}$ & $\begin{array}{c}\text { Very } \\
\text { Accurate }\end{array}$ & $\begin{array}{l}\text { Does not } \\
\text { Apply }\end{array}$ \\
\hline $\begin{array}{l}\text { 1. Is physically } \\
\text { vigorous and } \\
\text { healthy }\end{array}$ & & & $\longrightarrow$ & - & - & - \\
\hline
\end{tabular}

Figure 10. Measure of administrators' physical vigor as perceived by colleagues. 
TABLE XXXV

\section{MEASURES OF VALIDITY FOR MOTIVATION SUBSCALE}

\begin{tabular}{lc}
\hline Validity Measure & Motivation Subscale \\
\hline Job stress & $-.08 * *$ \\
Amount of stress in work & $-.25 * * *$ \\
Felt stress & \\
Desire to leave job & $-.46 * * *$ \\
$\begin{array}{l}\text { Desire for early retirement } \\
\text { Reason for early retirement }\end{array}$ & .03 \\
Level of burnout & $-.53 * * *$ \\
Colleague Questionnaire & $.25 *$ \\
Emotional exhaustion & .21 \\
Observer measure of motivation & -.04 \\
\hline
\end{tabular}

*Significant at .05 level

**Significant at .01 level

***Significant at .001 level

As was done with the Expectation subscale, an analysis of variance, using level of burnout as the independent variable and the Motivation score as the dependent variable was performed; alpha level was set at .05. The statistical hypothesis that there would be no significant difference between the Motivation means of the three burnout groups (H: $\left.\mu_{1}=\mu_{2}=\mu_{3}\right)$ was rejected $(\mathrm{p}<.001)$. Table XXXVI shows the means and standard deviations at each level of burnout. Table XXXVII provides the analysis of variance. 
Since the statistical hypothesis in tine univariate analysis of variance was rejected, two or more of the means were not equal. Further analysis, using the scheffe test, was conducted to see which pairs of the means differed significantly at alpha $=.05$. Using the procedure previousIy described for the difference between the ARPI means, the following pairs of Motivation means were tested: $\overline{\mathrm{x}}_{\boldsymbol{1}}$ $\bar{x}_{2} ; \bar{x}_{1}-\bar{x}_{2}-\bar{x}_{3}$. A significant difference was found for each pair. Calculations for this test were done according to the procedure shown for the ARPI means in Appendix $\mathrm{H}$.

TABLE XXXVI

MEAN MOTIVATION SCORES OF BURNOUT GROUPS

\begin{tabular}{lccc}
\hline Group & Sample $\bar{x}$ & $\sigma$ & $n$ \\
\hline 1--Low Burnout & 37.44 & 3.93 & 623 \\
2--Moderate Burnout & 33.56 & 4.19 & 499 \\
3--High Burnout & 29.80 & 4.21 & 96 \\
\hline
\end{tabular}

TABLE XXXVII

ANOVA FOR LEVEL OF BURNOUT AND MOTIVATION SCORES

\begin{tabular}{lrrr}
\hline Source of Variation & df & MS & F \\
\hline Between groups & 2 & 3630.50 & $219.79 *$ \\
Within groups & 1217 & 16.52 & \\
\hline
\end{tabular}

\footnotetext{
*Significant at .001 level

$.999 \quad F_{2,1215}=6.97$
} 
Validation of the Psycho-physical state subscale.

This subscale was validated through the comparison of measures of other variables with the Psycho-physical state subscale scores. The measure of job stress, desire to leave the job, and level of burnout were administrator self-perceptions. The perceptions of others, as indicated through the Colleague Questionnaire total scores, the measure of emotional exhaustion, and the measure of physical vigor, were used in assessing the validity of this subscale. Question 1 on the colleague Questionnaire was used to measure the latter variable, as shown in Figure 10. scoring for this variable was in the same direction as scoring for the subscale, where higher scores indicate greater vigor.

The correlations between the Psycho-physical state subscale and the measures of the variables used in assessing the validity are shown in Table XXXVIII. 


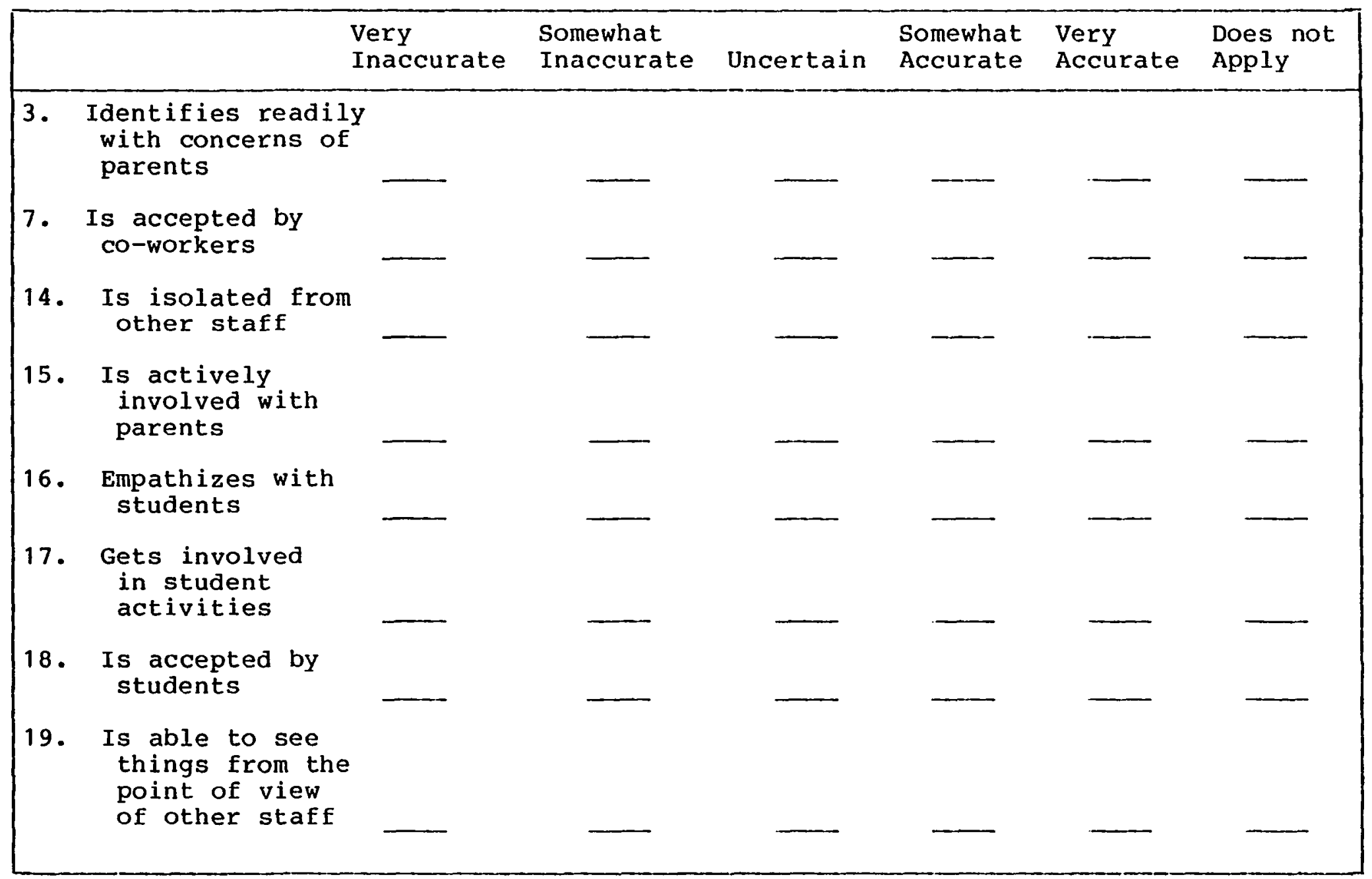

Figure 11. Measures of administrators' relationships as perceived by colleagues. 
TABLE XXXVIII

MEASURES OF VALIDITY FOR PSYCHO-PHYSICAL STATE SUBSCALE

\begin{tabular}{lc}
\hline Validity Measure & Psycho-physical State Subscale \\
\hline Job stress & $-.28 * * *$ \\
Amount of stress in work & $-.48 * * *$ \\
Felt stress & $-.33 * * *$ \\
Desire to leave job & $.10 * * *$ \\
Desire for early retirement & $-.58 * * *$ \\
Reason for early retirement & $.23 *$ \\
Level of burnout & $.38 * * *$ \\
Colleague Questionnaire & .09 \\
Emotional exhaustion & \\
Physical vigor &
\end{tabular}

\footnotetext{
*Significant at .05 level

**Significant at .01 level

***Significant at .001 level

An analysis of variance, using level of burnout as the independent variable and the Psycho-physical state score as the dependent variable was performed; alpha level was set at .05. The statistical hypothesis that there would be no significant difference between the Psycho-physical State means of the three burnout groups ( $\mathrm{H}: \mu_{1}=\mu_{2}=\mu_{3}$ ) was rejected $(p<.001)$. Table XXXIX shows the means and standard deviations at each level of burnout. Table XI provides the analysis of variance.
} 
TABLE XXXIX

MEAN PSYCHO-PHYSICAL STATE SCORES OF BURNOUT GROUPS

\begin{tabular}{lccc}
\hline Group & Sample $\overline{\mathrm{x}}$ & $\sigma$ & $\mathrm{n}$ \\
\hline 1--Low Burnout & 36.32 & 5.38 & 623 \\
2--Moderate Burnout & 30.27 & 5.31 & 499 \\
3--High Burnout & 25.05 & 5.05 & 96 \\
\hline
\end{tabular}

TABLE XL

ANOVA FOR LEVEL OF BURNOUT AND

PSYCHO-PHYSICAL STATE SCORES

\begin{tabular}{lrrr}
\hline Source of Variation & df & MS & F \\
\hline Between groups & 2 & 8315.12 & $293.14^{*}$ \\
Within groups & 1215 & 28.37 & \\
\hline
\end{tabular}

*Significant at .001 level

$.999 \quad F_{2,1215}$

Since the statistical hypothesis in the univariate analysis of variance was rejected, two or more of the means were not equal. Further analysis, using the scheffe test, was conducted to see which pairs of the means differed significantly, at alpha .05. Using the procedure described earlier for the differences between the ARPI means, the following pairs of Psycho-physical state means were tested: $\overline{\mathrm{x}}_{1}-\overline{\mathrm{x}}_{2}$; $\bar{x}_{1}-\bar{x}_{3}$ and $\bar{x}_{2}-\bar{x}_{3}$. A significant difference was found for each pair. 
Validation of the Relationships subscale. The subscale was validated through the comparison of measures of other variables with the Relationships subscale scores. The measures of job stress, desire to leave the job, and level of burnout were administrator self-perceptions. Emotional exhaustion and the total Colleague Questionnaire score, both measures of the perceptions of others, were also used. A number of other measures of the perceptions of others of the subjects' relationships were used. These questions came from the Colleague Questionnaire and are illustrated in Figure 11.

The scoring of direction for these questions was adjusted during the analysis so that high scores would be in the direction of positive relationships, which is the way the subscale is scored. The correlations between the relationships subscale and the measures of the variables used in assessing the validity are shown in Table XLI. 


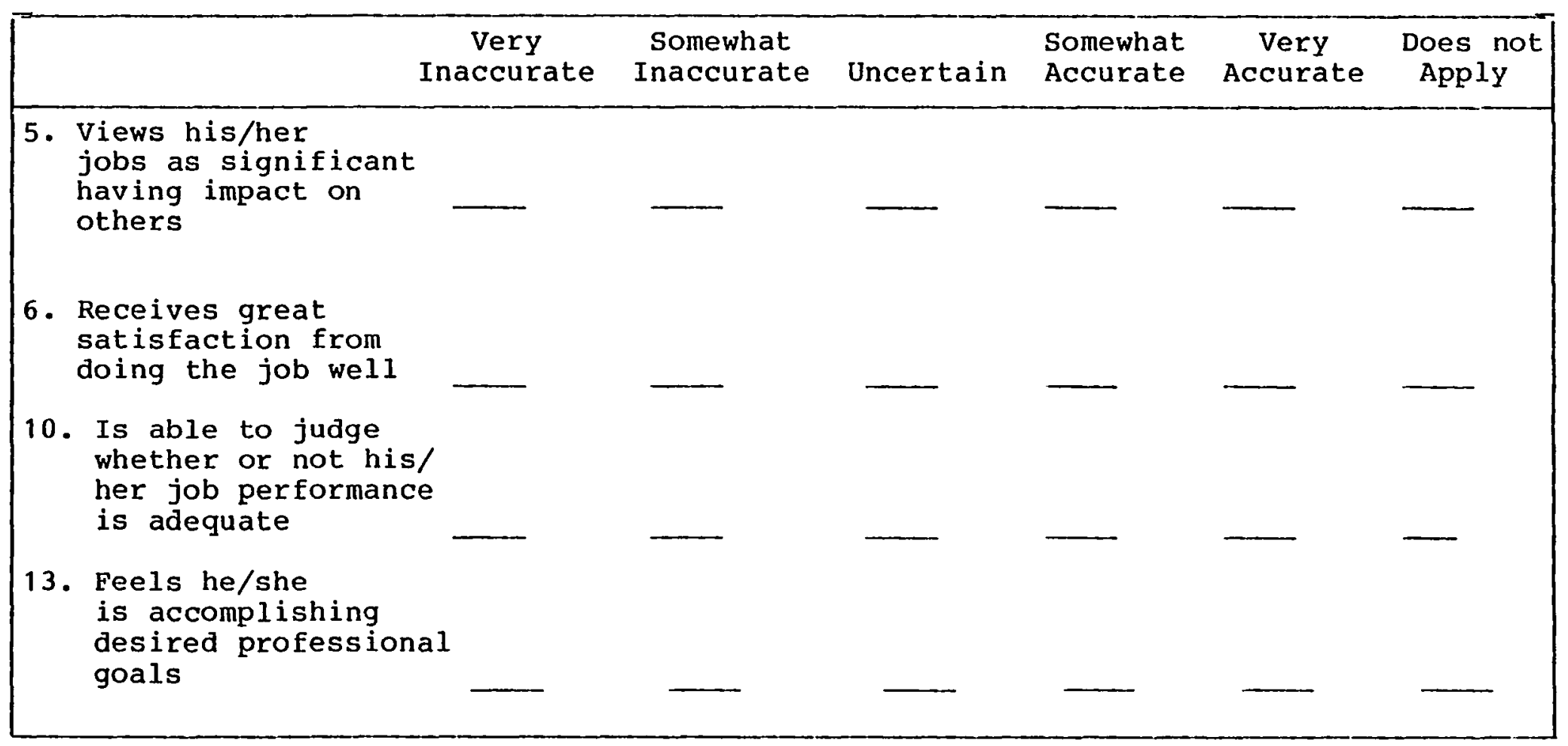

Figure 12. Measures of administrators' sense of accomplishment as perceived by colleagues. 
TABLE XLI

MEASURES OF VALIDITY FOR RELATIONSHIPS SUBSCALE

\begin{tabular}{lc}
\hline Validity Measure & Relationships Subscale \\
\hline Job stress & $-.08 * *$ \\
Amount of stress in work & $-.18 * *$ \\
Felt stress & $-.24 * * *$ \\
Desire to leave job & .05 \\
$\quad \begin{array}{l}\text { Desire for early retirement } \\
\text { Reason for early retirement }\end{array}$ & $-.32 * \star *$ \\
Level of burnout & .21 \\
Colleague Questionnaire & .21 \\
Emotional exhaustion & .02 \\
Identification with parents & .14 \\
Acceptance by co-workers & $.25 *$ \\
Isolation from staff & .10 \\
Involvement with parents & .03 \\
Involvement with students & .02 \\
Acceptance by students & -.06 \\
Identification with staff & .02 \\
Empathy for students & \\
\hline
\end{tabular}

*Significant at the .05 level
$* *$ Significant at the .01 level
$* * *$ Significant at the .001 level


Correlations between the Relationships subscale and the self-perceived measures of stress, desire to leave the job, and level of burnout are all significant at the .001 level, except for reason for early retirement, which is not significant.

Correlations between the Relationships subscale and the observer perceptions are insignificant, except for isolation from staff, which is significant at the .05 level. All significant correlations are in the expected direction. An analysis of variance, using level of burnout as the independent variable and the Relationship score as the dependent variable was performed; alpha level was set at .05 . The statistical hypothesis that there would be no significant difference between the Relationships means of the three burnout groups $\left(\mathrm{H}: \mu_{1} \Psi_{2}=\mu_{3}\right)$ was rejected $(\mathrm{p}<.001)$. Table XLII shows the means and standard deviations at each level of burnout. Table XLIII provides the analysis of variance.

Since the statistical hypothesis in the univariate analysis of variance was rejected, two or more of the means were not equal. Further analysis, using the Scheffe test, was conducted to see which pairs of the means differed significantly, at alpha $=.05$. Using the procedure described earlier for the differences between the ARPI means, the following pairs of Relationships means were tested: $\overline{\mathrm{X}}_{1}-\overline{\mathrm{X}}_{2} ; \overline{\mathrm{X}}_{1}-\mathrm{X}_{3} ;$ and $\overline{\mathrm{X}}_{2}-\overline{\mathrm{X}}_{3}$. A significant difference 
was found between the means of the low and moderate burnout groups and also between the low and high burnout groups. The means between the moderate and high groups on burnout did not differ significantly.

TABLE XLII

MEAN RELATIONSHIPS SCORES OF BURNOUT GROUPS

\begin{tabular}{lccc}
\hline Group & Sample $\overline{\mathrm{x}}$ & $\sigma$ & $\mathrm{n}$ \\
\hline 1--Low Burnout & 40.22 & 4.11 & 623 \\
2--Moderate Burnout & 38.08 & 4.03 & 499 \\
3--High Burnout & 36.41 & 4.56 & 96 \\
\hline
\end{tabular}

TABLE XLIII

ANOVA FOR LEVEL OF BURNOUT AND RELATIONSHIPS SCORES

\begin{tabular}{lrrr}
\hline Source of Variation & df & MS & F \\
\hline Between groups & 2 & 996.05 & $58.83^{*}$ \\
Within groups & 1215 & 16.93 & \\
\hline
\end{tabular}

*Significant at .001 level

$.999 \mathrm{~F}_{2,1215}=6.97$

Validation of the Accomplishment subscale. The subscale was validated through the comparison of measures of other variables with the Accomplishment subscale scores. The measures of job stress, desire to leave the job, and level of burnout were subject self-perceptions. Emotional 
exhaustion and the total Colleague Questionnaire score, both measures of the perceptions of others, were also used. A number of other measures of the perceptions of others of the subjects' feelings about accomplishment were used. These questions came from the Colleague Questionnaire and are illustrated in Figure 12 .

since the items are all written positively, no scoring adjustments were needed for the analysis. Higher scores indicate higher feelings of accomplishment, as is the case with the accomplishment subscale. The correlations between the accomplishment subscale and the measures of the variables used in assessing the validity are shown in Table XIIV.

Correlations between the Accomplishment subscale and the self-perceived measures of stress, desire to leave the job, and level of burnout vary in significance; all are in the expected direction. Correlations between the Accomplishment subscale and the observer perceptions also vary in significance, but all are in the expected direction. An analysis of variance, using level of burnout as the independent variable and the Accomplishment score as the dependent variable was performed; the alpha level was set at .05. The statistical hypothesis that there would be no significant difference between the Accomplishment means of the three burnout groups ( $\mathrm{H}: \mu_{1}=\mu_{2}=\mu_{3}$ ) was rejected $(p<.001)$. Table XLV shows the means and standard 


\begin{tabular}{|c|c|c|c|c|c|c|c|}
\hline & & $\begin{array}{c}\text { Very } \\
\text { Inaccurate }\end{array}$ & $\begin{array}{l}\text { Somewhat } \\
\text { Inaccurate }\end{array}$ & Uncertain & $\begin{array}{l}\text { Somewhat } \\
\text { Accurate }\end{array}$ & $\begin{array}{c}\text { Very } \\
\text { Accurate }\end{array}$ & $\begin{array}{l}\text { Does not } \\
\text { Apply }\end{array}$ \\
\hline 2 . & $\begin{array}{l}\text { Longs for the } \\
\text { "good old days" }\end{array}$ & $\bar{L}$ & & 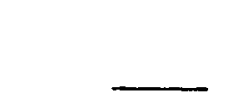 & - & $\ldots$ & $\ldots$ \\
\hline
\end{tabular}

Figure 13. Measure of administrators' time orientation as perceived by colleagues. 
TABLE XLIV

MEASURES OF VALIDITY FOR ACCOMPLISHMENT SUBSCALE

\begin{tabular}{lc}
\hline Validity Measure & Accomplishment subscale \\
\hline Job Stress & -.01 \\
Amount of stress in work & $-.19 * * *$ \\
Felt stress & \\
Desire to leave job & $-.30 * * *$ \\
$\quad \begin{array}{l}\text { Desire for early retirement } \\
\text { Reason for early retirement }\end{array}$ & $-11 * * *$ \\
Level of burnout & $.40 * * *$ \\
Colleague Questionnaire & $.31 * *$ \\
Emotional exhaustion & $.24 *$ \\
Impact of job & $.34 * *$ \\
Satisfaction from job done well & $.35 * *$ \\
Able to judge adequacy of work & .03 \\
Accomplishing desired professional goals & .21
\end{tabular}

*Significant at the .05 level

**Significant at the .01 level

$* * *$ Significant at the .001 level

deviations at each level of burnout. Table XLVI provides the analysis of variance.

Since the statistical hypothesis in the univariate analysis of variance was rejected, two or more of the means were not equal. Further analysis, using the scheffe test, was conducted to see which pairs of the means differed significantly, at alpha $=.05$. Using the procedure previously described for the difference between the means, the following pairs of Accomplishment means were tested: 
$\overline{\mathrm{x}}_{1}-\overline{\mathrm{x}}_{2} ; \overline{\mathrm{x}}_{1}-\overline{\mathrm{x}}_{3} ;$ and $\overline{\mathrm{x}}_{2}-\overline{\mathrm{x}}_{3}$. A significant difference was found for each pair.

TABLE XLV

MEAN ACCOMPLISHMENT SCORES OF BURNOUT GROUPS

\begin{tabular}{lccc}
\hline Group & Sample $\bar{x}$ & $\sigma$ & $n$ \\
\hline 1--Low Burnout & 41.21 & 3.69 & 623 \\
2--Moderate Burnout & 38.52 & 3.70 & 499 \\
3--High Burnout & 36.19 & 4.95 & 96 \\
\hline
\end{tabular}

TABLE XLVI

ANOVA FOR LEVEL OF BURNOUT AND ACCOMPLISHMENT SCORES

\begin{tabular}{lrrr}
\hline Source of Variation & df & MS & F \\
\hline Between groups & 2 & 1651.49 & $113.93 *$ \\
Within groups & 1215 & 14.50 & \\
\hline
\end{tabular}

*Significant at .001 level

$.999 \mathrm{~F}_{2,1215}=6.97$

Validation of the Time subscale. The subscale was validated through the comparison of measures of other variables with the time subscale scores. The measures of job stress, desire to leave the job, and level of burnout were administrator self-perceptions. Emotional exhaustion and the total Colleague Questionnaire score, both measures of the perceptions of others, were also used. An additional measure of the perceptions of others of the administrators' time orientation was question 2 on the Colleague questionnaire, as illustrated in Figure 13. 


\begin{tabular}{|c|c|c|c|c|c|c|}
\hline & $\begin{array}{l}\text { Very } \\
\text { Inaccurate }\end{array}$ & $\begin{array}{l}\text { Somewhat } \\
\text { Inaccurate }\end{array}$ & Uncertain & $\begin{array}{l}\text { Somewhat } \\
\text { Accurate }\end{array}$ & $\begin{array}{l}\text { Very } \\
\text { Accurate }\end{array}$ & $\begin{array}{l}\text { Does not } \\
\text { Apply }\end{array}$ \\
\hline $\begin{array}{l}\text { 9. Is highly moti- } \\
\text { vated, action- } \\
\text { oriented, pro- } \\
\text { active. }\end{array}$ & & & & & & \\
\hline
\end{tabular}

Figure 9. Measure of administrators' motivation as perceived by colleagues. 
Since this item was written in the negative, reverse scoring was employed during analysis so that higher scores would indicate a positive time orientation. The correlations between the time subscale and the measures of the variables used in assessing the validity are shown in Table XLVII.

TABLE XLVII

MEASURES OF VALIDITY FOR TIME SUBSCALE

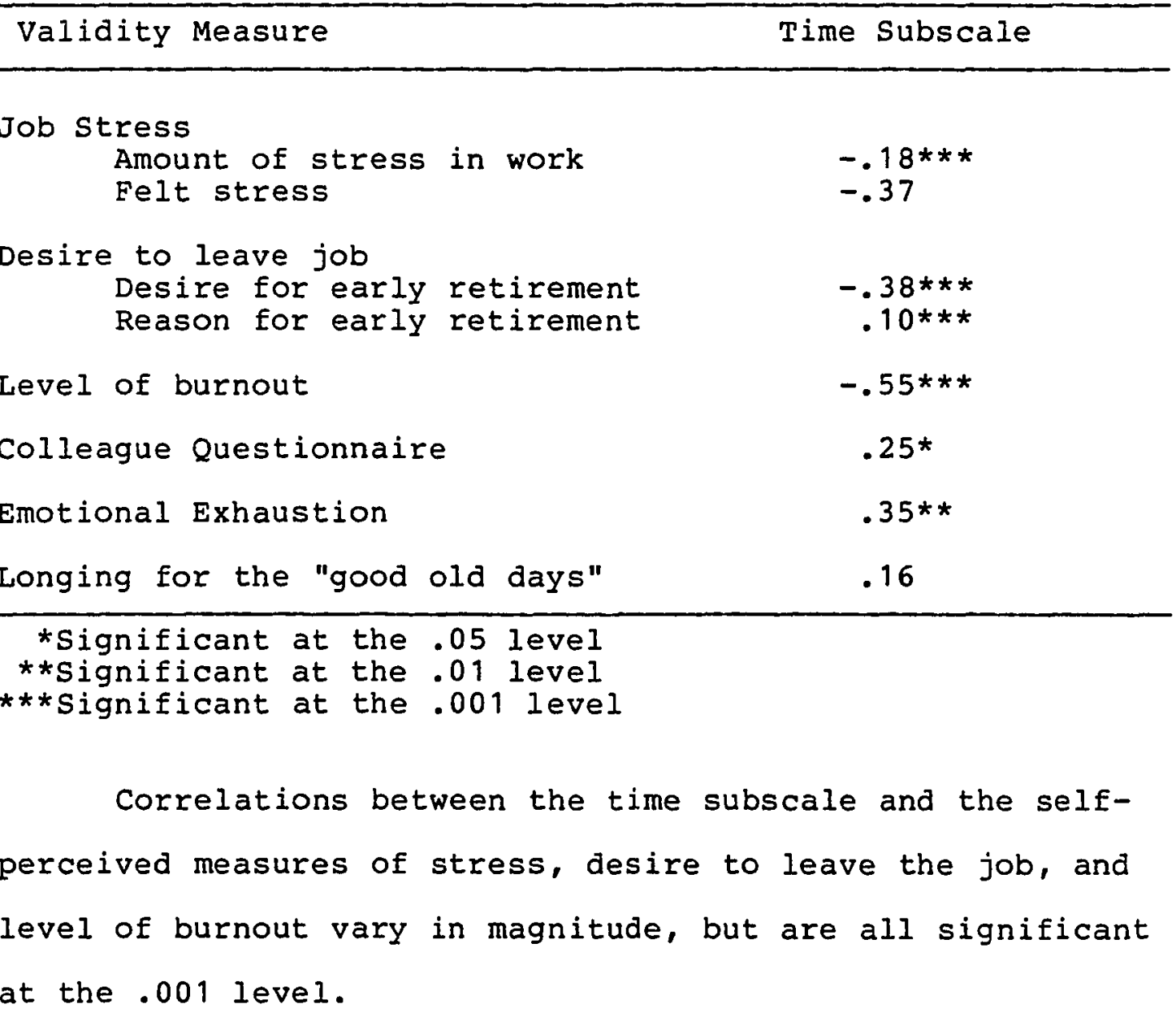


Correlations between the time subscale and the colleague perceptions also vary in significance and magnitude, but all are in the expected direction.

An analysis of variance, using level of burnout as the independent variable and the Time score as the dependent variable was performed; alpha level was set at .05. The statistical hypothesis that there would be no significant difference between the Time means of the three burnout groups ( $\mathrm{H}: \mu_{1}=\mu_{2}=\mu_{3}$ ) was rejected $(\mathrm{p}<.001)$. Table XIVIII shows the means and standard deviations at each level of burnout. Table XLIX provides the analysis of variance.

TABLE XLVIII

MEAN TIME SCORES OF BURNOUT GROUPS

\begin{tabular}{lccc}
\hline Group & Sample $\overline{\mathrm{x}}$ & $\sigma$ & $\mathrm{n}$ \\
\hline 1--Low Burnout & 30.98 & 3.86 & 623 \\
2--Moderate Burnout & 26.87 & 4.12 & 499 \\
3--High Burnout & 23.09 & 4.18 & 96 \\
\hline
\end{tabular}

TABLE XLIX

ANOVA FOR LEVEL OF BURNOUT AND TIME SCORES

\begin{tabular}{lrrr}
\hline Source of variation & df & MS & F \\
\hline Between groups & 2 & 7911.37 & $247.63 *$ \\
Within groups & 1215 & 15.97 & \\
\hline
\end{tabular}

\footnotetext{
*Significant at .001 level

$.999 \quad \mathrm{~F}_{2,1215}$

$=6.97$
} 
Since the statistical hypothesis in the univariate analysis of variance was rejected, two or more of the means were not equal. Further analysis, using the Scheffe test, was conducted to see which pairs of the means differed significantly, at alpha $=.05$. Using the procedure described earlier, the following pairs of Time means were tested: $\overline{\mathrm{X}}_{1}-\overline{\mathrm{X}}_{2} ; \overline{\mathrm{X}}_{1}-\overline{\mathrm{X}}_{3} ;$ and $\overline{\mathrm{X}}_{2}-\overline{\mathrm{X}}_{3} \cdot \mathrm{A}$ significant difference was found for each pair.

Summary. The preceding sections have outlined the results obtained in the procedures for assessing the criterion-related validity of the ARPI and each of its subscales. Significant correlations with the self-perceived measures of job stress, desire for early retirement, and level of burnout exist for the total ARPI scale and for each of the subscales. Significant correlations with the colleague Questionnaire were found for the total ARPI and for the Motivation, Psycho-physical state, Accomplishment, and Time subscales. Significant correlations with the measure of emotional exhaustion were found for the total ARPI, and the Expectation, Psycho-physical State, Accomplishment, and the Time subscales. All of the correlations identified above differ in degree of significance and in magnitude. A multivariate analysis of variance was performed on the five separate subscales of the ARPI: Expectation, Motivation, Accomplishment, Psycho-physical State, and 
Relationships, using the procedure found in statistical Package for the Social Sciences Update 7-9. (Hull and Nie, 1981). The Time subscale and the Total ARPI were excluded because these scales are comprised of items from the five separate subscales. Following the multivariate analysis of variance, a separate univariate analysis of variance was performed for each of the subscales, and for the ARPI. In each analysis, the three levels of burnout (low, moderate, high) were the independent variable. All pairs of means differed significantly at the .05 level, with the exception of the means for Relationships in the high and moderate burnout groups. 
CHAPTER V

SUMMARY, CONCLUSIONS, AND RECOMMENDATIONS

This chapter summarizes the purpose, procedures, and results of the study. The conclusions of the study and its limitations are presented; and recommendations are also addressed.

\section{Summary}

The major purpose of this study was to investigate the reliability, subscale intercorrelations, and validity of the Administrator Role Perception Inventory. This instrument was developed over the course of a year by the investigator and a co-author. It contains five subscales that are separate from each other, and a sixth composed of items from the other subscales. These subscales are: Expectation, Motivation, Accomplishment, Psycho-physical state, Relationships, and Time.

For this study, the active members of the Confederation of Oregon School Administrators were given the inventory by mail during August of 1982. Of the 2,113 members who received the materials, 1300 members returned them; 1270 returns were received in time for inclusion in the data analysis. The sample of active administrators had the following characteristics: (1) a mean age in years of 46 
(2) held the position of school building principal or viceprincipal and (3) had held that position for four years or less. On each of the subscales and on the total ARPI score, the sample was generally symmetrically distributed. There was more variation in the scores on Psycho-physical state than on any other subscale; scores on Accomplishment showed the least spread.

The areas for investigation were the reliability, subscale intercorrelations, and validity of the Administrator Role Perception Inventory and its subscales. Each of these areas is summarized in the succeeding paragraphs. Internal consistency, as measured by coefficient alpha, was used to assess the reliability of the subscales and the ARPI as a whole. The coefficients for the subscales fell between .70 and .85 ; the coefficient for the entire ARPI was . .91 .

The degree to which the pairs of subscales are separate from each other was determined by producing the subscale intercorrelations. These intercorrelations ranged from a low of .31 for Expectation and Relationships to a high of .64 between Accomplishment and Motivation. (The Time subscale had higher correlations with the other subscales because it is composed of items from the other subscales.)

Two areas of validity were addressed: content validity and criterion-related validity. Content validity was achieved by the development of items which represented the 
areas of burnout previously suggested by other authors, by asking people in the field of school administration for descriptions of a burned-out administrator, and by logically weighing and judging the resulting items. The items were field tested with graduate students and with school administrators in urban, suburban, and rural school districts. During this process, two forms of the ARPI were developed, revised, and field tested prior to the development of the third form, which is the focus of this study. Criterion-related validity was assessed by comparing ARPI scores and subscale scores with self-perceptions of the administrators and with the perceptions of administrators' colleagues. These comparisons were made using such variables as job stress, desire to leave the job as indicated by wish for early retirement, level of self-perceived burnout, emotional exhaustion, disillusionment, motivation, physical vigor, and quality of relationships. With the selfperceived variables of job stress, desire to leave the job, and level of burnout, the correlations for both the ARPI scores and the subscale scores were significant to the .001 level; they ranged from -.41 to -.59 . (The instrument scores and the variable scores were in the opposite direction). One measure of desire to leave the job, "reason for early retirement" provided no significant correlations. The general observations of others as indicated by the colleague 
Questionnaire scores correlated at .31 with the ARPI. Observer perceptions of administrators' level of emotional exhaustion correlated at .36 with the ARPI. Correlations between separate observer measures (individual questions on the Colleague Questionnaire) and the subscale scores were generally in the predicted direction, but not always significantly so.

Criterion-related validity was also assessed by performing an analysis of variance on each of the separate subscales and on Time and on ARPI. The level of burnout was the independent variable. For every subscale except Relationships, the means of the subscale were significantly different for the levels of burnout. This was also true for the mean ARPI scores. There were only two pairs of means that differed significantly on Relationships; the third pair, the difference between means in the moderate and high burnout groups, was not significant.

\section{Conclusions}

Reliabilities Comparable to Those of Similar Instruments

In evaluating a reliability coefficient, Nunnally

\section{(1972) cautioned:}

A particular reliability coefficient is meaningful only if it is computed on a sample of students [subjects] that is typical of the population of students with which the test will be used. . . 
If the sample is more homogeneous than the population in which the test will be used, the reliability will be underestimated. In contrast, if the standard deviation is larger than that in the population in which the test will be used, the reliability will be overestimated. (p. 117)

The reliability of the ARPI, as indicated by its internal consistency as measured by coefficient alpha, has been shown to be .91. The sample of administrators on which this value was computed constitutes 62 percent of the active membership of COSA, or approximately 1300 administrators, and is representative of the various types of administrative positions held by the members, as shown in Table $x$ on page 69. Thus, it is safe to conclude that the value of .91 is not an overestimate. Futhermore, this value is certainly comparable to other self-report inventories which use a Likert type scale. (Please see Appendix F for examples.) Nunnally (1972) pointed out, "Most of the commercially distributed tests of achievement and aptitude have reliability coefficients of .90 or higher. Very few of the self-report inventories reach this high level of reliabilty, and many of them dip below .80" (p. 477). Thus, the ARPI appears to be an internally consistent measure of administrator role perceptions and comparable to other similarly constructed instruments in degree of reliability. The Maslach Burnout Inventory is similar to the ARPI in terms of what is being measured, but not in format or 
scaling. Internal consistency for that scale was found to be .83 for frequency and .84 for intensity.

The subscales of the ARPI also have reliabilities that are comparable with those of the Maslach Burnout Inventory. The reliabilities of the ARPI subscales range from .70 to . 85; the reliabilities for the separate scales of the Maslach Burnout Inventory ranged from .57 to .89 .

Thus, it can be concluded that the reliabilities of the ARPI and its subscales are comparable to those of instruments similar in format and similar in variables being measured.

Subscale Inter-relationship

The subscale intercorrelations indicate that there are different levels of independence among the subscales. Motivation appears to have the least degree of independence from the other subscales. It shares about 38 percent of its variance with Accomplishment; 34 percent, with Psycho-physical state; 21 Percent, with Relationships; and 12 percent, with Expectation.

Psycho-physical state shares about 21 perent of its variance with Relationships; 25 percent, with Accomplishment; 31 percent with Expectation; and 34 percent, with Motivation. One interpretation of these patterns is support for the view that burnout is a state of emotional and physical exhaustion which manifests itself in a reduction of 
motivation and a lessened sense of accomplishment, with the secondary characteristics of unmet expecations and decreased quality of relationships. The interrelatedness of the subscales also suggests that the ARPI should be used as an entire scale and that the separate subscales be viewed as several of the many facets of role perception, not necessarily discrete.

Validity Comparable to that of Other Instruments

There are many ways of determining criterion-related validity. Very often the methods involve correlating one set of measures with another set. In this study, correlations were made between the ARPI scores and single item scales for self-perception of desire to leave the job, felt job stress, and level of burnout; these correlations were: $-.41,-.42$, and -.59 , all significant at the .001 level. These correlations are comparable to those produced in similar studies. For example, Maslach and Jackson found a correlation of .68 between police officers' desire to quit and their MBI scores (1981).4 other significant correlations reported by Maslach and Jackson from the same study are: .30 between emotional exhaustion and amount of time in direct contact with clients; -.21 between scores on meaning-

\footnotetext{
${ }^{4}$ The MBI is scored so that higher scores are in the direction of higher burnout; this is opposite to the scoring of the ARPI.
} 
fulness of work on the Job Diagnostic Survey and depersonalization; .30 between absenteeism and depersonalization. Measures of validity for other instruments were based on correlations between the instrument scores and measures such as other test scores, ratings by observers, interview data, and subject-written essays. These correlations ranged from .10 to .90 , as shown in Appendix F.

Validity of the individual subscales was also assessed. The correlations between job stress (felt stress) and each subscale were significant at least at the .01 level; they ranged from -.18 to -.48 . The correlations between each of the subscales and the measure of desire to leave the job were also significant, at least at the .01 level; they ranged from -.23 to -.46 . Lastly, the correlations between each of the subscales and the measure of self-perceived burnout were significant at the .01 level, at least; they ranged from -.32 to -.58 .

Validation of the ARPI and its subscales was also accomplished by comparing administrators' scores with the ratings of an observer, as reflected in the colleague Questionnaire. Administrators who scored lower on the ARPI were also given lower scores on the Colleague Questionnaire by their colleagues $(x=.31$, at a level of significance of $.01)$. In addition, administrators who scored lower on the ARPI were also observed as having higher levels of emotional exhaustion $(r=.36$, at $p<.01)$. These correlations are 
similar to those obtained by Maslach and Jackson (1981) in their reports on external validation of the MBI and its subscales.

Validation of the individual subscales was also addressed. Scores on Expectation correlated with colleague perceptions of emotional exhaustion and disillusionment ( $r=$ .28 and $r=.19$, respectively $p<.05$ in each case). Scores on Motivation showed no significant correlations with the observer measures of emotional exhaustion and motivation, but showed a correlation of .25 at the .05 level with the total Colleague Questionnaire score. The Psycho-physical state subscale showed a correlation of .38 at the .001 level with emotional exhaustion, as rated by an observer; it also showed a correlation of .23, significant at the .05 level, with the total Colleague Questionnaire. No significant correlation was found between this subscale and the observer rating of physical vigor. The Relationships subscale showed only one significant correlation with any of the observer ratings, an $r=.25$ at the .05 level with isolation from staff. The Accomplishment subscale showed significant correlations at either the .01 or .05 level with colleague ratings of the subjects' satisfaction from a job well done, feeling that one's job has impact, and emotional exhaustion, as well as with the total Colleague Questionnaire; these correlations were, respectively, .35,.34,.24, and .31. The last subscale, Time, showed a correlation of .25 at the 
.05 level with the total Colleague Questionnaire, and a correlation of .35 at the .01 level with emotional exhaustion. No significant correlation was found between the subscale and the observers' ratings of the subjects' longing for "the good old days."

\section{Significant Correlations Affirm Previous Studies}

Both Warnath and Shelton (1976) and Leeson (1980)

suggested the relationship between expectation discrepancy and burnout. The results of the study of the ARPI support that relationship.

Otto (1980) identified decreased motivation as a major component of burnout. This relationship was also found in the present study.

Emotional and physical exhaustion as important aspects of burnout were identified by Maslach and Jackson (1981). The correlations between the ARPI subscale Psycho-physical state and burnout substantiate their assertion. They also identified the feeling of lack of accomplishment as a component of burnout, and this, too, was found in the study of the ARPI.

\section{Additional Variable Associated with Burnout syndrome}

The relationship between time orientation and burnout had apparently been unresearched prior to this study. Of the six subscales comprising the ARPI, Time had the second 
highest correlation with burnout. Whether this reflects a desire for the specific conditions of the past or a desire for the comfort of the certainty that is acquired through hindsight is not clear.

Insignificant Correlations Suggest Key to Burnout Debate

It is clear that there are ample significant correlations to indicate the validity of both the ARPI and its subscales. However, the correlations which did not reach significance are also important.

The measure of reason for early retirement failed to correlate with anything. Careful reading of the question points out its poor wording; the choices at either end of the continuum are not opposites, and they should be. Perhaps a better measure of reason for early retirement would consist of two questions as shown in Figure 14 .

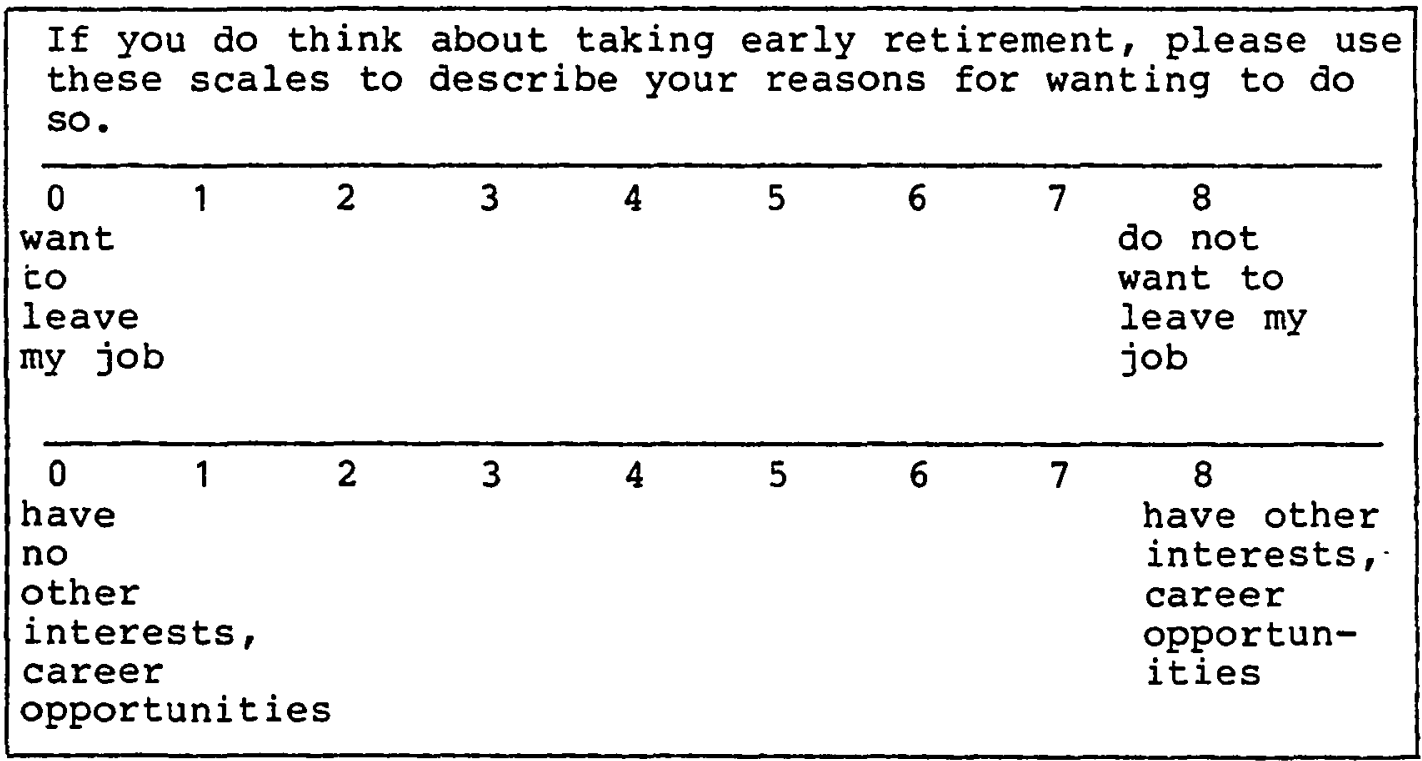

Figure 14. Improved questions on early retirement. 
The following list of measures which showed no significant correlation with the subscale to which they were directed should be examined.

$\begin{array}{ll}\text { Is highly motivated, action- } & \text { Motivation } \\ \text { oriented, pro-active } & \\ \text { Is physically vigorous and } & \begin{array}{l}\text { Psycho-physical } \\ \text { state }\end{array} \\ \begin{array}{l}\text { Identifies readily with concerns } \\ \text { of parents }\end{array} & \text { Relationships } \\ \text { Is accepted by co-workers } & \text { Relationships } \\ \text { Is actively involved with } & \text { Relationships } \\ \text { parents } & \\ \text { Gets involved in student } & \text { Relationships } \\ \text { activities } & \\ \text { Is able to see things from } & \text { Relationships } \\ \text { the point of view of other } & \\ \text { staff } & \\ \text { Empathizes with students } & \text { Relationships } \\ \text { Is able to judge whether or } & \text { Accomplishment } \\ \text { not job performance is } & \\ \text { adeguate } & \end{array}$

All of these items are observer measures of the subjects. Although several observer measures did correlate substantially with the subjects' measures, there is much less correlation than was found between the self-perceptions of the 
subjects and their ARPI scores. One possible conclusion is that the role perceptions that correlate with burnout are difficult for an outsider to witness. This would be one explanation for the debate mentioned at the beginning of this study--the vast difference of opinion on whether or not burnout exists. This pattern of correlations suggests that the perceptions that are associated with burnout are very private; one who has experienced them may recognize them in other people, but one who has not, will doubt their existence.

Another key to the burnout debate may be found in the measures of Relationships. The administrator self-perceptions of their Relationships correlated with their selfperceptions of their level of burnout, but not to the degree found between burnout and the other subscales. Also, this subscale was the only one where only two pairs of means differed significantly, rather than all three pairs. It may be that depersonalization and withdrawal, which are important aspects of relationships, are not as important in the burnout syndrome in the sample of administrators as they were in the syndrome experienced by professionals studied by other investigators. Nevertheless, these administrators clearly are experiencing other aspects of burnout. It is interesting to speculate on possible reasons for this; perhaps this difference lies in the fact that the client problems faced by administrators are not always caused by 
the deficit situations noted in Chapter I. This may also be a reason that the percentage of administrators assessing their level of burnout as high was only eight percent, rather than a larger percent.

\section{Limitations of the Study}

The limitations of this study include: (1) geographic location of the population (2) seasonal nature of the building administrator's job and (3) differences in job description and responsibilities, especially between central office and building administrators. A brief description of each limitation follows.

\section{Geographic Location}

Although the study included 2,113 of Oregon's practicing school administrators, no subjects from other states were involved. It is not known whether or not attributes of Oregon admnistrators cause them to belong to a different population than administrators in other states.

\section{Seasonal Nature of the Job}

The time of the year of the study was thought to be that which would produce the most conservative results. In other words, if responses correlating with burnout appeared, they would not be the result of a momentary and fleeting perception due to the seasonal pressures associated with public schooling. The disadvantage of this conservative 
approach is that there may have been legitimate instances of burnout which were temporarily alleviated, masked by the atypical conditions of this period in late summer when school is not in session.

\section{Difference in Job Descriptions and Responsibilities}

All school administrators deal with the same general issues and problems. However, the specifics of their jobs can be very different, as well as the characteristics of the people with whom they work each day.

\section{Recommendations}

The intent of this study was to assess the reliability and the validity of the ARPI. However, other issues should be dealt with in the future. These issues are treated in the following sections.

\section{Applications in Education}

The ARPI can be used by educational administrative groups as a tool for organizational diagnosis and evaluation. Because expectation discrepancy is closely associated with burnout, discussion of the group's scores on this subscale could lead to organizational commitments toward reducing that discrepancy. This might include both improved systems of planning and communication, discussion groups for sharing common problems and successful ways of handling them, as well as inservice to improve technical competence 
in dealing with some of the more difficult current issues in educational administration.

The association between the feeling of lack of accomplishment and burnout has also been demonstrated. Awareness of these feelings in an administrative unit could lead to attention to and emphasis on increased recognition for personnel. Other logical outcomes might be greater development of team management which would provide the support which enhances accomplishment.

Group scores in the area of physical and emotional vigor could provide impetus for the implementation of wellness programs and training in examining one's approaches to stressful events. Certainly the very foundation of the ARPI, the perceptions of administrators of their roles, is closely related to the program described in Increasing Human Effectiveness (Moawad, 1978).

Application to Other Professional Areas

Managers in fields other than education may wish to examine the variables upon which the ARPI is based. Although it would be inappropriate to use the instrument for groups other than school administrators, the concepts of expectation discrepancy, feeling of lack of accomplishment, and time orientation may provide useful clues to decreased employee motivation. 
The ARPI could serve as a model for the development of an instrument for use in public administration. Certain aspects of administration are common to both fields, though the clientele and specific purposes differ.

\section{Directions for Further Research}

It is recommended that this study be replicated on a smaller scale at the end of the school year and in the middle of it. Such a replication would provide valuable test-retest data, as well as uncover burnout that might have been masked by the time of year of this study.

The ARPI also may be a useful tool for further research in the field of educational administration, especially in regard to the characteristics of effective principals. There is agreement on the importance of the principal's leadership in establishing and maintaining quality education. The ARPI would have value in the further identification of the administrative role perceptions that are associated with the leadership in schools shown to be effective.

In conclusion, it is apparent that the ARPI has sufficient reliability and validity that it should not suffer the fate of so many special instruments--one use for one study, only to be cast aside and forgotten. 


\section{BIBLIOGRAPHY}

Austin, G. Process evaluation: A comprehensive study of outliers. Baltimore, Maryland: Maryland state Department of Education, 1978. (ERIC Document Reproduction Service No. ED 160644 )

Bardo, P. The pain of teacher burnout. Phi Delta Kappan, $1979,61,252-254$.

Bensky, J. M., Shaw, S., Gouse, A., Bates, H., Dixon, B., and Beane, $W$. PL 94-142 and stress: An analysis and direction for the future. Manuscript submitted for publication, 1980 .

Bishop, J. E. The personal and business costs of 'job burnout.' The Wall Street Journal, June 23, 1981, 31 and 34 .

Bloch, A. M. Combat neurosis in inner city schools. American Journal of Psychiatry. 1978, 135, 1189-1192.

Brandt, R. On school improvement: A conversation with Ronald Edmonds. Educational Leadership, 1982, 40, 13-15.

Brookover, W. \& Lezotte, L. Change in school characteristics coincident with changes in student achievement. Institute for Research in Teaching, Michigan state University, May 1977.

Cannon, W. B. Bodily changes in pain, hunger, fear, and rage. (2nd ed.). New York: Appleton, 1929.

Chance, P. That drained-out, used-up feeling. Psychology Today, January, 1981, 88-89.

Clark, D. L; Lotto, L. S; and McCarthy, M. M. Factors associated with success in urban elementary schools. Phi Delta Kappan, 1980, 61, 467-470.

Cooley, E. and Savicki, V. Preliminary investigations of environmental and individual aspects of burnout in teachers. Paper presented at the conference of the Oregon Educational Research Association, Otter Rock, October 1981. 
Cooper, H. M. Scientific guidelines for conducting integrative research reviews. Review of Educational Research, 1982, 52, 291-302.

Coulson, J. E. Overview of the national evaluation of the Emergency School Aid Act. Santa Monica, California: System Development Corporation, 1977.

Dohrenwend, B. S. and Dohrenwend, B. P. What is a stressful life event? In H. Selye (Ed.), Selye's guide to stress research. New York: Van Nostrand Reinhold, 1980 .

Edelwich, J. and Brodksy, A. Burn-out. New York: Human Sciences Press, 1980.

Edmonds, R. Effective schools for the urban poor. Educational Leadership, October, 1979, 22-23.

Edwards, A. L. The measurement of personality traits. New York: Holt, Rinehart and winston, 1970.

Esper, G. Non-work-related activities termed key to fighting occupational burnout. The Sunday Oregonian, April $5,1981, \mathrm{~A} 20$.

Festinger, L. The motivating effect of cognitive dissonance. In W. E. Natemeyer (Ed.), Classics of organizational behavior. Oak Park, Illinois: Moore, 1978.

Freudenberger, H. J. Staff burn-out. Journal of Social Issues, $1974,30,159-165$.

Freudenberger, H. J. Burn-out: The organizational menance. Training and Development Journal, July 1977, $26-27$.

Freudenberger, H. J. Burnout: The high cost of high achievement. New York: Anchor Press, 1980.

Garcia, A. S. Predictors of job satisfaction and worker burnout among child welfare workers (Doctoral dissertation, University of Texas at Austin, 1980). Dissertation Abstracts International, 1981, 41, 4839A (University Microfilms No. 81-09166, 271.

Gentile, L. M. and McMillan, M. M. Combating burnout: A must for secondary urban reading teachers. Reading World, $1980,19,332-337$.

Giammatteo, M. C. and Giammatteo, D. M. Forces on leadership. Reston, Virginia: National Association of Secondary School Principals, 1981. 
Glass, G. V and Stanley, J. C. Statistical methods in education and psychology. Englewood Cliffs, New Jersey: Prentice-Hall, 1970.

Gmelch, W. $H$. Beyond stress to effective management. Eugene, Oregon: University of Oregon, 1977. (ERIC Document Reproduction Service No. ED 140440 )

Gmelch, W. H. and Swent, B. Stress at the desk and how to cope effectively. oregon school study council Bulletin, 21, Eugene, Oregon: University of Oregon, 1977 .

Green, B. F. Attitude measurement. In G. Lindsey (Ed.), Handbook of social psychology. Cambridge, Mass.: Addison-Wesley, 1954.

Greenberger, R. S. Job hazard: How burnout affects corporate managers and their performance. The Wall street Journal, June 23, 1981, 1 and 10 .

Greenwald, A. G. Consequences of prejudice against the null hypothesis. Psychological Bulletin, 1975, 82, 1-20.

Hackman, J. R., and Lawler, E. Employee reactions to job characteristics. Journal of Applied Psychology, 1971, 55, 259-286.

Heflin, J. F. Alternative organizational arrangements, educational equity and school improvement: Issues and prospects for educational research and development. Interorganizational arrangements for collaborative efforts. Portland, Oregon: Northwest Regional Educational Laboratory, 1980.

Help! Teacher can't teach. Time, June 16, 1980, 51-57.

Hillier, A. Teacher burnout-responsibilities of the educator. Unpublished manuscript, 1981. (Available from Al Hillier, Centennial School District, $18135 \mathrm{SE}$ Brooklyn, Portland, OR 97235).

Hull, C. H. and Nie, N. H. SPSS Update 7-9. New York: McGraw-Hill, 1981.

Kahn, R. L. Job burnout prevention and remedies. Public Welfare, 1978, 36, 61-63.

Kerlinger, F. N. Foundations of behavioral research. New York: Holt, Rinehart, and Winston, Inc., 1973.

Lawler, E., and Suttle, J. I. Expectancy theory and job behavior. Organizational Behavior and Human Performance, $1974, \underline{9} 482-503$. 
Leeson, B. S. Professional burnout: The effect of the discrepancy between expectations and attainment on social workers in a mental hospital (Doctoral dissertation, University of Michigan, 1980). Dissertation Abstracts International, $1980,41, .3953$ A. (University Microfilms No. 81-06 177, 243).

Levinson, H. When executives burn out. Harvard Business Review, May-June, 1981, 73-81.

Lipham, J. A. Effective principal, effective school. Reston, Virginia: National Association of Secondary School Principals, 1981.

Lipovenko, Dorothy. The 'Burnout' syndrome. World Press Review, August, 1981,60 .

Marshall, J. C. and Hales, L. W. Classroom test construction. Reading, Mass.: Addison-Wesley, 1971.

Maslach, C. Burnout. Human Behavior, 1976, $\underline{5}, 16-22$.

Maslach, C. Job burn-out: How people cope. Public Welfare, $1978,36,56-58$.

Maslach, C. and Jackson, S.E. Burnout in health professions: a social psychological analysis. Manuscript submitted for publication, 1977.

Maslach, C. and Jackson, S. E. The measurement of experienced burnout. Journal of Occupational Behaviour, $1981, \underline{2}, 99-113$.

Maslach, C., and Jackson, S. E. Burned-out cops and their families. Psychology Today, 1979, 12, 59-62.

Maslach, C. \& Pines, A. The burn-out syndrome in the day care setting. Child Care Quarterly, 1977, 6, 100-113.

Mattingly, M. A. Sources of stress and burn-out in professional child care workers. Child Care Quarterly, $1977, \underline{6}, 127-137$.

McNemar, Q. At random: Sense and nonsense. American Psychologist, $1960,15,295-300$.

Minahan, A. Burnout and organizational change. Social Work, $1980, \underline{25}, 87$.

Moawad, B. Increasing human effectiveness participant's guide. U.S.A.: ULIEDGE Systems, 1978 . 
Morrow, L. The burnout of almost everyone. Time, september 21,1981, p. 84 .

Nie, N. H., Hull, C. H., Jenkins, J. G., Steinbrenner, K., and Bent, D. H. Statistical package for the social sciences. New York: McGraw-Hill, 1975.

Norman, Beverly. Career burnout. Black Enterprise, July, $1981,45-48$.

Nunnally, J. C. Educational measurement and evaluation. (2nd ed.). New York: McGraw-Hill, 1972.

Otto, N. R. Professional burnout: A Delphic probe to determine its definition, causes, and solutions. (Doctoral dissertation, University of Minnesota, 1980). Dissertation Abstracts International. 1980, 41,2865 A. (University Microfilms No. 81-02146, 169).

Pines, A. \& Maslach, C. Characteristics of staff burnout in mental health settings. Hospital and Community Psychiatry, $1978,29,233-237$.

Reed, S. What you can do to prevent teacher burnout. National Elementary Principal. 1979, 58, 67-70.

Ricken, R. Teacher burnout: A failure of the supervisory process. National Association of Secondary Princpals Bulletin, 1980, 64, 21-24.

Rizzo, J. R., House, R. J., Lirtzman, S. Role conflict and role ambiguity in complex organizations. Administrative Science Quarterly, 1970, 150-163.

Robinson, J. P. and Shaver, P. R. Measures of social psychological attitudes. Ann Arbor, Michigan: Publications Division, Institute for Social Research, University of Michigan, 1970.

Savicki, V. Job stress: Theory and research on burnout, the state of the art. Paper presented at the conference of the Oregon Psychological Association, Cottage Grove, April 1980.

Savicki, V. and Cooley, E. Theoretical and research considerations of burnout. Manuscript submitted for publication, 1980 .

Schwab, R. I. and Iwanicki, E. F. Perceived role conflict, role ambiguity, and teacher burnout. Educational Administration Quarterly, 1982 18, 60-74. 
Selye, H. Stress without distress. New York: McGraw-Hill, 1969 .

Selye, H. (Ed.). Selye's guide to stress research. New York: Van Nostrand Reinhold, 1980.

Shaw, M. E. and Wright, J. M. Scales for the measurement of attitudes. New York: McGraw-Hill, 1967.

Sparks, D. A teacher center tackles the issue. Today's Education, $1979, \underline{68}, 37$.

Truch, s. Teacher burnout and what to do about it. Novato, Cal.: Academic Therapy Publications, 1980.

Veninga, R. L. and Spradley, J. P. How to cope with "Job Burnout". Readers Digest, December, 1981, 109-112. (a)

Veninga, R. L. and Spradley, J. P. The work stress connection: How to cope with job burnout. Boston: Little, Brown and Co., 1981. (b)

Warnath, C. F. and Shelton, J. L. The ultimate disappointment: The burned-out counselor. Personnel and Guidance Journal, $1976,55,172-175$.

Wolfe, T. The me decade and the third great awakening. New West, August 30,1976 , pp. 27-48. 
APPENDIX A 
APPENDIX A

EXAMPLES OF EARLY RETIREMENT PROGRAMS

\begin{tabular}{|c|c|c|c|}
\hline Pre-Qualifications & Beaverton & $\begin{array}{l}\text { Lake } \\
\text { Oswego }\end{array}$ & $\begin{array}{c}\text { North } \\
\text { Clackamas }\end{array}$ \\
\hline Age & 58 & 58 & 58 \\
\hline Years of Service & $10+$ & & 15 \\
\hline Medical-Dental & $\begin{array}{l}\text { Full Family } \\
\text { Until } 65\end{array}$ & $\begin{array}{l}\text { Full Family } \\
\text { Until } 65\end{array}$ & $\begin{array}{l}\text { Full Family } \\
\text { (also group } \\
\text { life ins.) }\end{array}$ \\
\hline Compensation & $\begin{array}{l}\$ 400 / \mathrm{mo} \text {. } \\
\text { up to } 48 \text { mos. } \\
\text { or eligibility } \\
\text { for FICA }\end{array}$ & $\$ 400$ & \\
\hline Responsibility & $\begin{array}{l}15 \text { days } \\
\text { service }\end{array}$ & None & None \\
\hline
\end{tabular}


APPENDIX B 
2437 N.E. Regents Drive Portland, Oregon 97212 May 25, 1982

Dr. R. L. Rose

Confederation of Oregon School Administrators

710 12th Street S. E.

Salem, Oregon 97301

Dear Ozzie:

Thank you for your willingness to take my request for endorsement of my project to the COSA council. The telephone conversations you and I have had have been useful in helping me prepare the materials for the council's consideration.

Enclosed is my request for endorsement; it includes an overview of the project, action, and materials needed from COSA.

Receiving the endorsement is very important to me; I expect it will increase both the rate and the promptness of returns of the questionnaire, making my work more credible and useful. If you think I should be available to answer questions from the board, please let me know.

Thank you very much for your help.

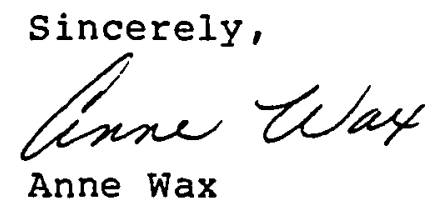

Encl. 
May 25, 1982

TO: Confederation of Oregon School Administrators

FROM: Anne S. Wax

RE: COSA Endorsement of Research on Administrator Role Perception

\section{Request}

I am seeking COSA endorsement of the following project, which is associated with my dissertation for the Doctor of Education in Educational Administration at Portland State University and the University of Oregon. (My advisor is Dr. John Heflin.) Specifically, I would like:

1. A set of mailing labels for every other $\cos A$ member.

2. Copies of a letter of endorsement to enclose with my questionnaire. (A suggested draft is enclosed for your consideration.)

3. The use of the bulk mailing permit.

4. Sufficient envelopes for the mailing and the return of the information.

I expect to pay for postage, and would be willing to pay for other costs if necessary.

I want to do the mailing on June 21; therefore, I would like to pick up the requested materials in Salem as soon after June 1 as is convenient for the COSA board and Staff.

\section{Synopsis of the Stuay}

Rationale

Administrators face many challenges today--Iimited funding, collective bargaining, special interest pressure groups, community politics, increasingly complex student needs, etc. How administrators view their role can affect the way they meet these challenges. Many professionals believe that stress and "burnout" are related to role perceptions. Studies related to these phenomena have been conducted with hospital workers, lawyers, social workers, teachers, and school counselors. 
Confederation of Oregon School Administrators Page 2 of 3

May 25, 1982

Though Gmelch and Swent have studied stress in administrators, no studies have been published on factors that may contribute to administrator burnout. A number of people doubt its existence; others decry its dire consequences.

If the phenomenon exists in educational administrators, it can have important implications for school effectiveness, educational leadership, staff morale, inservice education, absenteeism, and early retirement. It is hoped that a study such as the one for which endorsement is sought can be useful in the identification and prevention of the burnout syndrome.

\section{Purpose}

It is the purpose of this study to:

1. Investigate the reliability and validity of a questionnaire for identifying and measuring factors in administrator role perception. This instrument is called the Administrator Role Perception Inventory.

2. Determine if a relationship exists between these factors and burnout.

3. Report descriptively the results obtained from the sample of administrators who participate in the study.

\section{Procedures}

All individuals in the sample will be asked to respond to the Administrator Role Perception Inventory and to a job data sheet, returning them to me by July 15 in the envelope provided. (The questionnaire has undergone two field tests with administrators from four school districts and two graduate classes at Portland State University.) Sub-samples of individuals will be selected at random, by zip code, to receive an additional inventory for a close colleague of their choice to answer and return to me. These responses will be coded by $z$ ip code to the matching Administrator Role Perception Inventory for correlational purposes; the responses will be anonymous and no record of named will be compiled. The colleague inventory has importance for the validation aspects of the study. 
Confederation of Oregon School Administrators Page 3 of 3

May 25,1982

All responses on all instruments will be confidential; only group data will be reported.

Results and Conclusions

Results and conclusions will be reported in my dissertation. The approximate date for completon of this work is October, 1982. A condensed report will be provided for CosA use.

Importance of the Endorsement

Thank you very much for your consideration. I know that your endorsement can make a great difference in the number of responses that I will receive; this naturally affects the credibility and utility of the study.

Enclosures

1. Administrator Role Perception Inventory

2. Job Data form

3. Return envelope for Administrator Role Perception Inventory

4. Colleague packet

a. Colleague Questionnaire

b. Return envelope for Colleague Questionnaire

5. Letter from me which will accompany the questionnaire and inventories. 
ADMINISTRATOR ROLE PERCEPTION INVENTORY

\section{Directions}

This inventory contains 50 perceptions concerning life as an administrator. Read each statement and decide to what extent you agree or disagree with it. For each statement, please mark an $x$ on the line which corresponds best to your opinion. 
ADMINISTRATOR ROLE PERCEPTION INVENTORY

Strongly

Disagree

Disagree

Neutral Agree

Strongly

1. I never expected to spend so much time documenting what I've sald and done.

2. I approach my work with less eagerness now.

3. My work depresses me more now than it used to.

4. I have the support of parents.

5. I've made a number of important accomplishments.

6. I thought I'd have more time for creative educational planning.

7. I look forward to going to work.

B. I seldom feel fatigued.

9. Parents and I are able to see each other's point of view.

10. In my fob as an administrator, I have a positive effect on other people's lives.

11. I have about as much time for planning as I had expected.

12. I look for ways to lessen my responsibilities.

13. I wish that I did not have to work so closely with other people.

14. It is often difficult for me to establish rapport with parents.

15. I an not an effective administrator. 
Strongly

Disagree

Disagree

Neutral

Strongly

Agree

16. Being a school administrator is no more difficult than I thought it would be.

17. I don't want to go to work.

13. By the end of the day, I'm washed out.

19. Parents used to trust me more than they seem to now.

20. My professional life seems empty.

21. I thought people would be more appreciative of my efforts.

22. I am more motivated than I used to be.

23. Although I work hard, I'm not exhausted at the end of the work day.

24. Students frequently smile and speak to me.

25. I suspect that other administrators think I'm not as effective as I used to be.

26. I didn't know that I'd have to spend so many evenings working.

27. I volunteer for special committees less than I used to.

28. My fob is more emotionally draining than it used to be.

29. I find myself treating students

as If they are a set of variables, rather than as individual people.

30. My recent accomplishments seem to be of little importance. 
31. My training gave me a good Idea of what to expect in my job.

32. My fob provides right amount of challenge for me.

33. I don't laugh as often as I used to.

34. Staff members tend to contact me only when they feel it is essentlal for them to do so.

35. When there's a hard fob to be done, people often ask for my help.

36. It is harder to establish priorities than I thought it would be.

37. It is important for me to push myself to be all that I can be.

38. I indulge in self-pity more than I used to.

39. I am more effectlve now in working with students' problems.

40. I do a good job in handling staff problems.

41. People are more irrational than I had suspected.

42. I frequently initiate changes in order to improve our school.

43. I seldom feel weary.

44. I really do not understand today's students. 
$\begin{array}{lll}\text { Strongly } & \text { Strongly } \\ \text { Disagree Disagree Neutral Agree } & \text { Agree }\end{array}$

45. I can list a number of accomplishments that I have made in the last year.

46. In my job today, I deal with problems I never could have imagined 10 years ago.

47. I look for opportunities to further demonstrate $\mathrm{my}$ talents and skills to my superiors.

48. I am seldom grouchy.

49. Helping staff learn new ways of working with students has become more important to me.

50. I can now make a more positive impact at work than I could before. 
JOB DATA

Please provide the following information:

1. Job title

2. Which of these definitions best describes your present job?

line

(a position in the direct line of authority from superintendent to principal; direct and specific accountability for instruction.)*

staff

(a position whose function is to help line administrators; provides service, support, analysis.)

3. For how many people are you responsible in your job? adults students

4. Which of the following most accurately describes your position?

central office elementary school

middle school/junior high school high school

5. For how many years have you held this position (same location, job responsibilities, etc.)? years

6. What is your age?

years

*This definition may extend to vice-principals. 
For questions 7 through 11 , circle the number which best reflects your perception.

7. How often do you think about taking early retirement?

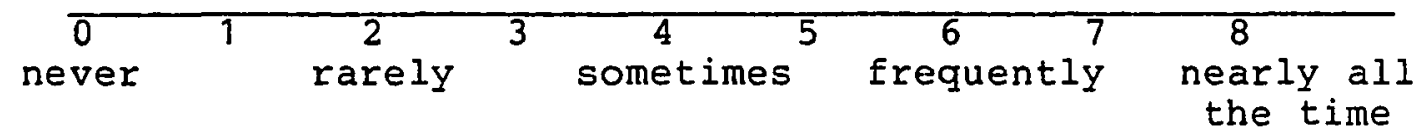

8. If you do think about taking early retirement, is it mostly because you want to leave your job, or is it mostly because you have other interests or career opportunities that you are anxious to pursue?

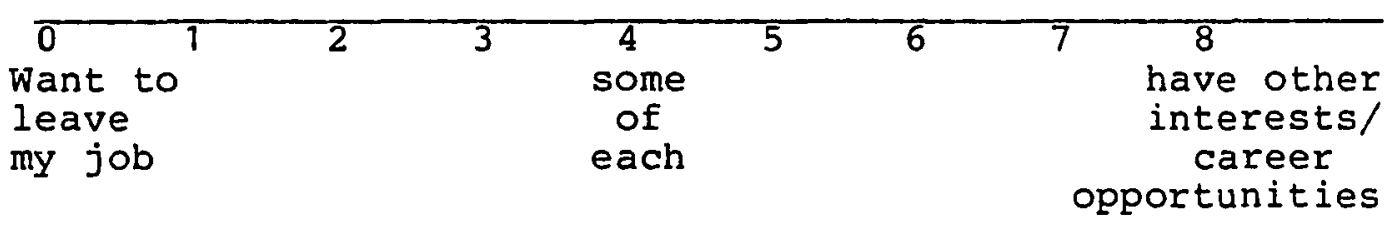

9. How much stress is in your work?

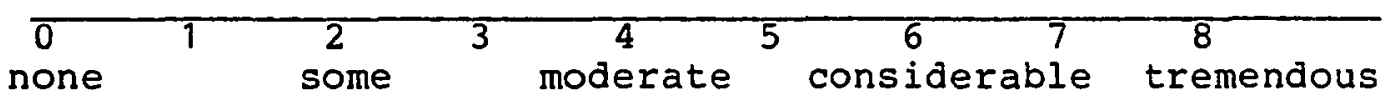

10. How much stress do you feel?

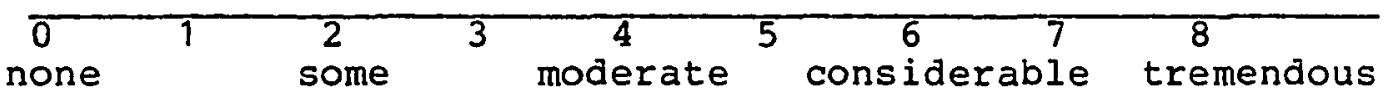

11. Please indicate your current level of burnout.

\begin{tabular}{ccccccc}
\hline 0 & 1 & 2 & 3 & 4 & 5 & 6 \\
none & some & & moderate & & considerable & 8 \\
& & & &
\end{tabular}

12. Is there a zip code written at the top of your questionnaire?

If "no", you have completed all the information requested. Please mail the Administrator Role Perception Inventory and the Job Data form to me in the enclosed, stamped envelope. Again, thank you very much for your help. 
If "yes", you have also received an envelope containing an inventory to be completed by a colleague of your choice (supervisor, peer, subordinate--anyone with whom you work). This person is being asked for information which will help to validate the Administrator Role Perception Inventory. Please ask your colleague to. provide the information requested and to send it to me in the special, separate envelope provided in that packet. Thank you so much for your cooperation and help. 


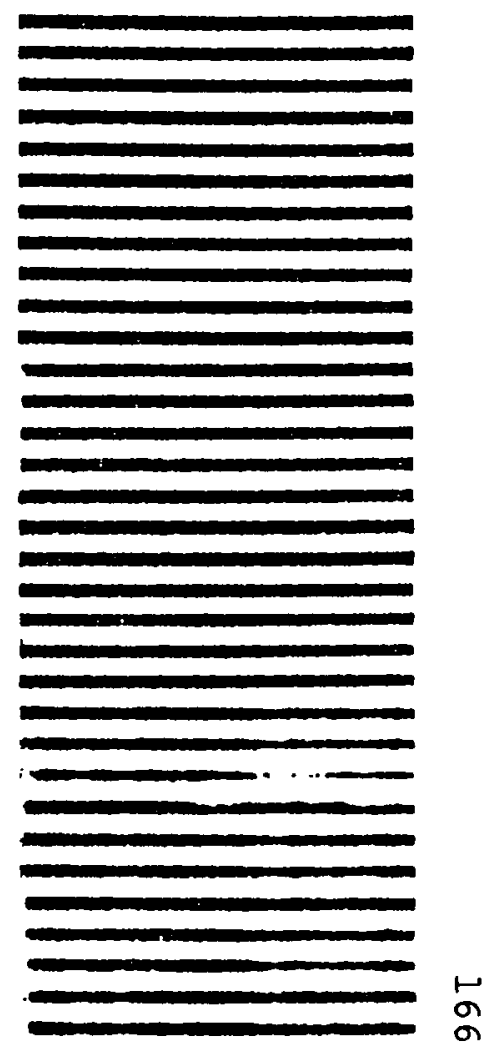

CONFEDERATION OF OREGON SCHOOL ADMINISTRATORS

71012 th Street SE

Salem, OR 97301

Attention: Anne Wax 


\title{
COLLEAGUE PACKET
}

\author{
Please give this envelope to \\ one of your colleagues. Ask \\ him or her to provide the \\ information requested and to \\ mail it in the envelope provided.
}

THANK YOU 
The administrator who gave you this packet is participating in a study on administrator role perception and its possible relationship to burnout. You are being asked to provide the following information in order to help validate the Administrator Role Perceptio;n Inventory, which is the questionnaire being used in the study. Zip code matching is being done to provide for correlation. All the information is confidential and anonymous; no record of names will be made, all data reported will be group data.

\section{Directions}

Please indicate, in your ofinion, the extent to which each phrase describes the person who gave you this questionnaire. Mark an $X$ on the line which corresponds best to your opinion.

$\begin{array}{cccc}\text { Very } & \text { Somewhat } & \text { Somewhat } & \text { Very Does Not } \\ \text { Inaccurate } & \text { Inaccurate Uncertain Accurate Accurate Apply }\end{array}$

1. Is physically vigorous and healthy.

2. Longs for the "good old days."

3. Identifies readily with concerns of parents.

4. Would like to take early retirement to "get away from this mess."

5. Views his/her fob as significant, having impact on others.

6. Recelves great satisfaction from doing the job well.

7. Is accepted by coworkers.

8. Is emotionally dralned.

9. Is highly motivated, action-oriented, proactive.

10. Is able to fudge whether or not his/her fob performance is adequate. 


$\begin{array}{cccc}\text { Very } & \text { Somewhat } & \text { Somewhat } & \text { Very Does Not } \\ \text { Inaccurate } & \text { Inaccurate Uncertain Accurate Accurate Apply }\end{array}$

11. Feels disillusioned about

how the job has turned

out.

12. Has the support of the community.

13. Feels he/she is accomplishing disired professional goals.

14. Is isolated from other staff.

15. Is actively involved with parents.

16. Empathizes with students.

17. Gets involved in student activities.

18. Is accepted by students.

19. Is able to see things from point of view of other staff.

The person whom I am describing is my:

\begin{tabular}{l} 
Superior \\
Peer \\
\hline Subordinate
\end{tabular}

Thank you very much for your help. Please return this materlal to

Anne S. Wax

COSA

710 12th Street S.E.

Salem, OR 97301

by September 15, 1982 in the stamped envelope provided. 
$\cos A$

71012 th Street SE

Salem, OR 97301
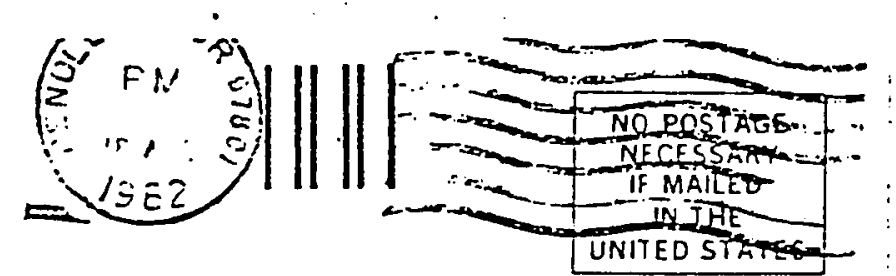

BUSINESS REPLY MAIL
first class Permi no. 1489 SALEM, OREGON

CONFEDERATION OF OREGON

SCHOOL ADMINISTRATORS

710 12th Street SE

Salem, OR 97301

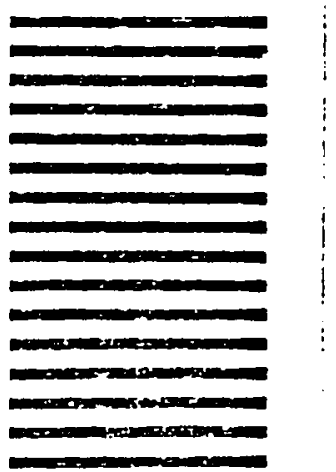

Attention: Anne Wax 
Dear CosA Member,

All of us know the many challenges faced by administrators today--limited funding, collective bargaining, special interest pressure groups, community politics, increasingly complex student needs, etc. How we meet these challenges is affected by our perception of our administrative role; this is one aspect of a study being conducted by one of our members, Anne Wax, for her Doctorate in Educational Administration.

We view her research as making an important contribution to the knowledge base in educational leadership and professional growth. The results of her study should prove valuable to educational administrators in oregon. We enthusiastically endorse her study and encourage your participation.

Sincerely,

Ozzie Rose

Executive Director 
June 21,1982

Dear CoSA Member,

Many professionals believe that stress and burnout are phenomena of importance to the field of educational

administration today. If this is so, then these characteristics may be related to role perceptions. Your responses to the enclosed inventory would help determine if such a relationship exists.

All members in the sample are receiving: (1) the Administrator Role Perception Inventory and (2) an accompanying Job Data form. A small group of members are also receiving materials to be filled in by a colleague of their choice. To preserve anonymity and at the same time allow correlation, these materials are identified by $z$ ip code. No record of names is being made.

I know how busy you are, but I would very much appeciate your taking the time to provide the requested information and to have it returend to me in the envelope(s) provided.

Thank you again for your contribution to this study.

sincerely,

Anne S. Wax 
APPENDIX C 


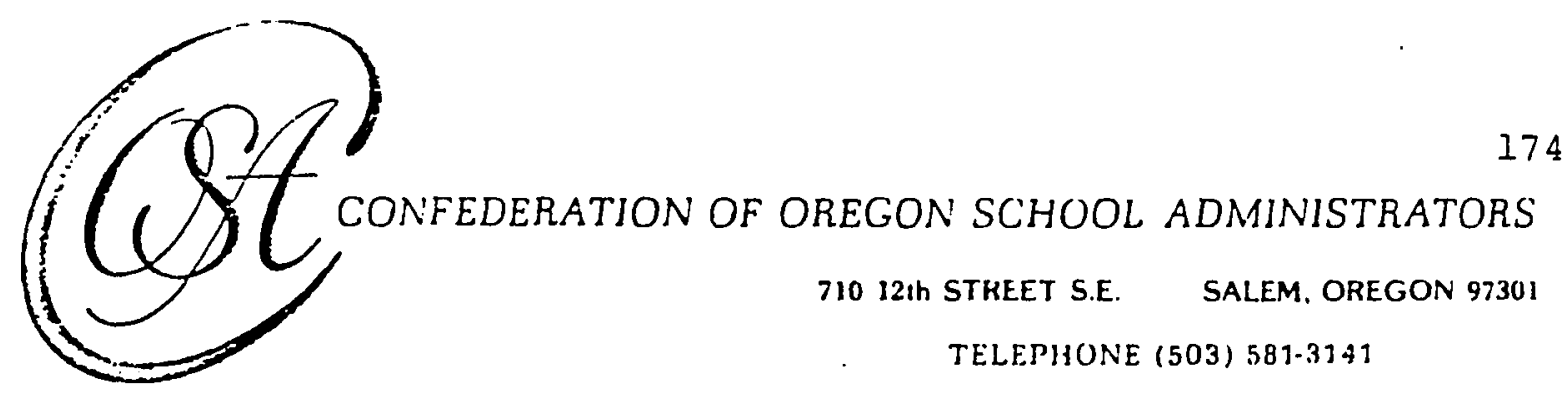

August 15, 1982

Dear COSA Member,

All of us know the many challenges faced by administrators today-limited funding, collective bargaining, special interest pressure groups, community politics, increasingly complex student needs, etc. How we meet these challenges is affected by our perception of our administrative role; this is one aspect of a study being conducted by one of our members, Anne Wax, for her Doctorate in Educational Administration.

We view her research as making an important contribution to the knowledge base in educational leadership and professional growth. The results of her study should prove valuable to educational administrators in Oregon. We enthusiastically endorse her study and encourage your participation.

Sincerely,

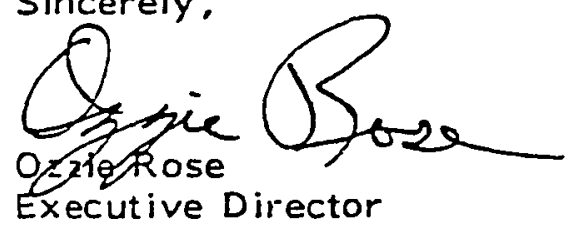

OR :oh 


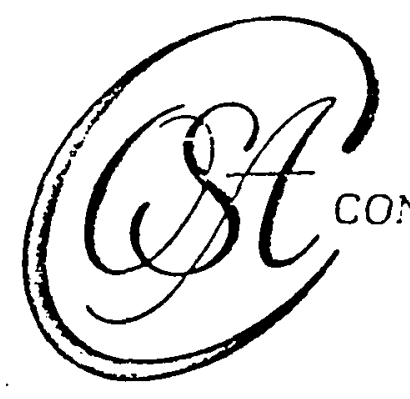

OREGON SCHOOL ADMINISTRATORS

71012 sh STREET S.E. SALEM. OREGON 97301

TELEPHONE (503) 583-3141

August 15, 1982

Dear COSA Member.

Many professionals believe that stress and burnout are

phenomena of importance to the field of educational administration today. If this is so, then these characteristics may be related to role perceptions. Your responses to the enclosed inventory would help determine if such a relationship exists.

All members are receiving: (1) the Administrator Role Perception Inventory and (2) an accompanying Job Data form. A small group of members are also receiving supplemental materials to be filled in by a colleague of their choice. To preserve anonymity and at the same time allow correlation, these materials are identified by zip code. No record of names is being made.

I know how busy you are, but 1 would very much appreciate your taking the time to provide the requested information and to have it returned to $m e$ in the envelope provided.

Thank you again for your contribution to this study.

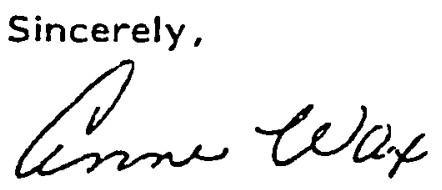

Anne S. Wax

ASW :oh

Encl... 
ADMINISTRATOR ROLE PERCEPTION INVENTORY

\section{Directions}

This inventory contains 50 perceptions concerning life as an administrator. Read each statement and decide to what extent you agree or disagree with it. For each statement, please mark an $x$ on the line which corresponds best to your opinion. 
ADMINISTRATOR ROLE PERCEPTION INVENTORY

$\begin{array}{llcc}\text { Strongly } & & \text { Strongly } \\ \text { Disagree } & \text { Disagree } & \text { Neutral Agree } & \text { Agree }\end{array}$

1. I never expected to spend so much time documenting what I've said and done.

2. I approach my work with less eagerness now.

3. My work depresses me more now than it used to.

4. I have the support of parents. -

5. I've made a number of important accomplishments.

6. I thought I'd have more time for creatlve educational planning.

7. I look forward to golng to work.

8. I seldom feel fatigued.

9. Parents and I are able to see each other's point of view.

10. In my job as an administrator, I have a positive effect on other people's lives.

11. I have about as much time for planning as I had expected.

12. I Look for ways to lessen my responsibilities.

13. I wish that I did not have to work so closely with other people.

14. It is often difficult for me to establish rapport with parents.

15. I am not an effective administrator. 
16. Being a school administrator is no more difficult than I thought it would be.

17. I don't want to go to work.

18. By the end of the day, I'm washed out.

19. Parents used to trust me more than they seem to now.

20. My professional life seems empty.

21. I thought people would be more appreciative of my efforts.

22. I am more motivated than I used to be.

23. Although I work hard, I'm not exhausted at the end of the work day.

24. Students frequently smile and speak to me.

25. I suspect that other administrators think I'm not as effectlve as I used to be.

26. I didn't know that I'd have to spend so many evenings working.

27. I volunteer for special committees less than I used to.

28. My job is more emotionally draining than it used to be.

29. I find myself treating students as if they are a set of variables, rather than as individual people.

30. My recent accomplishments seem to be of little importance. 
31. My training gave me a good idea of what to expect in my job.

32. My fob provides right amount of challenge for me.

33. I don't laugh as often as I used to.

34. Staff members tend to contact me only when they feel it is essential for them to do so.

35. When there's a hard job to be done, people often ask for my help.

36. It is harder to establish priorities than I thought it would be.

37. It is important for me to push myself to be all that I can be.

38. I indulge in self-pity more than I used to.

39. I am more effective now in working with students' problems.

40. I do a good fob in handling staff problems.

41. People are more Irrational than I had suspected.

42. I frequently initiate changes in order to improve our school.

43. I seldom feel weary.

44. I really do not understand today's students. 
Strongly

Disagree

Disagree

Neutral

Strongly

Agree

45. I can list a number of accomplishments that I have made in the last year.

46. In my fob today, I deal with problems I never could have imagined 10 years ago.

47. I look for opportunities to further demonstrate my talents and skills to my superiors.

48. I am seldom grouchy.

49. Helping staff learn new ways of working with students has become more important to me.

50. I can now make a more positive impact at work than I could before. 
JOB DATA

Please provide the following information:

1. Job title

2. Which of these definitions best describes your present job?

I ine

Iine

staff (a position in the direct line of authority from superintendent to principal; direct and specific accountability for instruction.)*

(a position whose function is to help line administrators; provides service, support, analysis.)

3. For how many people are you responsible in your job?

adults
students

4. Which of the following most accurately describes your position?

central office

elementary school

middle school/junior high school

high school

5. For how many years have you held this position (same location, job responsibilities, etc.)?

$$
\text { years }
$$

6. What is your age?

years

*This definition may extend to vice-principals. 
For questions 7 through 11 , circle the number which best reflects your perception.

7. How often do you think about taking early retirement?

\begin{tabular}{ccccccc}
\hline 0 & 1 & 2 & 3 & 4 & 5 & 6 \\
never & rarely & & $\begin{array}{c}6 \\
\text { sometimes }\end{array}$ & $\begin{array}{c}8 \\
\text { frequently }\end{array}$ & $\begin{array}{c}\text { nearly all } \\
\text { the time }\end{array}$
\end{tabular}

8. If you do think about taking early retirement, is it mostly because you want to leave your job, or is it mostly because you have other interests or career opportunities that you are anxious to pursue?

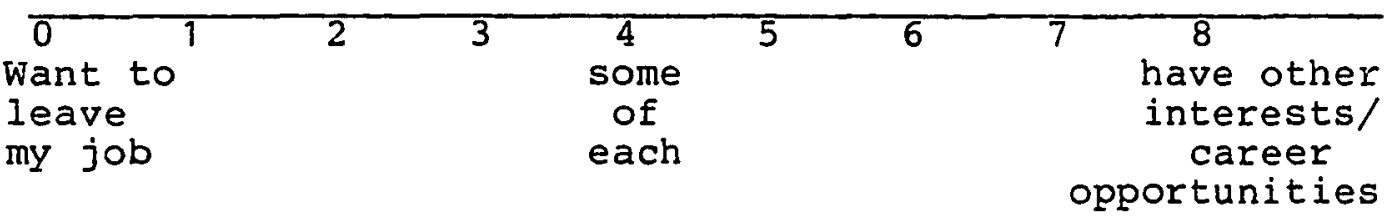

9. How much stress is in your work?

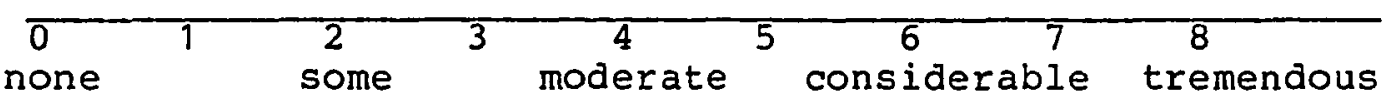

10. How much stress do you feel?

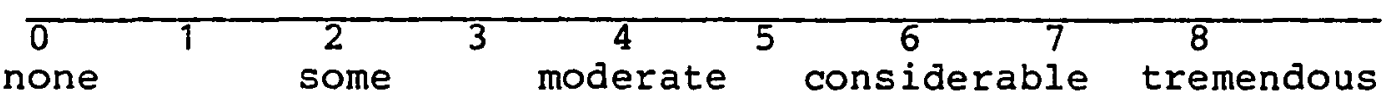

11. Please indicate your current level of burnout.

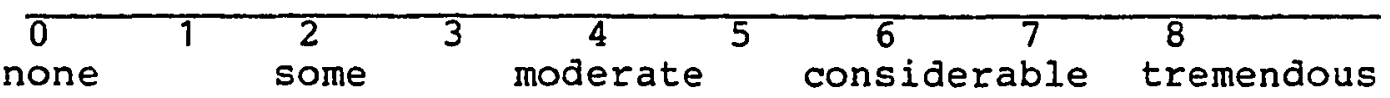

12. Is there a zip code written at the top of your questionnaire?

If "no", you have completed all the information requested. Please mail the Administrator Role Perception Inventory and the Job Data form to me in the enclosed, stamped envelope. Again, thank you very much for your help. 
If "yes", you have also received an envelope containing an inventory to be completed by a colleague of your choice (supervisor, peer, subordinate--anyone with whom you work). This person is being asked for information which will help to validate the Administrator Role Perception Inventory. Please ask your colleague to provide the information requested and to send it to me in the special, separate envelope provided in that packet. Thank you so much for your cooperation and help. 


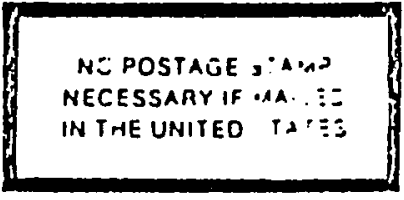

BUSINESS REPLY MAIL
FIRST CLASS PERMIT NO. 1489 SALEM, OREGON

Postage will be paid by Addressee

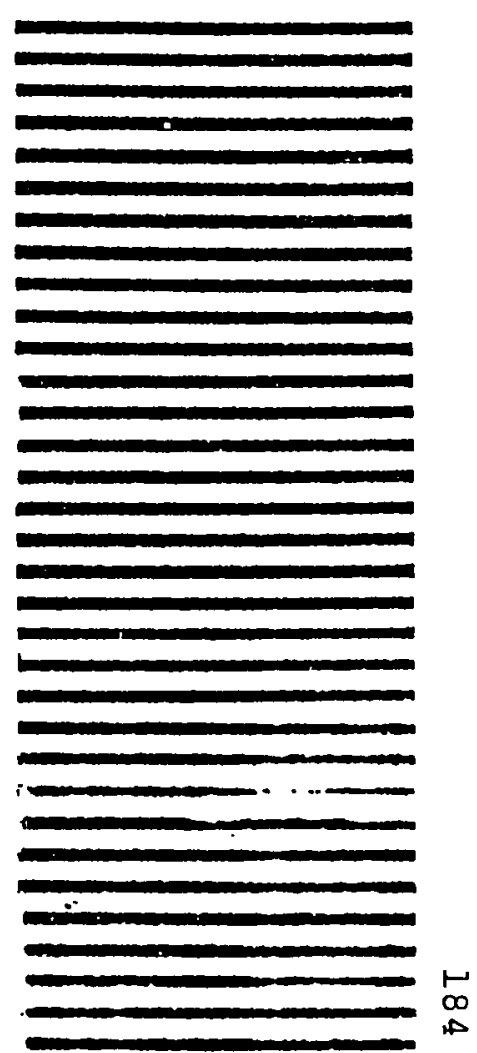

CONFEDERATION OF OREGON

SCHOOL ADMINISTRATORS

71012 th Street SE

Salem, OR 97301 
APPENDIX D 
COLLEAGUE PACKET

Please give this envelope to
one of your colleagues. Ask
him or her to provide the
information requested and to
mail it in the envelope provided.

THANK YOU 


\section{COLLEAGUE QUESTIONNAIRE}

The administrator who gave you this packet is participating in a study on administrator role perception and its possible relationship to burnout. You are being asked to provide the following Information in order to help validate the Administrator Role Perceptio;n Inventory, which is the questionnaire belng used in the study. Zip code matching is being done to provide for correlation. All the information is confidentlal and anonymous; no record of names will be made, all data reported will be group data.

\section{Directions}

Please indicate, in your opinion, the extent to which each phrase describes the person who gave you this questionnaire. Mark an $X$ on the line which corresponds best to your opinion.

$\begin{array}{cccc}\text { Very } & \text { Somewhat } & \text { Somewhat } & \text { Very Does Not } \\ \text { Inaccurate } & \text { Inaccurate Uncertain Accurate Accurate Apply }\end{array}$

1. Is physically vigorous and healthy.

2. Longs for the "good old days."

3. Identifles readily with concerns of parents.

4. Would like to take early retirement to "get away from this mess."

5. Views his/her fob as significant, having impact on others.

6. Receives great satisfaction from doing the job well.

7. Is accepted by coworkers.

9. Is emotionally drained.

9. Is highly motivated, action-oriented, proactive.

10. Is able to fudge whether or not his/her fob performance is adequate. 


$\begin{array}{cccc}\text { Very } & \text { Somewhat } & \text { Somewhat } & \text { Very Does Not } \\ \text { Inaccurate } & \text { Inaccurate Uncertain Accurate Accurate Apply }\end{array}$

11. Feels disillusioned about how the job has turned out.

12. Has the support of the community.

13. Feels he/she is accomplishing disired professional goals.

14. Is Isolated from other staff.

15. Is actively involved with parents.

16. Empathizes with students.

17. Gets involved in student activities.

15. Is accepted by students.

19. Is able to see things from point of view of other stapf.

The person whom I am describing is my: Superior Peer SubordInate

Thank you very much for your help. Please return this material to

Anne S. Wax

$\operatorname{COSA}$

710 12th Street S.E.

Salem, OR 97301

by September 15, 1952 in the stamped envelope provided. 
$\cos A$

710 12th Street SE

Salem, OR 97301
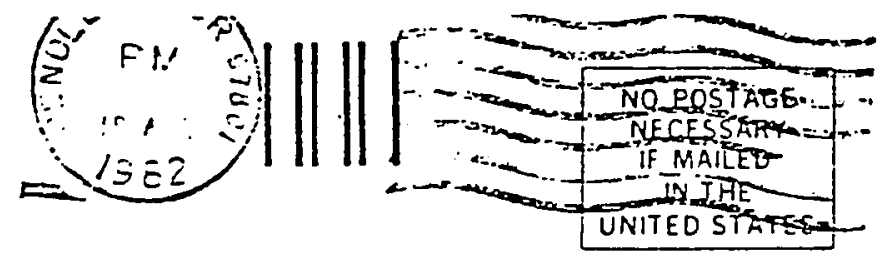

\section{BUSINESS REPLY MAIL \\ FIRST CLASS PERMT NO. 7489 SALEM, OREGON \\ POSTAGE WILL BE PAD BY ADORESSEE}

CONFEDERATION OF OREGON

SCHOOL ADMINISTRATORS

71012 th Street SE

Salem, OR 97301

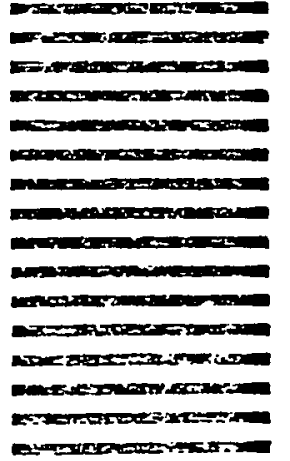

Attention: Anne Wax 
APPENDIX E 
APPENDIX E

Dear cosA Member:

Within the last few weeks, you received materials requesting your participation in a study on administrative role perception.

Many thanks if you have already responded and mailed the information back to $\cos A$. If not, would you please take a minute now to take care of this; I would like to have all the materials returned by September $15,1982$.

Thank you,

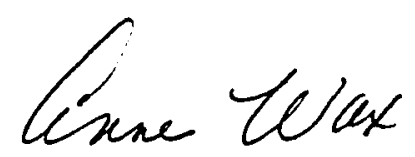

Anne Wax

AW : oh

$9 / 82$ 
APPENDIX F 
APPENDIX $F$

RELIABILITY AND VALIDITY MEASURES OF INSTRUMENTS SIMILAR IN FORMAT TO THE ARPI

\begin{tabular}{|c|c|c|c|c|}
\hline Title, Author, Date & Variable Measured & Rellability & $\begin{array}{l}\text { Measure } \\
\text { of Validity }\end{array}$ & $\begin{array}{l}\text { Correlation/ } \\
\text { Probability }\end{array}$ \\
\hline $\begin{array}{l}\text { Index of Adjustment } \\
\text { Values (Bills, Vance, } \\
\text { McLean, 1951) in } \\
\text { Robinson \& Shaver, } 1970\end{array}$ & $\begin{array}{l}\text { adfustment } \\
\text { values }\end{array}$ & .88 to .91 & $\begin{array}{l}\text { Correlated } \\
\text { with Rorschach } \\
\text { results; also } \\
\text { with pre and } \\
\text { post tests in } \\
\text { mental hygiene } \\
\text { class. }\end{array}$ & Not given \\
\hline $\begin{array}{l}\text { Self-Esteem Scale } \\
\text { (Rosenberg, 1965) in } \\
\text { Robinson \& Shaver, } 1970\end{array}$ & $\begin{array}{l}\text { attitudes } \\
\text { toward } \\
\text { self }\end{array}$ & .85 & $\begin{array}{l}\text { Correlated } \\
\text { with ratings } \\
\text { by nurses, } \\
\text { with other } \\
\text { test scores, } \\
\text { with psychoso- } \\
\text { matic symptoms }\end{array}$ & 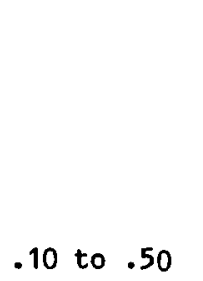 \\
\hline $\begin{array}{l}\text { Low Self-Esteem } \\
\text { (Hunt, Singer, and } \\
\text { Cobb, 1967) in } \\
\text { Robinson \& Shaver, } 1970\end{array}$ & $\begin{array}{l}\text { lowered self - } \\
\text { esteem }\end{array}$ & & $\begin{array}{l}\text { Correlated with } \\
\text { diagnosis of de- } \\
\text { pression; with } \\
\text { interview ratings }\end{array}$ & \\
\hline $\begin{array}{l}\text { Personal Competence } \\
\text { (Campbell, et. al., 1960) } \\
\text { in Robinson \& Shaver, 1970 }\end{array}$ & $\begin{array}{l}\text { personal } \\
\text { efflcacy }\end{array}$ & .30 & $\begin{array}{l}\text { Correlated with } \\
\text { education and } \\
\text { "sense of } \\
\text { political effect- } \\
\text { iveness" }\end{array}$ & Not given \\
\hline $\begin{array}{l}\text { Acceptance of Self and } \\
\text { Others (Berger, 1952) } \\
\text { In Shaw and Wright, } 1967\end{array}$ & $\begin{array}{l}\text { attitude } \\
\text { toward self } \\
\text { and toward } \\
\text { others }\end{array}$ & .78 to .88 & $\begin{array}{l}\text { Correlated with } \\
\text { essays written } \\
\text { about self and } \\
\text { others; as } \\
\text { rated by fudges. } \\
\text { Scores of college } \\
\text { students compared } \\
\text { to scores of } \\
\text { prisoners. } \\
\text { Prisoners scored } \\
\text { lower. }\end{array}$ & .73 to .90 \\
\hline
\end{tabular}


APPENDIX G 
APPENDIX G

MEANS AND STANDARD DEVIATIONS FOR SUBSCALES AND TOTAL ARPI FOR ADMINISTRATORS IN COLLEAGUE SAMPLE

\begin{tabular}{lcc}
\hline Subscale & Mean & Standard Deviation \\
\hline Expectation & 27.88 & 5.40 \\
Motivation & 36.18 & 3.91 \\
Psycho-physical State & 33.49 & 6.13 \\
Relationships & 39.52 & 3.28 \\
Accomplishment & 39.90 & 3.99 \\
Time & 29.42 & 4.19 \\
Total ARPI & 176.97 & 17.38 \\
\hline
\end{tabular}


APPENDIX H 
APPENDIX H

SCHEFFE TEST FOR SIGNIEICANCE BETWEEN PAIRS OF MEANS ARP I SCORES :

Estimate of Contrast

$$
\begin{aligned}
& \bar{x}_{1}-\bar{x}_{2}=185.09-166.85=18.24 \\
& \bar{x}_{1}-\bar{x}_{3}=185.09-151.69=33.40 \\
& \bar{x}_{2}-\bar{x}_{3}=166.85-151.69=15.16
\end{aligned}
$$

Estimate of Variance of Contrast

$$
\begin{aligned}
& \text { MS }_{W}\left(\frac{1}{\pi_{1}}+\frac{1}{\pi_{2}}\right)=250.33\left(\frac{1}{\pi^{2}}+\frac{1}{49}\right)=.9012 \\
& M_{W}\left(\frac{1}{\hbar}+\frac{1}{\hbar}\right)=250.33\left(\frac{1}{\sqrt{23}}+\frac{1}{46}\right)=3.040 \\
& M S_{W}\left(\frac{1}{n_{2}}+\frac{1}{n_{3}}\right)=250.33\left(\frac{14}{419}+\frac{16}{96}\right)=3.1041
\end{aligned}
$$

Square Roots of Estimates of Variance of Contrast

$$
\begin{aligned}
\frac{\sqrt{.9012}}{\sqrt{3.0040}} & =1.7332 \\
\sqrt{3.1041} & =1.7618
\end{aligned}
$$

Ration of Contrast to Square Root of Estimate of Variance of Contrast

$$
\begin{aligned}
\frac{18.24}{.9493} & =19.21 \\
\frac{33.40}{1.7332} & =19.27 \\
\frac{15.16}{1.7618} & =8.60
\end{aligned}
$$

Criterion Formula for Values Against which to Compare Absolute Value of the Ratio

$$
\begin{aligned}
& \begin{array}{ll}
(\mathrm{J}-1) \quad{ }^{\mathrm{F}} & \text { Where } \mathrm{J}=\text { number of groups } \\
& \mathrm{N}=\text { number of cases }
\end{array} \\
& \alpha=\text { probability }
\end{aligned}
$$

$$
(3-1)^{\left(399^{F}\right.} 2,1215
$$

$2(6.97)$

$$
13.94=3.73
$$


Comparison of Ratios to Criterion Value

$$
\begin{aligned}
& 3.73<19.21 \\
& 3.73<19.27 \\
& 3.73<8.60
\end{aligned}
$$

